\title{
Cancer drugs targeting DNA replication: \\ Molecular strategies to enhance specificity and efficacy
}

\author{
Dissertation \\ for the award of the degree \\ "Doctor rerum naturalium" \\ of the Georg-August-Universität Göttingen \\ within the doctoral program Molecular Medicine \\ of the Georg-August University School of Science (GAUSS)
}

submitted by

Yizhu Li

from Shanghai, China

Göttingen 2020 


\section{Thesis Committee}

Prof. Dr. Matthias Dobbelstein, Institute of Molecular Oncology, UMG

Prof. Dr. Bernd Wollnik, Institute of Human Genetics, UMG

Prof. Dr. Heidi Hahn, Institute of Human Genetics, UMG

\section{Members of the Examination Board}

Referee: Prof. Dr. Matthias Dobbelstein, Institute of Molecular Oncology, UMG

$2^{\text {nd }}$ Referee: Prof. Dr. Bernd Wollnik, Institute of Human Genetics, UMG

\section{Further members of the Examination Board}

Prof. Dr. Heidi Hahn, Institute of Human Genetics, UMG

Dr. Ufuk Günesdogan, Department of Developmental Biology, GZMB

Dr. Nuno Raimundo, Institute for Cellular Biochemistry, UMG

(Name, Department/Group, Institution)

(Name, Department/Group, Institution)

Date of oral examination: 


\section{Abstract}

The DNA molecule stands at the center of cancer origin and treatment. Cancer cells are addicted to DNA mutations and DNA replication, therapeutic non-responders are often based on the rate of mutations and ability to replicate DNA. Conversely, DNA, being the most vulnerable spot of a tumor, is also the main target for chemotherapies. The in-depth understanding of cellular processes upon errors in the DNA genetic code is therefore crucial for designing new chemotherapeutic drugs and new combinations of drugs; specifically, it is the main endeavor to induce and exacerbate DNA damage in cancer cells. The combination of new small-molecule inhibitors with established chemotherapeutics, to increase their effect on the tumor and to decrease the side effects for the patient, is currently of great interest in preclinical and clinical research. In this work we have investigated a small-molecule inhibitor against the DNA damage response kinase MK2 that increases cytotoxicity of the DNA crosslinker cisplatin but relieves replicative stress upon co-treatment with the nucleoside analogue Gemcitabine. We verified these effects using both drugs in the same biological system, with a dependence on the cell cycle phase. Taken together, the combination of new compounds with established chemotherapeutic drugs is a very promising approach to benefit cancer patients, but the effects can vary dependent on the specific chemotherapeutic and should be applied in the clinics with great care. In another project we have further developed the idea of cyclotherapy, i.e. using a pharmacological pulse activation of a tumor suppressor to halt the cell cycle, which protects non-transformed cells, while targeting tumor suppressor mutated cancer cells with DNA damaging chemotherapeutics. We used a Click Chemistry reaction of the nucleoside analogue 5-Vinyl-2'-deoxyuridine (5-VdU) and a novel DNA-intercalator in a pretargeting approach, meaning the separation of the specific targeting component and the cytotoxic component of a drug. Moreover, we utilized Nutlin-3a to stabilize p53, arresting the cell cycle in p53 proficient cells. As a result, these cells did not incorporate 5-VdU and were not susceptible to the novel DNA-intercalator, while p53 -/- cells failed to be protected by Nutlin-3a. We thereby present a promising treatment scheme to target tumor suppressor mutated cells only, while sparing tumor suppressor wildtype cells. In summary, we present strategies to enhance the specificity and efficacy of existing chemotherapeutics, and novel compounds to selectively exacerbate DNA damage in cancer cells. 
This work is dedicated to my wife Sasha who is my motivation, strength and peace of mind and to my daughter Matilda

who is everything I expected from life and so much more 


\section{Table of Contents}

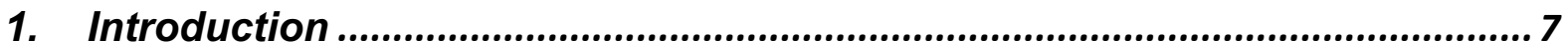

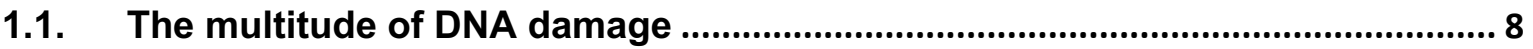

1.1.1 The chemotherapeutic drugs Gemcitabine and cisplatin ................................................. 9

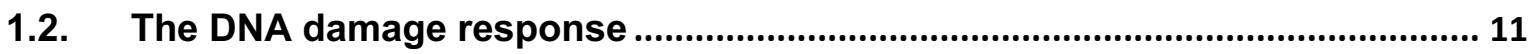

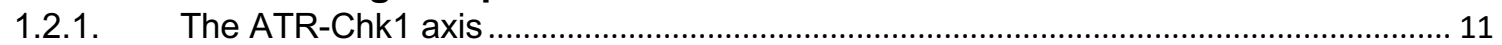

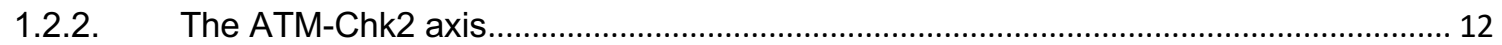

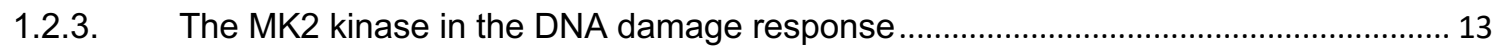

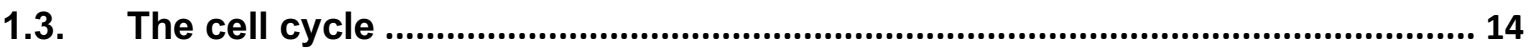

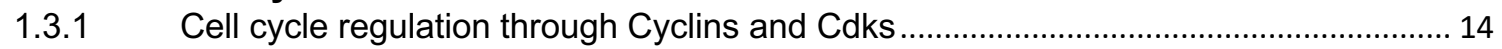

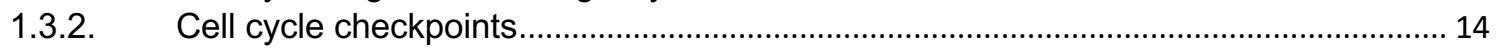

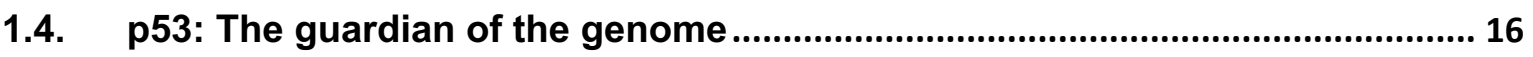

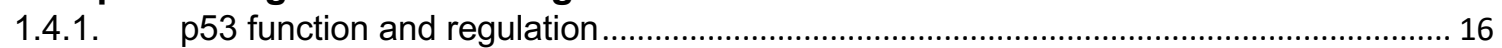

1.4.2. Pharmacological stabilization of $\mathrm{p} 53$ and cyclotherapy ………................................. 17

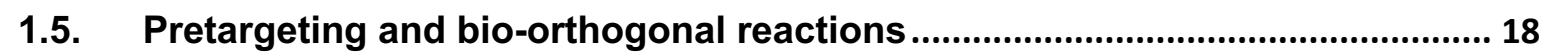

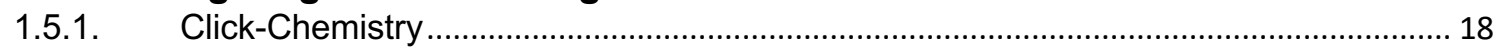

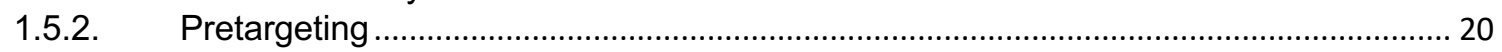

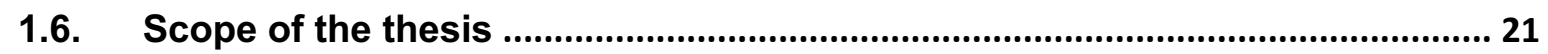

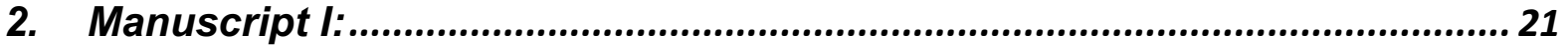

2.1. Inhibition of MAPKAPK2/MK2 facilitates DNA replication upon cancer cell treatment with gemcitabine but not cisplatin................................................................... 21

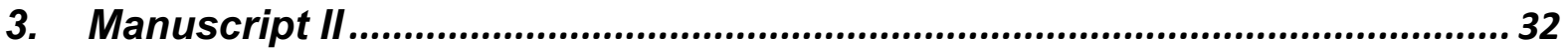

3.1. A two-step bio-orthogonal reaction enables specific targeting of p53-mutant cells via Nutlin-3a mediated protection of p53-wildtype cells ........................................ 32

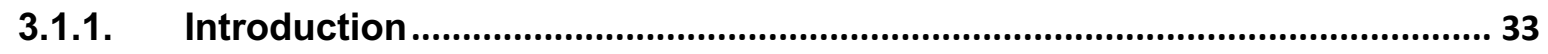

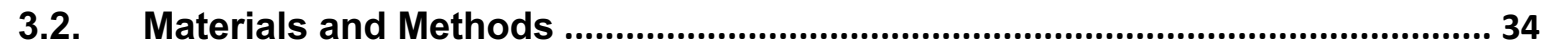

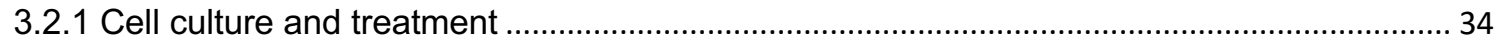

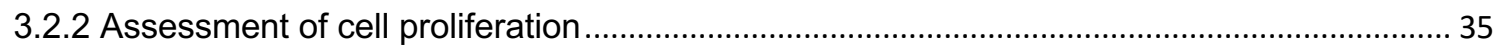

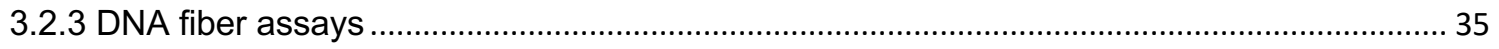

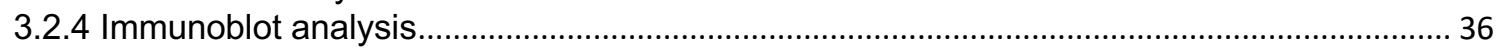

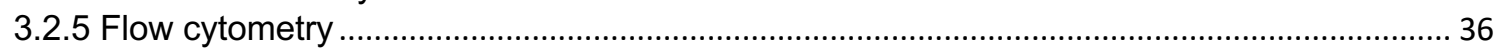

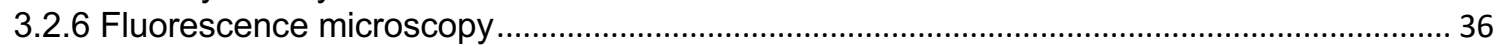

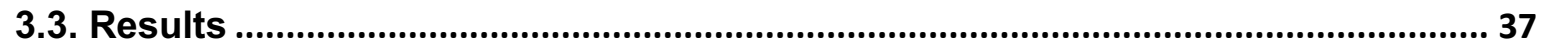

3.3.1 The combination of 5-VdU and compound B exhibits synergistic lethality in human

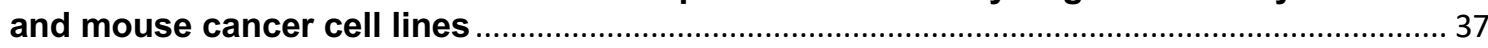

3.3.2. 5-VdU is incorporated into the cellular DNA, binds compound $B$ and can be

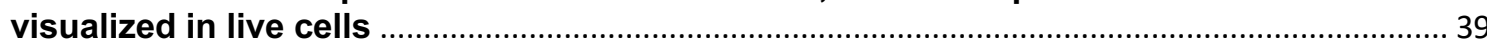

3.3.3. The combination of 5-VdU and compound B impedes the progression of DNA replication forks and leads to accumulation of cells in mitosis .......................................... 40 3.3.4. Nutlin-3a selectively protects cultured cells against the combination of 5-VdU and

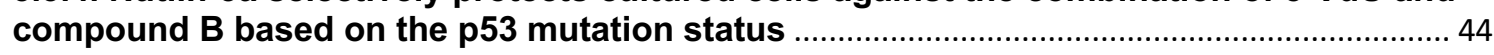

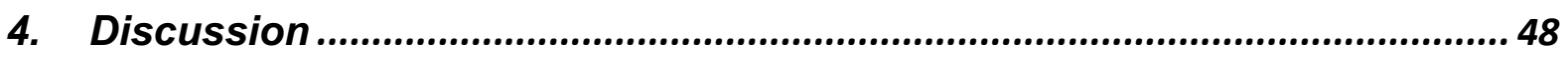

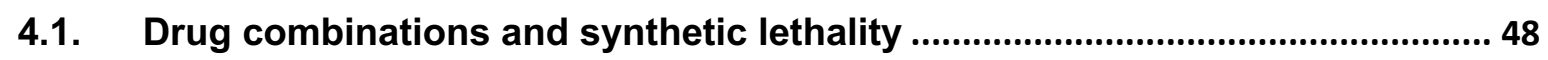

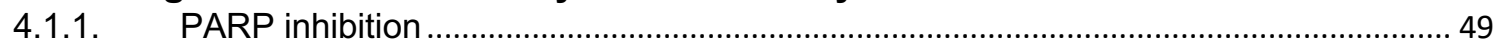

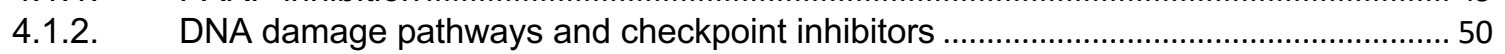


4.2. Tumor suppressor activating drugs revisited .................................................. 51

4.3 Specific targeting of cancer cells with tumor suppressor mutations............. 53

4.3.1. Improvement of the current cyclotherapy model ......................................................... 53

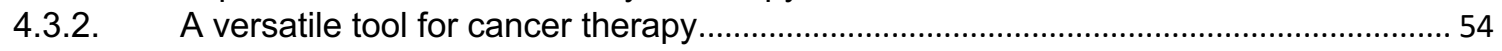

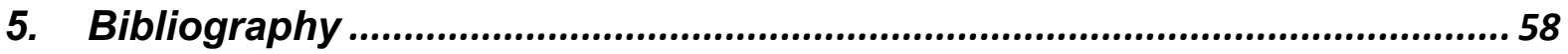

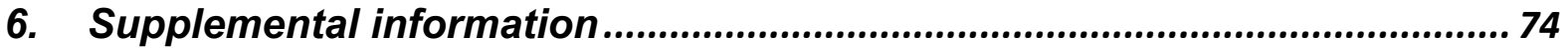

6.1. Supplemental figures for manuscript I .............................................................. 74

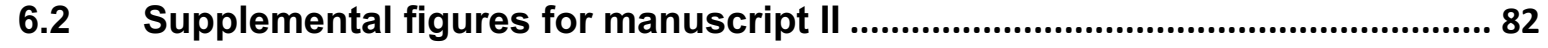

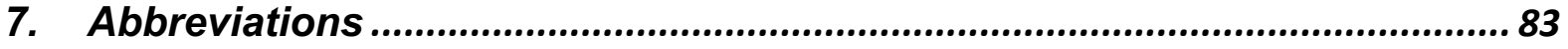

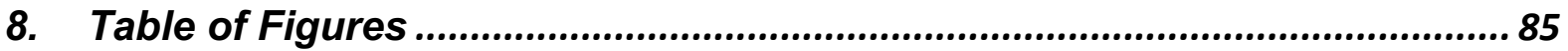




\section{Introduction}

Ever since Watson and Crick correctly described the double helical structure of deoxyribonucleic acid (DNA) in 1953 ${ }^{1}$, the molecule has been recognized as the carrier of genetic information, having the protagonist role in the central dogma of molecular biology 2 . To protect this genetic information, the genetic code consists of two complementary DNA strands and is replicated with a high fidelity in a semiconservative way ${ }^{3}$. The DNA remains in a supercoiled and tightly packed state for most of the time ${ }^{4}$, as so-called heterochromatin, protecting it from exogenous and endogenous stressors. However, this protected state sometimes has to be temporarily abandoned for vital cellular functions to occur, such as transcription, DNA replication and mitosis. During these processes the DNA is dissociated from histones, unwound and sometimes even separated and split open ${ }^{5}$. This is when the DNA is most vulnerable to DNA damaging stressors, which are unfortunately ubiquitous and multimodal $^{6}$. These eventually lead to mutations on the DNA level, namely base substitutions, insertion and deletion mutations ${ }^{7}$. The resulting effects on the protein level can be either silent, moderate or, for example in case of nonsense or frameshift mutations, devastating. Luckily, a sophisticated and intricate molecular machinery detects and repairs most of these damages ${ }^{8}$, this enables life to persist in an environment of oxidative stress and UV irradiation. However, not all damages are detected and repaired, which can result in the accumulation of mutations, cellular aging and ultimately cancer development. One of the breakthroughs in cancer research was the acceptance, that cancer is a genetic disease ${ }^{9}$, making mutations and DNA damaging stressors the core of its origin. Consequently, DNA also emerged as the most effective target for early chemotherapies, as DNA damaging agents are able to temporarily slow tumor progression in patients ${ }^{10}$. This puts the DNA molecule in the center of attention for the origin and therapy of cancer. The disease is based on DNA mutations and is addicted to DNA replication as cells proliferate rapidly. Therefore, the mechanistical study of established chemotherapeutics, the discovery of novel anti-cancer drugs, and the synergistic combination of both are the ongoing frontiers to target tumor DNA in clinical chemotherapy and cancer research. 


\subsection{The multitude of DNA damage}

Due to its high frequency of occurrence and ubiquity, a certain amount of DNA damage must be regarded as physiological for a living cell. An important classification of DNA damage is whether its origins are endogenous or exogenous. Sources of exogenous DNA damage surround us every day. As an example, all land-living species have to deal with DNA damaging UV irradiation during daytime, which is more intense the closer one gets to the equator. UV light, notably UV-A and UV-B, can cause pyrimidine dimer formation and induction of reactive oxygen species (ROS) ${ }^{11}$. Sources of endogenous DNA damage originate from within the cell. All oxygen breathing organisms are under constant oxidative stress, as the element of oxygen can form very aggressive reaction partners that disturb highly ordered biochemical structures. The main source of ROS originates from toxic metabolic byproducts of the oxidative metabolism of a cell ${ }^{12}$. Other DNA damages occur during DNA replication ${ }^{13}$ and RNA transcription-DNA replication collisions ${ }^{14}$.

As an estimation, a human cell nucleus has to cope with more than 10.000 events of DNA damage per day. For example, it has to deal with frequently losing DNA bases, i.e. up to 5.000 depurinations ${ }^{15}$ and up to 600 depyrimidinations ${ }^{16}$. On top of that there are DNA backbone breakages, frequently occurring during DNA replication, in average 50.000 single stranded breaks ${ }^{17}$ and up to 50 double stranded breaks ${ }^{18}$, which represent the most toxic DNA lesions to the cell. Furthermore, there are an estimated 3.000 formations of O6-methylguanines ${ }^{17}$ and 200 cytosine deaminations ${ }^{17}$. There are discrepancies in age and cell types, young rats have been evaluated to carry only one third of the DNA damage old rats have ${ }^{19}$, and cells of the central nervous system have been reported to have a four-fold number of DNA abasic sites when compared to other organs $^{20}$. These numbers are estimates and the list of DNA damage types is incomplete, but they should highlight the DNA damage burden that organisms have to deal with every day.

Apart from natural occurring exogenous DNA damage, there is DNA damage artificially inflicted to cells for cancer therapeutic purposes. Radiotherapists utilize ionizing irradiation to target inoperable tumors and micro-metastases, inducing DNA double-stranded breaks (DSB), which become cytotoxic after a certain threshold ${ }^{21}$. 
Also, the majority of chemotherapeutics induces DNA damage. This was historically unknown and only revealed after years of anti-cancer drug application to patients. One group of DNA damaging chemotherapeutics are alkylating agents, such as cyclophosphamide ${ }^{22}$, which induce cytotoxic intra- and interstrand DNA crosslinks ${ }^{23}$. Platinum-based anticancer drugs, such as cisplatin ${ }^{24}$, act in a similar way. Furthermore, the group of topoisomerase inhibitors, such as irinotecan ${ }^{25}$ against topoisomerase type I and etoposide ${ }^{26}$ against topoisomerase type II, induces DNA single-stranded breaks (SSB) and DSBs by blocking the enzymatic ligation step. Another group are the anthracyclins, such as doxorubicin ${ }^{27}$, which act as direct DNA intercalators and topoisomerase II inhibitors to primarily impact DNA replication. The large group of precursor analogues and nucleoside analogues, such as Gemcitabine $^{28}$, interferes with the synthesis and incorporation of DNA and RNA nucleotides, they are highly effective in inducing DNA damage as they imbalance the nucleotide pool and therefore the synthesis of DNA itself ${ }^{29}$. Last but not least there is the group of peptide antibiotics, such as bleomycin ${ }^{30}$, which also induces DNA strand breaks. Taken together, many DNA damaging substances have been found to be highly effective in anti-cancer therapies, as the tumor DNA stands at the hub of carcinogenesis and cancer progression. The chemotherapeutic drugs Gemcitabine and cisplatin will be further introduced in greater detail, as they are an integral part of the findings in this dissertation.

\subsubsection{The chemotherapeutic drugs Gemcitabine and cisplatin}

The nucleoside analogue Gemcitabine is a deoxycytidine/pyrimidine analogue, in which the hydrogen residues of the 2'-carbon have been substituted by fluorine residues. As a prodrug, Gemcitabine is converted into its active triphosphate metabolite 2', 2'-difluorodeoxycytidine triphosphate (dFdCTP) after cellular uptake ${ }^{28}$. In its active state, Gemcitabine inhibits ribonucleotide reductase to deplete nucleotide pools and also impedes DNA replication directly by incorporation and sterical hindrance of DNA polymerases ${ }^{31}$, efficiently inducing DNA damage in actively replicating cells ${ }^{29}$. Actively replicating cells already exhibit moderate levels of DNA damage stress, so-called replicative stress ${ }^{29}$, originating from endogenous and exogenous DNA stressors as mentioned above, but also through stalled replication forks, which halt at sites of damaged DNA. If the damage can be repaired, replication 
continues, but if the damage persists, the replication fork collapses through loss of DNA polymerases ${ }^{32}$ and gives rise to a highly cytotoxic $\mathrm{DSB}^{33}$. Cancer cells are more prone to replicative stress and DNA damage in general, as they have lost compensation mechanisms against oxidative stress and DNA repair pathways during their carcinogenesis ${ }^{34}$. Therefore, Gemcitabine is able to efficiently induce DNA damage, especially in tumor cells actively replicating their DNA in S-phase.

Similar to Gemcitabine, the platinum-agent cisplatin can also be considered a prodrug, as one of its chloride residues will be replaced by a water molecule in a process named aquation ${ }^{35}$. This reaction preferably takes place intracellularly due to the low concentration of chloride within the cell. The water molecule is then easily exchanged by $\mathrm{N}$-heterocyclic bases on the DNA, a further displacement of the other chloride, with preferably Guanine, leads to intra- or interstrand DNA crosslinks ${ }^{24}$. These eventually lead to DSB formation, which are highly cytotoxic for the cell, primarily in mitosis, as a single unrepaired DSB can lead to structural chromosomal aberrations and cell death ${ }^{36}$. In summary, both Gemcitabine and cisplatin have DNA as their therapeutic target, but while Gemcitabine mainly hampers DNA replication in S-phase, cisplatininduced DSBs mainly impact mitosis. Clinically, the combination of Gemcitabine and cisplatin has been shown to be highly effective in comparison to other chemotherapeutic combinations ${ }^{37}$, this might be due to their DNA damaging effects in distinct cell cycle phases.

A

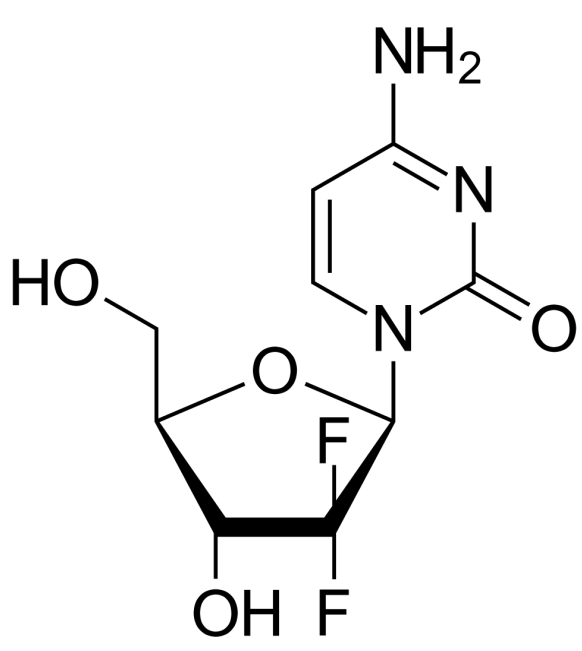

B

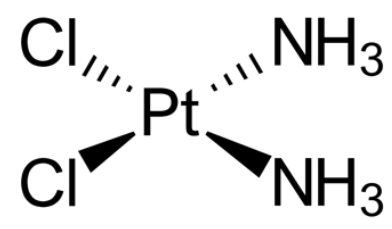

Figure 1: Chemical structures of (A) Gemcitabine ${ }^{38}$ and (B) cisplatin ${ }^{39}$. 


\subsection{The DNA damage response}

The DNA damage response (DDR) consists of an intricate molecular machinery with a multitude of factors, responding to all different types of DNA damage and activating the correct corresponding DNA damage repair pathways ${ }^{40}$. Depending on the nature and the extent of DNA damage, the cellular responses might also differ in intensity, ranging from transcriptional regulation, cell cycle arrest and DNA repair to activation of apoptosis pathways. The signal transduction of the DDR mainly functions through phosphorylation cascades, especially in the early stages of the response. At the apex of the DDR stand two kinases of the phosphatidylinositol 3- kinase-related kinase (PIKK) family, the Ataxia-Telangiectasia-Mutated (ATM) and ATM- and Rad3-related (ATR) kinases ${ }^{41}$. Their downstream signal transduction upon detection of SSB and DSB will be introduced in greater detail.

\subsubsection{The ATR-Chk1 axis}

As previously stated, SSBs frequently form during DNA replication. The lesion is first detected and bound by replication protein A (RPA), which then recruits ATR and its interacting protein, ATRIP42. ATR is subsequently activated and phosphorylates its many downstream targets, of which the most prominent is Checkpoint kinase 1 $(\text { Chk1 })^{43}$. Activated Chk1 can arrest the cell cycle through different pathways. For instance, it inhibits cyclin dependent kinases (Cdks) by marking its negative regulators Cdc25A/B for proteasomal degradation ${ }^{44}$. Chk1 also activates the Wee1 kinase, which phosphorylates Cdk1 at the inhibitory sites Tyr15 and Thr14, halting the cell cycle at the $\mathrm{G} 2 / \mathrm{M}$ checkpoint ${ }^{45}$. Inhibited Cdk1 can be activated by the Cdc25C phosphatase by removing the Tyr15 phosphorylation. However, Chk1 is able to phosphorylate Cdc25C at Ser216, marking it to be intercepted and thus inactivated by 14-3-3 proteins $^{46}$. The Chk1 kinase can therefore influence the activation of Cdks at different levels to inhibit cell cycle progression. 


\subsubsection{The ATM-Chk2 axis}

DSBs can originate from various sources, one of which is the prolonged stalling of the replication fork, which eventually leads to fork collapse. Upon DSB formation, inactive ATM dimers are activated through auto-phosphorylation at Ser1981 and dissociate into active monomers ${ }^{47}$. These are then recruited to the DSB site via the MRE11/RAD50/NBS1 (MRN) complex ${ }^{48}$, where they activate their primary target, the Checkpoint kinase 2 (Chk2), by phosphorylation at Thr68 ${ }^{49}$. Similar to Chk1, Chk2 kinase activity also leads to degradation of $\mathrm{Cdc} 25$ proteins and can therefore arrest the cell cycle upon DNA damage ${ }^{48}$. ATM and Chk2 also influence the p53 pathway, either by activating p53 via phosphorylation directly, or by disrupting the MDM2/p53 interaction by MDM2 phosphorylation at Ser39549. The ATM-Chk2 axis is therefore able to halt the cell cycle upon incidence of DNA damage either through inactivation of Cdks or activation of the p53 pathway. Furthermore, ATM plays a crucial role in the initiation of DNA repair. The kinase phosphorylates the histone $\mathrm{H} 2 \mathrm{~A}$ isoform $\mathrm{H} 2 \mathrm{AX}$ at Ser139, which is then called $y$ h2ax ${ }^{50}$. Together with ATM, yh2ax forms a chromatin complex with mediator of DNA damage checkpoint 1 (MDC1), which is also an ATM target ${ }^{51}$. This complex then spreads the DNA damage signal up- and downstream the site of DNA damage. The yh2ax marked chromatin leads to the recruitment of the Ring Finger proteins 8 and 168 (RNF8 and RNF168), which act as E3 ubiquitin ligases to mark yh2ax ${ }^{52}$. Polyubiquitinated $y$ h2ax then acts as a scaffold for DNA repair protein complexes, which then promote either non-homologous end joining (NHEJ) or homologous recombination (HR), based on the nature of the occurred DNA damage. ATM is therefore not only an early detector of DNA damage, but also an important initiator of DNA repair. 


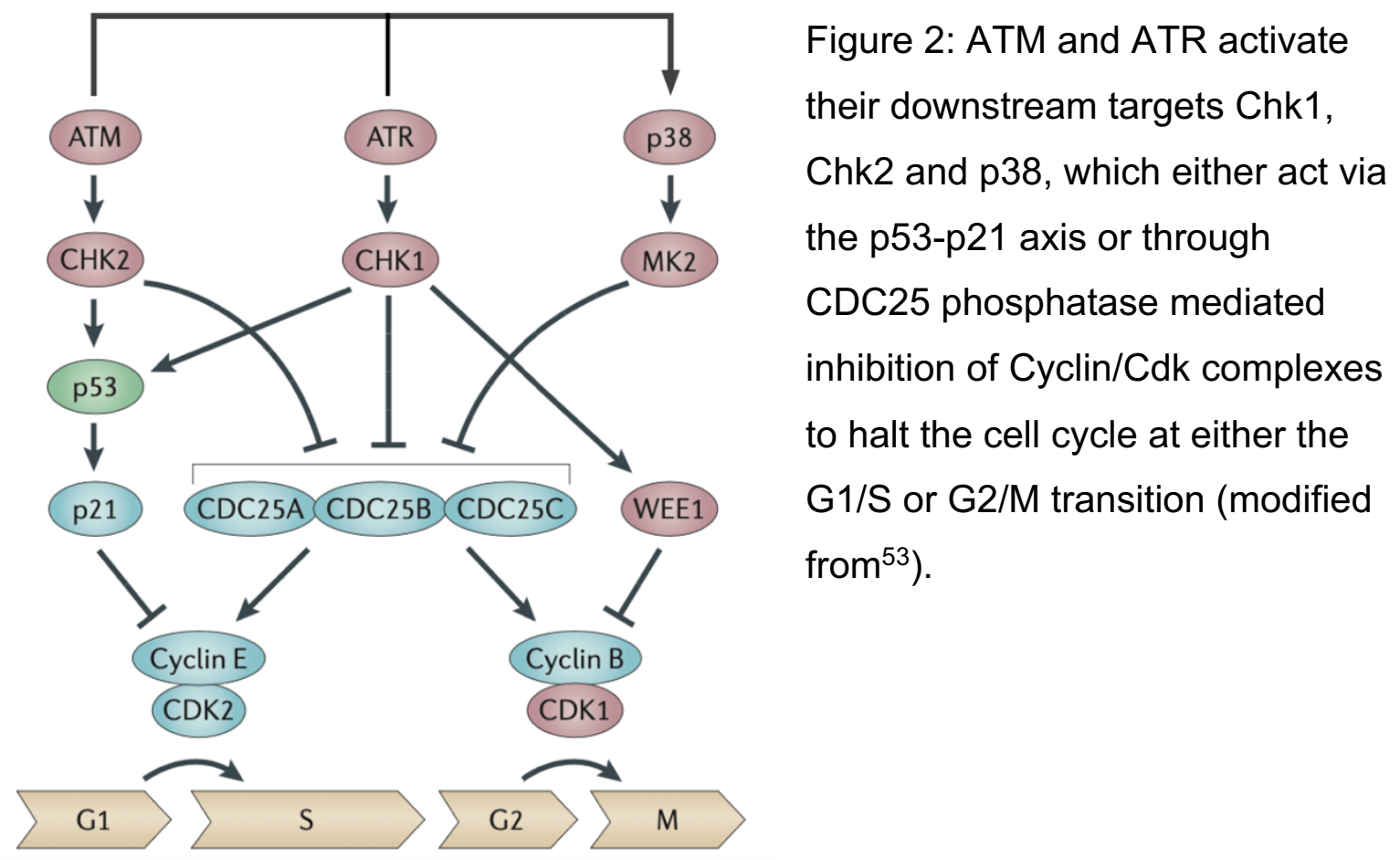

\subsubsection{The MK2 kinase in the DNA damage response}

One important downstream effector of ATM and ATR is the mitogen activated protein kinase (MAPK) 14 , commonly named $p 38-\alpha$, and its substrate MAPK activated protein kinase 2 (MAPKAPK2), or, in short, MK2. MK2 plays a pivotal role in the first manuscript of this dissertation and will be therefore introduced in greater detail.

In their inactive state, MK2 and p38 form a nuclear localized heterodimer ${ }^{54}$. Upon activation, MK2 is phosphorylated by p38 at Thr $334^{55}$, which triggers its nuclear export and function in the cytoplasm ${ }^{56}$. The p38/MK2-axis was first associated with the DDR when it was shown that p38 plays a role in promoting the G2/M-phase cell cycle checkpoint arrest by targeting Cdc25 proteins ${ }^{57}$. It has been subsequently reported that ATM and ATR stand upstream of p38/MK2 activation ${ }^{58,59}$. The induced G2/Mphase cell cycle arrest has been further explained by the finding that p38/MK2 mark Cdc25s for 14-3-3 protein binding, thus inhibiting their nuclear translocation. In addition, the p38/MK2-axis stabilizes Gadd45 $\alpha$ mRNA, while Gadd45 $\alpha$ protein stabilizes p38 and its activity ${ }^{60}$. Most interestingly, MK2 has been shown to be responsible for the G2/M-phase cell cycle checkpoint arrest in the absence of p53, as 
the absence of the MK2 kinase sensitizes p53-deficient tumors to cisplatin in vivo ${ }^{61}$. Taken together, the p38/MK2-axis controls the DDR at the G2/M-phase boundary to protect cellular mitosis against various genotoxic stressors. In seeming contrast, our group has previously described MK2 as a DNA damage inducing kinase, as pharmacological inhibition of MK2 relieves replicative stress upon Gemcitabine treatment ${ }^{62}$. Mechanistically, MK2 induces the activity of the translesion synthesis polymerases $\eta$ and $\zeta$, which promote DNA damage upon treatment with Gemcitabine. The investigation of these seemingly contrasting models of MK2 inhibition, in combination with Gemcitabine or cisplatin within the same biological system, is the main goal of the first manuscript included in this dissertation.

\subsection{The cell cycle}

\subsubsection{Cell cycle regulation through Cyclins and Cdks}

The cell cycle phases are tightly regulated by the Cyclin and Cyclin-dependent kinase (Cdk) protein families ${ }^{63}$. After complexing with their corresponding Cyclin, Cdks need to be further phosphorylated by Cdk-activating kinases (Caks) to drive cell cycle progression ${ }^{64}$. Cyclin D complexes with Cdk4 and Cdk6 during the G1-phase, while Cyclin E functions with Cdk2 to promote S-phase entry. During DNA replication, Cyclin A exchanges with Cyclin $E$ to form complexes with $\mathrm{Cdk} 2$, these then remain stable throughout the G2-phase of the cell cycle. Finally, the Cyclin A/B-Cdk1 complex drives the $\mathrm{G} 2 / \mathrm{M}$ transition into mitosis ${ }^{64}$.

\subsubsection{Cell cycle checkpoints}

The Cyclin-CdK complex mediated progression of the cell cycle can be disrupted by the onset of DNA damage at the G1/S and G2/M cell cycle boundaries, so-called cell cycle checkpoints. The G1/S cell cycle checkpoint is mainly regulated by the p53 tumor suppressor protein ${ }^{65}$. ATM and ATR trigger the degradation of the Cdk-activating phosphatase Cdc25A, which inhibits DNA replication by antagonizing the Cyclin E/ACdk2 complex function ${ }^{66}$. The DDR kinases also phosphorylate p53 at Ser15 and Ser20 directly, which activates its transcriptional activity and various downstream functions, such as cell cycle arrest, DNA repair and apoptosis ${ }^{47}$. One of its target 
genes is the G1/S-Cyclin-Cdk complex inhibitor p21 alias CDKN1A, which potently arrests the cell cycle by binding various $\mathrm{Cdks}^{67}$. p21 has also been reported to bind Proliferating Cell Nuclear Antigen (PCNA), which is an integral part of DNA replication and repair ${ }^{68}$. The p53/p21-axis is therefore a master effector of the $\mathrm{G} 1 / \mathrm{S}$ cell-cycle checkpoint, inhibiting S-phase progression by distinct mechanisms. In addition, p21 is able to halt the cell cycle within the S-phase by inhibiting Cdk1 and Cdk2, which is called the intra-S-phase checkpoint ${ }^{69}$. The second key regulator of the $\mathrm{G} / \mathrm{S}$ cell cycle phase transition is the pRb/E2F1 complex. The Retinoblastoma tumor suppressor protein $(\mathrm{pRb})$ is mutated in various tumors, while the name giving pathology is a rare cancer of the infant eye ${ }^{70}$. G1/S-Cyclin-Cdk complexes inhibit the pRb/E2F1 complex by phosphorylating $\mathrm{pRb}$, which disrupts its binding affinity to E2F1. An unbound E2F1 transcription factor exerts its function by promoting S-phase progression. As the p53/p21-axis inhibits Cyclin-Cdk function at the G1/S cell cycle boundary, pRb will not be in a phosphorylated state and inhibits DNA replication by restricting E2F1 transcriptional activity ${ }^{47}$. Upon the onset of DNA damage in the G2-phase, the G2/M cell cycle checkpoint is activated through ATM and ATR signaling targeting the Cyclin A/B-Cdk1 complex ${ }^{71}$, preventing entry into mitosis. p53 also plays an important role in the activation of the G2/M cell cycle checkpoint, as three of its target genes, namely GADD45, p21 and 14-3-30, have been shown to inhibit the Cyclin A/B-Cdk1 complex directly $^{72}$, preventing the cell cycle progression into mitosis. 


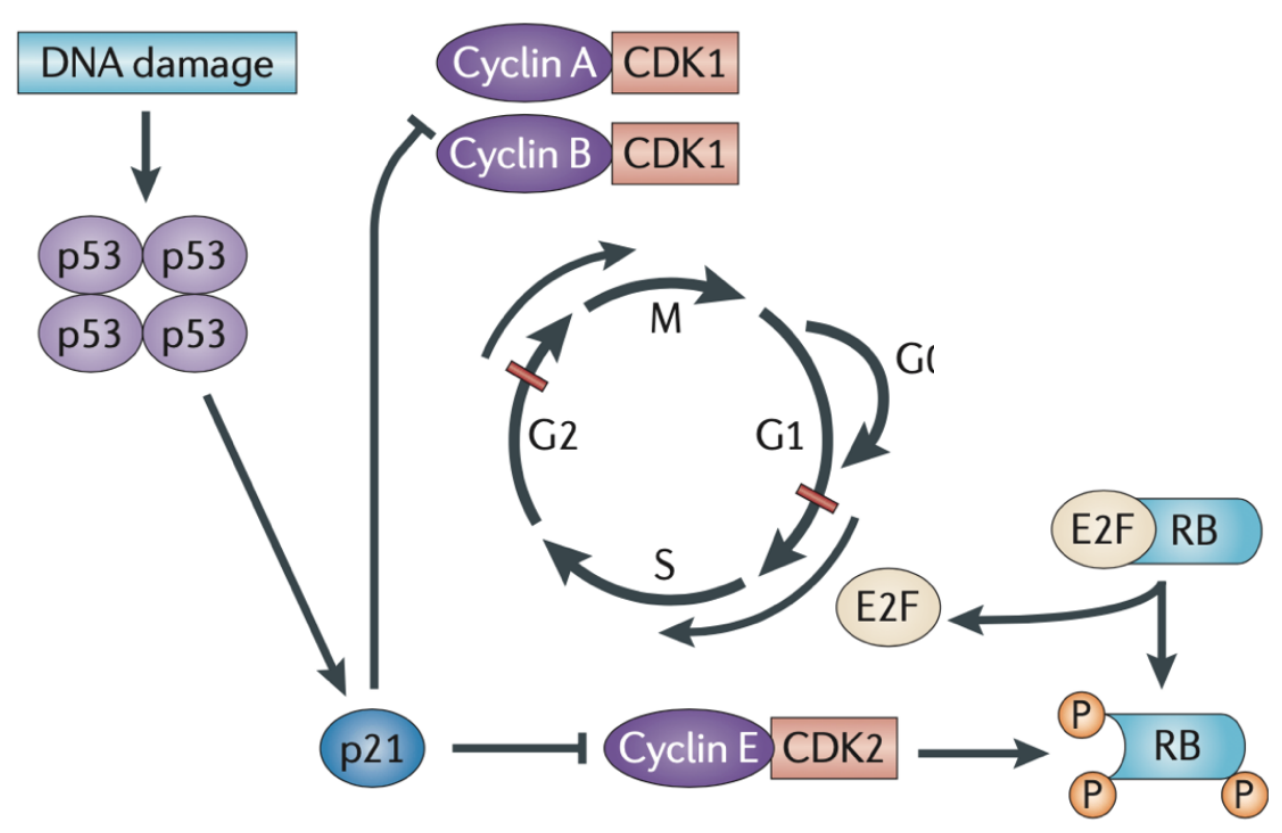

Figure 3: DNA damage induced G1/S cell cycle checkpoint activation is controlled by p53 and pRB. pRB inhibits the E2F1 transcription factor by complex formation and therefore prevents S-phase entry. p53 induces the cyclin-dependent kinase inhibitor p21, which inhibits Cyclin E-Cdk2, leading to pRb-E2F1 complex formation. In addition, $\mathrm{p} 21$ inhibits the $\mathrm{G} 2 / \mathrm{M}$ cell cycle transition by binding the mitosis promoting Cyclin A/B-Cdk1 protein complexes (modified from ${ }^{73}$ ).

\section{4. p53: The guardian of the genome}

\subsection{1. $p 53$ function and regulation}

Due to its important functions in genome maintenance and its common mutation in patient tumors, the p53 tumor suppressor protein has become the most studied protein in cancer research ${ }^{74}$. p53 is post-translationally modified by various cellular stress sensing pathways, which trigger its activity ${ }^{75}$. In the DDR, p53 is phosphorylated by all leading DNA damage kinases, namely ATM, ATR, Chk1 and Chk2 ${ }^{74}$. ATM and ATR mediated p53 activation at Ser15 disrupts its interaction with MDM2, a RING E3 ubiquitin ligase that tightly controls p53 in the absence of cellular stressors, and thus stabilizes its protein levels ${ }^{76}$. MDM2 marks p53 for proteasomal degradation by polyubiquitination, furthermore, it masks its $\mathrm{N}$-terminal transactivation domain to prohibit p53 transcriptional activity ${ }^{77}$. ATM is also able to phosphorylate MDM2 directly 
at Ser395, which further disrupts the interaction with $\mathrm{p} 53^{78}$. Chk1 and Chk2 phosphorylate p53 at Ser20 to induce protein tetramerization and its transcriptional activity ${ }^{75}$. Once transcriptionally active, p53 activates transcription of various target genes, including MDM2, GADD45, p21 and the pro-apoptotic proteins, such as Bax ${ }^{79}$. These target genes then execute their functions in various pathways such as cell cycle arrest, DNA repair, senescence or apoptosis ${ }^{80}$. p53 can therefore be regarded as a master regulator of cell fate.

\subsubsection{Pharmacological stabilization of p53 and cyclotherapy}

MDM2 inhibitors have already been established in preclinical research ${ }^{81}$ and clinical trials $^{82}$. One of them is Nutlin-3a, a small molecule inhibitor which antagonizes the p53-MDM2 protein interaction in a non-genotoxic manner ${ }^{83}$. As a result, p53 accumulates and overdrives its pathway to promote cell cycle arrest and apoptosis $^{84,85}$. An interesting feature of Nutlin-3a is that it activates wild-type p53 but does not induce similar activity when p53 is mutant. This feature gives rise to the concept of cyclotherapy, in which p53 wildtype cells can be protected from DNA damaging and mitotic chemotherapeutics by a short treatment with a tumor suppressor activating drug, such as Nutlin-3a, to arrest the cell cycle, whereas p53 mutant cells will not be arrested and stay susceptible to the chemotherapeutical treatment ${ }^{86,87}$. The concept of cyclotherapy has been of interest in the cancer research community $88,89,90$, with evidence that it functions in vivo ${ }^{91,92}$, however there have been no reports of applications in patients. In this dissertation, we have combined the cyclotherapy approach with the concept of pretargeting, which has generated promising results that encourage the application in an experimental mouse model. 


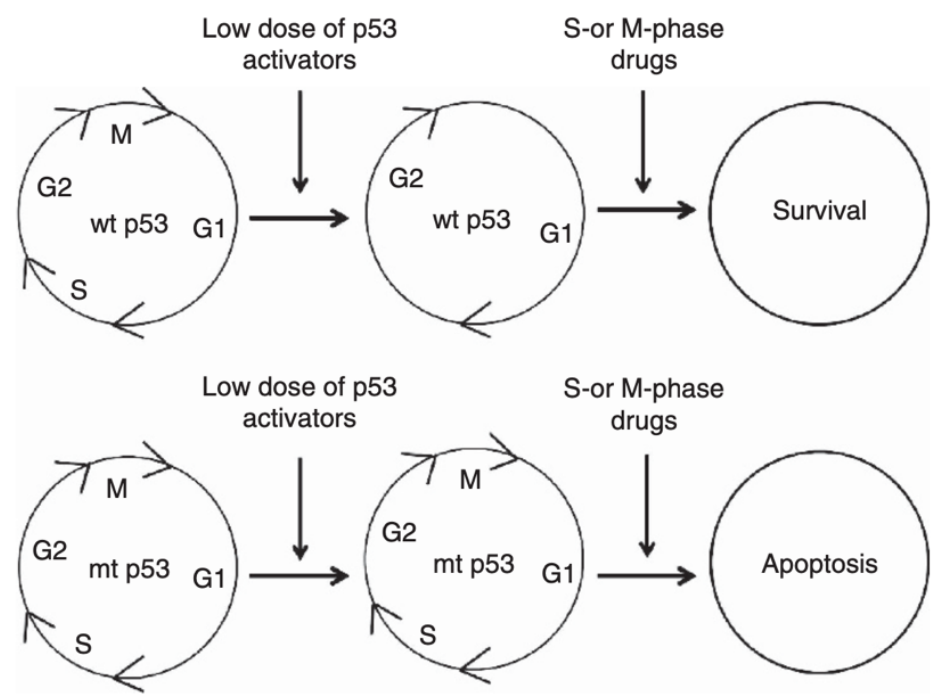

Figure 4: The concept of cyclotherapy ${ }^{93}$. p53 proficient cells arrest their cell cycle upon low-dose p53 activator treatment, whereas p53 deficient cells do not, these then stay susceptible for S-phase and M-phase targeting drugs.

\subsection{Pretargeting and bio-orthogonal reactions}

\subsubsection{Click-Chemistry}

The Copper catalyzed Azide-Alkyne Click (CuAAC) reaction is a highly specific reaction that can take place with a high fidelity within a biological system ${ }^{94}$, meaning that the reaction partners react with each other, but not with the naturally occurring biomolecules. So-called bio-orthogonal reactions have been widely applied and significantly contributed to molecular biological research ${ }^{95}$, as they have allowed researchers to specifically target and visualize cellular structures of their choice and interest ${ }^{96}$. A major advance in the field was the design of copper-free Click reactions, which, as copper is a cytotoxic agent, enabled the application of Click chemistry in living cells ${ }^{97}$. Researchers were now able to visualize ongoing cellular processes in motion. The two most important copper-free Click reactions are based on the Strainpromoted Azide-Alkyne Click Chemistry (SPAAC) ${ }^{98}$ and the tetrazine-alkene ligation ${ }^{99}$, which have lead the effort to develop Click-Chemistry based clinical theranostics ${ }^{100}$. In this work, we have utilized a tetrazine-alkene based reaction involving the nucleoside analogue 5-Vinyl-2'-deoxyuridine (5-VdU) $)^{101}$ and a novel compound, called Compound $\mathrm{B}$ as its structure cannot yet be revealed due to patenting endeavors, which carries a tetrazine group and acts as a DNA-intercalator. 5-VdU surprisingly shows almost no cytotoxicity in cellular assays and is readily incorporated into the DNA by cells, making it a promising candidate for the specific targeting drug of a pretargeting scheme. 
A

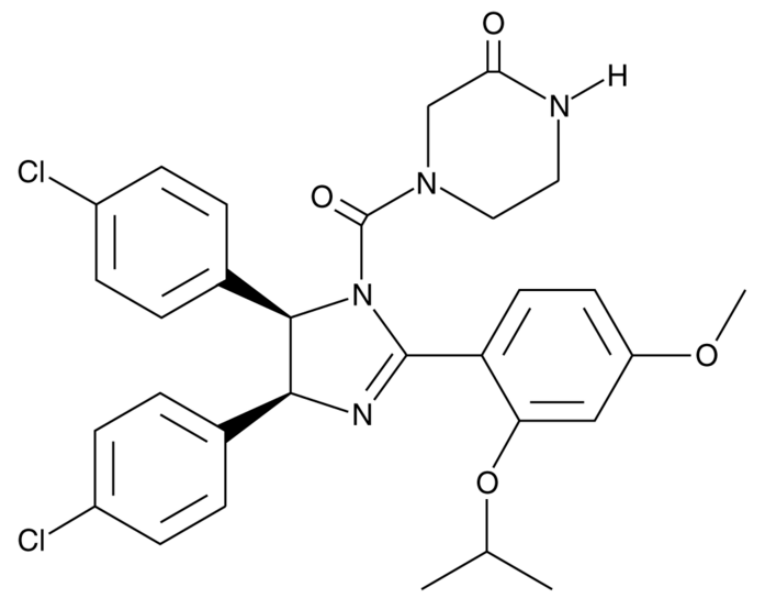

B<smiles></smiles>

Figure 5: Chemical structures of (A) Nutlin-3a ${ }^{102}$ and 5-Vinyl-2'-deoxyuridine (5$\mathrm{VdU})^{103}$.

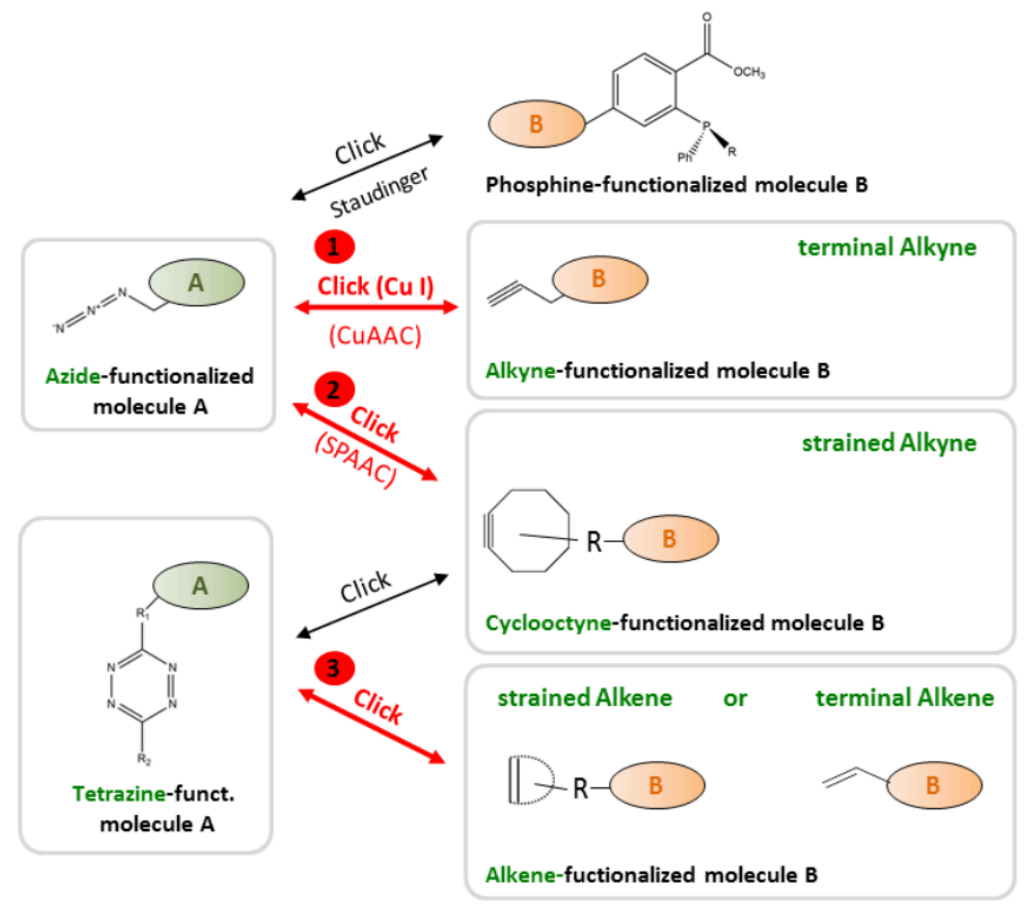

Figure 6: Overview of Click Chemistry reactions ${ }^{104}$ : (1) Copper-catalyzed Azide-Alkyne Click Chemistry reaction (CuAAC). (2) Copper-free Strain-promoted Azide-Alkyne Click Chemistry (SPAAC). (3) Copper-free Tetrazine - Alkene Ligation. 


\subsubsection{Pretargeting}

Bio-orthogonal reactions are ideal for the concept of clinical pretargeting, in which a chemotherapeutic drug is divided into its specific targeting and its cytotoxic components ${ }^{105}$. Pretargeting allows a high dosage of the specific component and only needs a lower concentration of the cytotoxic component to specifically influence targeted cells, which results in a better cost/effect-ratio for the patient due to less side effects. The concept of pretargeting has already been extensively investigated in clinical radiotherapy research, specifically the antibody binding of a tumor-specific target and subsequent specific linkage of a radiolabeled small molecule through streptavidin-biotin, bispecific antibodies, oligonucleotides or click-chemistry ${ }^{105}$.

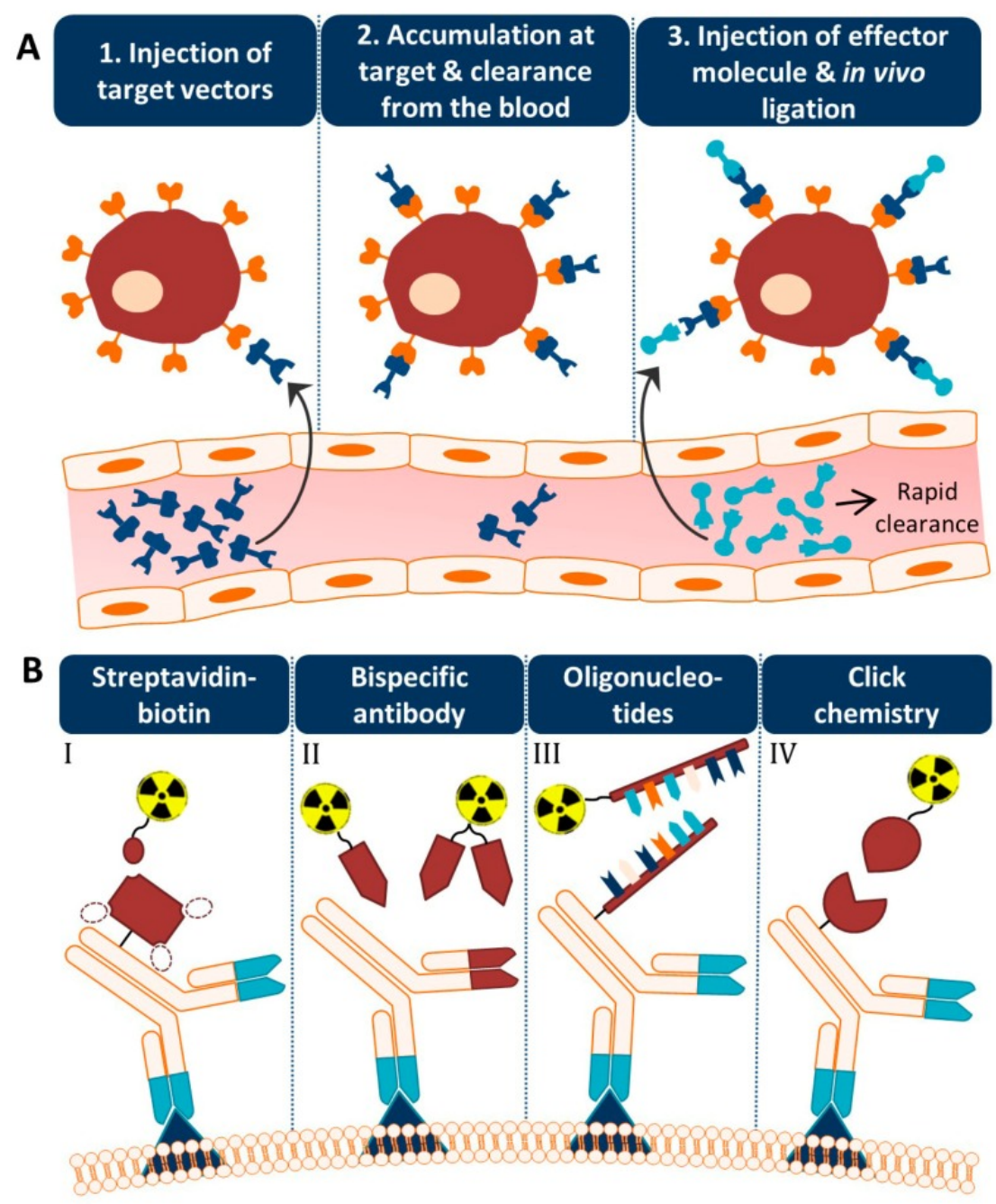

Figure 7: The concept of pretargeting in clinical radiotherapy research ${ }^{105}$. 


\subsection{Scope of the thesis}

In the first part of this dissertation we will investigate the downstream effects of MK2 kinase inhibition on co-treatment with different classes of chemotherapeutics, namely cisplatin and Gemcitabine. The project serves as an example that established chemotherapeutic drugs can be combined with newer substances to enhance their potency. However, as pharmacological inhibition of MK2 leads to different outcomes depending on the chemotherapeutic partner, these combinatory effects are context related and need to be carefully tested in a preclinical setup. In a second manuscript, we show the design of a molecular trap, involving the pretargeting and cyclotherapy treatment schemes, which leads to protection of p53 wildtype and destruction of p53 null cells. This study exemplifies the possibility to specifically mark, target and destroy tumor suppressor mutated cells with a high efficiency.

\section{Manuscript I:}

2.1. Inhibition of MAPKAPK2/MK2 facilitates DNA replication upon cancer cell treatment with gemcitabine but not cisplatin 
Original Articles

\title{
Inhibition of MAPKAPK2/MK2 facilitates DNA replication upon cancer cell treatment with gemcitabine but not cisplatin
}

\author{
Yizhu Li, Frederik Köpper, Matthias Dobbelstein \\ Institute of Molecular Oncology, Göttingen Center of Molecular Biosciences (GZMB), University Medical Center Göttingen, D-37077, Göttingen, Germany
}

\section{A R T I C L E I N F O}

\section{Article history:}

Received 19 January 2018

Received in revised form

10 April 2018

Accepted 22 April 2018

Keywords:

MAPKAPK2

MK2

Gemcitabine

Cisplatin

p38

DNA damage

DNA replication

DNA fiber assays

\begin{abstract}
A B S T R A C T
The signaling pathway driven by p38 and MAPKAPK2 alias MK2 is activated as part of stress responses, and these kinases represent attractive drug targets for cancer therapy. However, seemingly conflicting results were obtained when assessing the role of MK2 in chemotherapy. MK2 inhibitors were reported to either enhance or diminish the chemosensitivity of cancer cells. Here we show that this strongly depends on the particular chemotherapeutic drug. Two different MK2 inhibitors increased the proliferating fraction of pancreatic cancer-derived cells upon treatment with gemcitabine, whereas no consistent protection against cisplatin was observed. Both drugs enhanced, rather than attenuated, the toxicity of another DNA crosslinking agent, mitomycin C. Gemcitabine and cisplatin were each capable of activating MK2, and we did not observe differences in the intracellular localization of MK2 upon treatment. However, DNA replication fork progression, as determined by fiber assays, was restored by MK2 inhibition upon treatment with gemcitabine, but not when cisplatin was used. Thus, MK2 is required for the reduction in DNA replication in response to gemcitabine but not to cisplatin. These observations raise the need to carefully evaluate synergisms and antagonisms with conventional chemotherapeutics when taking MK2 inhibitors to the clinics.
\end{abstract}

(c) 2018 Elsevier B.V. All rights reserved.

\section{Introduction}

Treating cancer cells with conventional chemotherapeutics interferes with the function of cellular machineries, such as those for DNA replication and cell division. Cancer cells often undergo various stress conditions that result from their malignant transformation. The goal of chemotherapy is to exacerbate this stress to induce cell death [1]. This is also true when treating cancers of the exocrine pancreas. However, despite long-term efforts in clinical investigation, this type of cancer remains among the most devastating malignancies, and the best currently available chemotherapeutic regimen only prolongs survival by a few months on average [2].

A major stress response pathway is mediated by the p38 kinases, and their best-understood downstream partner is the protein kinase MAPKAPK2, shortly known as MK2. Stresses that induce p38/MK2 include ultraviolet irradiation, reactive oxygen species, and also chemotherapeutics [3].

Irradiation and chemotherapy represent challenges to DNA

\footnotetext{
* Corresponding author.

E-mail address: mdobbel@uni-goettingen.de (M. Dobbelstein).
}

integrity. This is particularly obvious when treating cells with nucleoside analogues. Gemcitabine is one of the drugs within this class, and it is commonly used in the treatment of pancreatic cancer [4]. It can be incorporated into the nascent DNA strands during replication, thus making it difficult to continue DNA synthesis. On the other hand, gemcitabine is an inhibitor of ribonucleotide reductase and thereby interferes with the synthesis of the dNTPs required for replication.

Co-treatment with platinum-based chemotherapeutics, such as cisplatin, provides a small but measurable benefit for pancreatic cancer patients, compared with gemcitabine therapy alone [5]. These drugs directly cause DNA damage by crosslinking of bases, both within (intra) and between (inter) DNA strands [6]. Interstrand crosslinks represent a particularly difficult-to-resolve alteration on DNA, and their removal requires the Fanconi anemia repair system [7]. Targeting components of this system, e. g. by inhibiting their stabilization by heat shock protein inhibitors, represents an opportunity of enhancing the efficacy of platinum-based drugs. Accordingly, we have recently identified synergistic activities of carboplatin and an HSP90 inhibitor [8].

One particularly vulnerable phase in the cell cycle consists in S phase. DNA damage in this phase will interfere with the 
progression of DNA replication forks, a condition commonly referred to as replicative stress or replication stress. Enhancing replicative stress in tumor cells represents an important strategy to eliminate them for therapeutic purposes [9]. On the other hand, the avoidance of replicative stress may contribute to cancer cell survival and chemoresistance. For instance, about $50 \%$ of all human cancers retain at least one intact copy of the p53-encoding gene, despite its tumor-suppressive activity. According to our previous findings, one advantage of maintaining p53 in its wildtype state consists in the reduction of replicative stress, both through cell cycle arrest upon DNA damage [10-12] and also through increasing replication processivity during $S$ phase [13].

We have previously established MK2 as a mediator of replicative stress. Specifically, MK2 activity is required to induce the stalling of DNA replication forks upon treatment of cells with gemcitabine, or with inhibitors of the checkpoint kinase Chk1. Mechanistically, MK2 limits the activity of the translesion synthesis polymerases $\eta$ and $\zeta$. A small compound (MK2 inhibitor III [14]) can be employed to inhibit MK2. In the presence of this inhibitor, DNA replication continues despite the presence of the chemotherapeutic nucleoside analogue gemcitabine. Thus, intracellular signaling is a determinant of tumor cell sensitivity towards this type of drugs [15,16]. MK2 was also reported to diminish Myc-driven DNA replication through induction of microRNA 34c [17].

In seeming contrast to our results, the groups headed by M. Yaffe and $\mathrm{C}$. Reinhardt found that the absence or inhibition of MK2 can lead to enhanced chemosensitivity. According to their data, when p53-deficient cells are treated with cisplatin, the absence of MK2 enhances cell death. Concerning the underlying mechanisms, it was proposed that MK2 phosphorylates regulators of mRNA stability, thereby enhancing the expression of specific genes and providing a block to mitotic entry before DNA repair occurs [18-20]. MK2 becomes essential for cell survival in this context, in particular when wild type p53 is deleted [21]. According to this concept, MK2 inhibition may provide a strategy for enhancing the response of pancreatic cancers to cisplatin.

At least at first glance, these findings seem contradictory to our previous results. However, it should be noted that not only different classes of chemotherapeutics were used by the two labs, but also different cell species. We therefore compared the impact of MK2 inhibition on chemosensitivity and DNA replication, using the same species of pancreatic cancer cells but different chemotherapeutics, namely gemcitabine and cisplatin. Strikingly, the inhibition of MK2 had differential effects on the sensitivity of these cells towards the two drugs. While MK2 inhibition uniformly diminished the efficacy of gemcitabine, different inhibitors modulated the cytotoxicity of cisplatin in varying directions, and the toxicity of mitomycin $C$ was uniformly enhanced by them. Thus, the previous observations from the two groups can be reconciled. Mechanistically, MK2 inhibition alleviates the impairment of DNA replication by gemcitabine, but not when cells were treated with cisplatin. Thus, MK2 inhibition differentially contributes to cancer cell response, depending on the chemotherapeutic drug that the inhibitor is combined with.

\section{Materials and methods}

\subsection{Cell culture and treatment}

Panc1 and MIA PaCa-2 cells were obtained from the German Collection of Cell lines (DSMZ, Braunschweig) and maintained in Dulbecco's modified Eagle's medium (DMEM) supplemented with $10 \%$ fetal bovine serum (FBS) and antibiotics, at $37^{\circ} \mathrm{C}$ in a humidified atmosphere with $5 \% \mathrm{CO}_{2}$. For treatment, gemcitabine (Gemzar, $100 \mathrm{nM}$, Eli Lilly), cisplatin (Cisplatin KL, Neocorp), MK2 inhibitor III (10 $\mu$ M Cayman Chemical), PF3644022 (10 $\mu \mathrm{M}$ Sigma) and sorbitol
(0,4 M, Roth), were diluted in pre-warmed medium and added to the cells for the indicated periods of time.

\subsection{Assessment of cell proliferation}

Cells were seeded at a density of 8000 cells/well in 96-well plates. $24 \mathrm{~h}$ later, the cells were treated with the drugs at the indicated concentrations, for $24 \mathrm{~h}$, and then incubated with fresh media again. Subsequently, the percentage of cell confluence was determined every $24 \mathrm{~h}$ by bright-field microscopy using a Celigo Adherent Cell Cytometer (Nexcelom). Cell proliferation was calculated from the increase in plate confluence using the Celigo software and evaluating three biological replica at each time point.

\subsection{DNA fiber assays}

DNA fiber assays to analyze replication fork progression and origin firing was essentially carried out as described previously [15]. The cells were pulse-labeled with $25 \mu \mathrm{M}$ 5-chloro-2'-deoxyuridine (CldU) for $20 \mathrm{~min}$, followed by $250 \mu \mathrm{M}$ 5-iodo-2'-deoxyuridine (IdU; both from Sigma-Aldrich) for 1 or $2 \mathrm{~h}$, along with treatment by gemcitabine and/or inhibitor as indicated. Cisplatin pretreatment was carried out for $24 \mathrm{~h}$. The cells were harvested, and DNA fibers were spread on glass slides. After acid treatment, CldU- and IdU-labeled tracts were detected by $1 \mathrm{~h}$ incubation at $37^{\circ} \mathrm{C}$ with rat anti-BrdU antibody (dilution 1:500 detects BrdU and CldU; AbD Serotec) and mouse anti-BrdU antibody (1:500, detects BrdU and IdU; Becton Dickinson). Slides were fixed in 4\% paraformaldehyde/PBS and incubated for $2 \mathrm{~h}$ at room temperature with Alexa Fluor 555-conjugated goat anti-rat antibody (dilution 1:250) or Alexa Fluor 488-conjugated goat anti-mouse antibody (dilution 1:250; both from Molecular Probes/Thermofisher). Samples were mounted in Vectashield (Vector Laboratories). Fiber images were acquired by fluorescence microscopy. The lengths of CldU- (red) and IdU- (green) labeled fibers were measured by using the Fiji software in pixels, converted to micrometers and subsequently converted to $\mathrm{kb}$ using the conversion factor $1 \mu \mathrm{m}=2.59 \mathrm{~kb}$. Replication structures were quantified by using the Cell Counter Plug-in for Fiji (Kurt De Vos, University of Sheffield, Sheffield, United Kingdom).

\subsection{Immunoblot analysis}

Cells were harvested in protein lysis buffer (20 mM TRIS-HCl pH 7.5, $150 \mathrm{mM} \mathrm{NaCl}, 1 \mathrm{mM} \mathrm{Na}_{2}$ EDTA, $1 \mathrm{mM}$ EGTA, $1 \mathrm{mM}$ betaglycerophosphate, $2 \mathrm{M}$ urea, protease inhibitor cocktail, Roche). After $10 \mathrm{~min}$ lysis on ice, the samples were briefly sonicated to disrupt DNA-protein complexes. Total protein concentration was measured using a Pierce BCA Protein assay kit (Thermo Scientific Fisher). After boiling the samples in Laemmli buffer at $95^{\circ} \mathrm{C}$ for $5 \mathrm{~min}$, equal amounts of protein samples were separated by SDSPAGE, transferred onto nitrocellulose, and visualized with the following antibodies, followed by peroxidase-coupled secondary antibodies and chemiluminescence: Phospho-MAPKAPK-2 (Thr334) (3007, Cell Signaling), Phospho-Hsp27 (Ser82) (2401, Cell Signaling), MAPKAPK-2 (MK2) (3042, Cell Signaling), Hsp27 (2402, Cell Signaling), beta-Actin (ab8227 Abcam), Phospho-KAP1 (Ser824) (ab70369, Abcam).

\subsection{Flow cytometry}

For cell cycle analysis, cells were fixed in ethanol and washed with $0.05 \%$ Triton-X in PBS. Subsequently, the cells were resuspended in $1 \mathrm{mg} / \mathrm{ml}$ RNAse A solution in PBS and incubated for $30 \mathrm{~min}$ at $37^{\circ} \mathrm{C}$, and then with propidium iodide (final 
concentration: $30 \mu \mathrm{g} / \mathrm{ml}$ ). Flow cytometry was performed using the Guava PCA-96 Base System (Millipore), and the distribution of DNA contents was determined using the Guava Express Pro software.

\subsection{Plasmid construction and establishment of stable cell lines}

U2OS cells were transfected with expression plasmids and selected with neomycin to obtain stable integrates. MK2-myc expression was verified by immunofluorescence analysis. A polyclonal U2OS cell line stably expressing Myc-MK2 WT was generated by transfection with the vector pIRESneo Myc-MK2 WT. To generate a control cell line, U2OS cells were transfected with the empty vector pIRESneo. pIRESneo encodes neomycin-resistance. Cells that integrated the construct into their genome were selected with $500 \mu \mathrm{g} / \mathrm{ml}$ geneticin.

\subsection{Immunofluorescence analysis}

Upon fixation (4\% paraformaldehyde, 20min) and permeabilization $(0.2 \%$ Triton X $100,30 \mathrm{~min})$, the cells were blocked with $10 \%$ FCS in PBS, and incubated with primary antibodies to the myc tag, clone 4A6, 1:200 (CA92590, Upstate) and a secondary antibody labeled with AlexaFluor488 goat anti-mouse (A-11029, Molecular Probes). Images were obtained by fluorescent microscopy Zeiss Axioscope A1, ZEN 2 software.

\section{Results}

\subsection{MK2 inhibition confers protection of cells specifically towards gemcitabine}

To directly compare the impact of MK2 inhibition on chemosensitivity, we treated Panc1 cells (pancreatic ductal epithelial carcinoma, carrying the p53 mutation $\mathrm{R} 273 \mathrm{H}$ and the K Ras mutation 12D [22]) with gemcitabine or cisplatin, at different concentrations. In addition, the cells were treated with an inhibitor of MK2 or control-treated. After replacing all drugs with fresh media, we followed the capability of the surviving cells to grow into confluence over several days, as monitored by translucent microscopy and quantitative image evaluation (Celigo). In the presence of gemcitabine, cell growth was rescued by the MK2 inhibitor III (Fig. 1A), as we had observed previously [15,16]. In contrast, however, the MK2 inhibitor III enhanced the cytotoxic activity of cisplatin (Fig. 1B). Thus, when cells were co-treated with MK2 inhibitor III and cisplatin, far less cells retained the capability of proliferation when compared to the individual treatment with each drug. Analogous observations were made with MIA PaCa-2 cells (KRas 12C, p53 248 W [22]; Fig. 1C and D). Thus, MK2 inhibitor III affects the sensitivity of cells towards each drug in opposite directions. It confers resistance towards gemcitabine, in agreement with our previous findings [15,16], but it also sensitizes the same p53-mutant cells towards cisplatin, in agreement with the reports from the Yaffe lab $[18,20,21]$. Using a different MK2 inhibitor, PF3644022 [23], reproduced the results obtained with gemcitabine in the MIA PaCa-2 cell line. Like MK2 inhibitor III, PF-3644022 profoundly reduced the toxicity of gemcitabine, further corroborating the notion that MK2 is a key mediator for the cytotoxic effect of gemcitabine (Fig. 1E). Interestingly, cell survival was differentially affected by the two MK2 inhibitors, as revealed by cotreatment with cisplatin and PF-3644022 (Fig. 1F). In contrast to MK2 inhibitor III (Fig. 1D), PF-3644022 enhanced the survival of cisplatin-treated cells to some extent, perhaps due to additional targets of the two drugs [24]. To test the impact of MK2 inhibitors on the efficacy of another DNA crosslinking agent, we treated the cells with mitomycin-c (MMC), with and without MK2 inhibitors, and followed cell survival by quantitative microscopy (Fig. 1G). Both MK2 inhibitor III as well as PF-3644022 decreased cell survival upon MMC treatment, in contrast to their pro-survival effects when combined with gemcitabine. We conclude that MK2 appears as a survival factor, rather than a mediator of cytotoxicity, in the presence of the DNA-cross-linker MMC.

\subsection{Gemcitabine and cisplatin are each capable of inducing MK2 activity}

Besides the classical DNA damage responsive signaling pathways driven by ATM/Chk2 and ATR/Chk1, chemotherapeutics also induce stress signaling through the p38 kinases and MK2, as we have previously reported for gemcitabine $[15,16]$. To test whether the same is true for cisplatin, we incubated MIA PaCa-2 cells with each drug, followed by immunoblot detection of phosphorylated Hsp27, a bona fide substrate of MK2 [25]. Cisplatin and gemcitabine each induced Hsp27 phosphorylation to comparable extents and with comparable kinetics (Fig. 2A). Hsp27 phosphorylation was strongly diminished by MK2 inhibition (quantified in Fig. S1), indicating that it was indeed reflecting MK2 activation. The same effect was observed using the MK2 inhibitor PF3644022 (Fig. 2B). Thus, both gemcitabine and cisplatin are comparable activators of MK2. Moreover, both drugs increased the phosphorylation of Kap1 (Fig. 2C), a substrate of ATM [26], with cisplatin having a stronger impact. Of note, the MK2 inhibitor III somewhat increased cisplatin-induced Kap1 phosphorylation, while gemcitabinemediated Kap1 phosphorylation was reduced by MK2 inhibition. Thus, the differential effect of MK2 inhibition on cell proliferation (Fig. 1) was reflected by the phosphorylation of Kap1 (Fig. 2C), arguing that ATM activity and thus the DNA damage response is aggravated by MK2 inhibition in the case of cisplatin, but attenuated upon gemcitabine treatment.

\subsection{Neither gemcitabine nor cisplatin detectably affect the intracellular location of MK2}

It was previously proposed that MK2 displays a cytoplasmic activity to stabilize Gadd45alpha, thus providing a protective checkpoint [20]. We therefore tested whether cisplatin or gemcitabine might change the intracellular location of MK2. First, we generated a cell line that stably expresses MK2 with an immunotag, thus enabling the detection of MK2 by immunofluorescence (endogenous MK2 levels were insufficient for detection by this method). MK2 was mostly found in the nucleus with some additional cytoplasmic staining (Fig. 3, quantified in Fig. S2A). However, we did not observe a change in this staining pattern when treating the cells with either cisplatin or gemcitabine. In contrast, incubation of the cells with the osmotic stressor sorbitol led to a mostly cytoplasmic location of MK2, in accordance with a previous report [27]. However, co-treatment with gemcitabine or cisplatin did not affect this distribution when compared to sorbitol alone, arguing that the drugs do not actively promote nuclear import of MK2 either. Neither did treatment with MK2 inhibitor affect the location of MK2, arguing that the activity of MK2 does not change its intracellular transport. We have further compared the phosphorylation of MK2 (and also the phosphorylation of its substrate HSP27, Fig. S2B) upon treatment with sorbitol vs. gemcitabine and cisplatin. Here, sorbitol showed by far the strongest activation of MK2. This might well be the reason why MK2 export was observed only with sorbitol. We conclude that, while MK2 is an important determinant of cellular responses to chemotherapy, its basal activity seems sufficient for this, without the need for strong activation, phosphorylation and export of MK2. We further conclude that a differential role of MK2 in the efficacy of the two drugs cannot be 

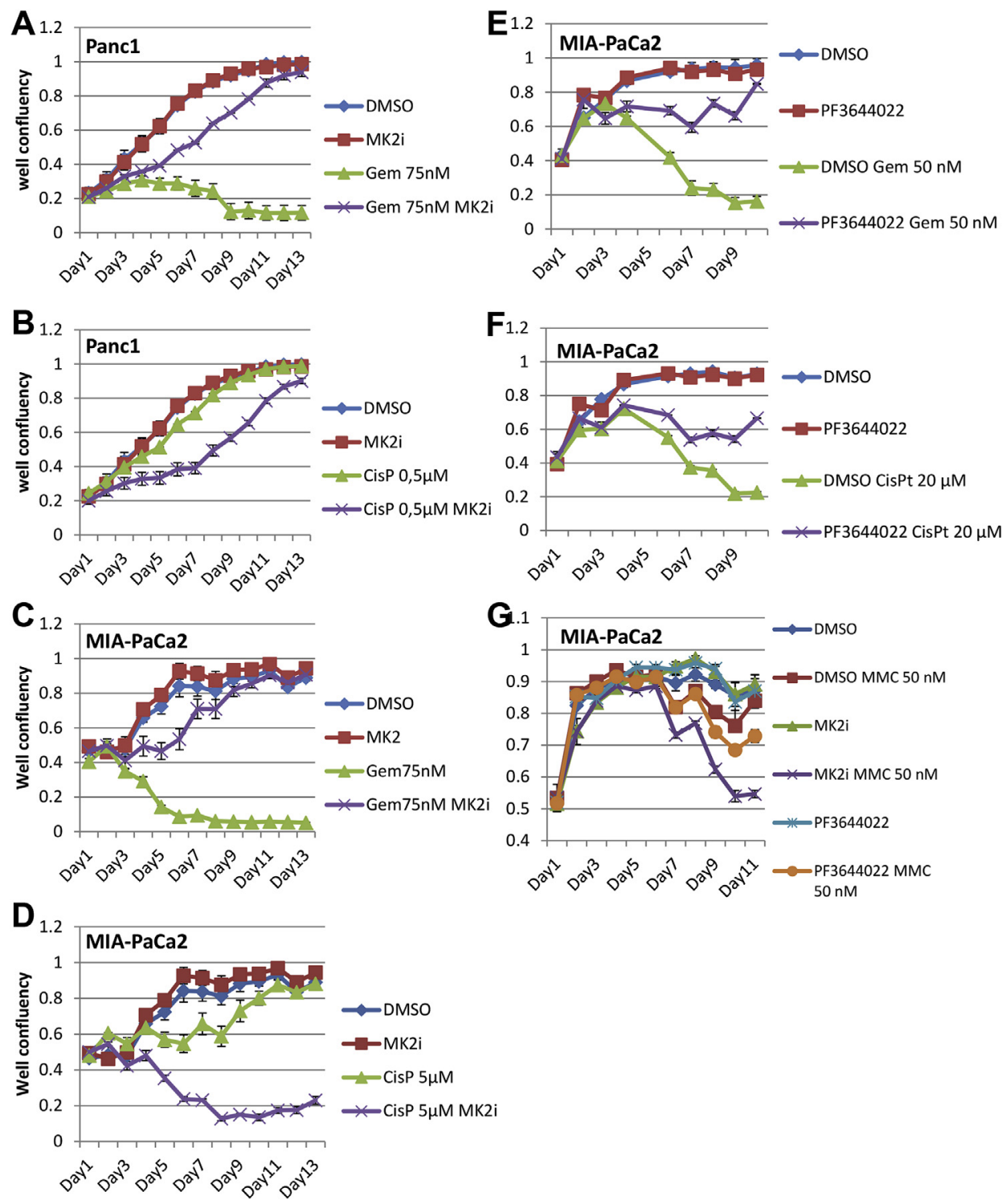

Fig. 1. MK2 inhibition protects pancreatic cancer cells against gemcitabine but sensitizes against cisplatin.

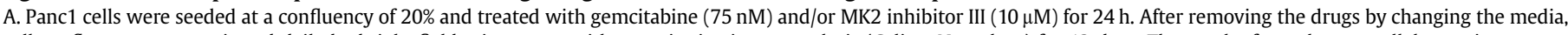

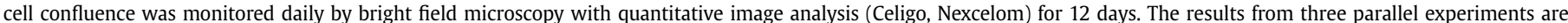

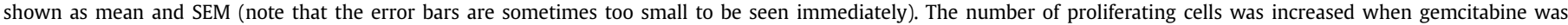

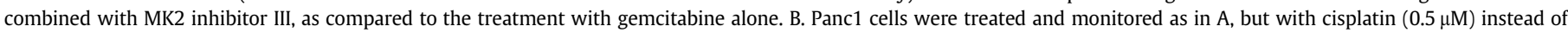

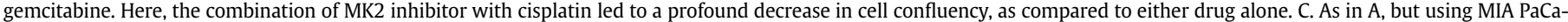

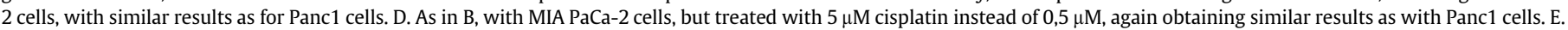

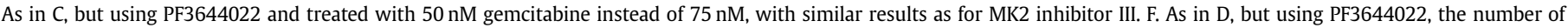

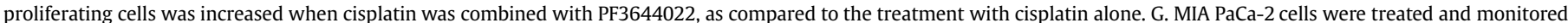

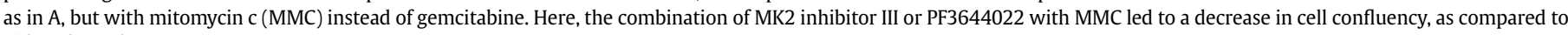
either drug alone.

explained by drug-induced differences in intracellular MK2 location.

\subsection{DNA replication fork progression is enhanced by $M K 2$} inhibition in the presence of gemcitabine but not cisplatin

To understand the differential sensitivity of MK2-inhibitortreated cells towards the two chemotherapeutics, we now explored the characteristics of DNA replication under each condition. First, we assessed the distribution of DNA content upon treatment of an asynchronous MIA PaCa- 2 cell population with either gemcitabine or cisplatin for $48 \mathrm{~h}$ (Fig. $4 \mathrm{~A}$ ). In the case of gemcitabine, most cells accumulated with a DNA content between $2 \mathrm{n}$ and $4 \mathrm{n}$, indicative of an arrest in $\mathrm{S}$ phase. In contrast, a large proportion of the cisplatintreated cells were found with a DNA content near $4 \mathrm{n}$, arguing that they still go through $S$ but arrest at G2/M. These notions were confirmed by quantitation of the cell cycle profiles. Thus, DNA replication is impaired by gemcitabine but only to a lesser extent by cisplatin.

To further address the impact of MK2 on DNA replication, DNA fiber assays were performed by incubating the pretreated cells with nucleosides that carry halogen substitutions in their bases. Upon incorporation of these nucleosides, newly synthesized DNA becomes detectable by antibodies. Subsequently, the cells were 

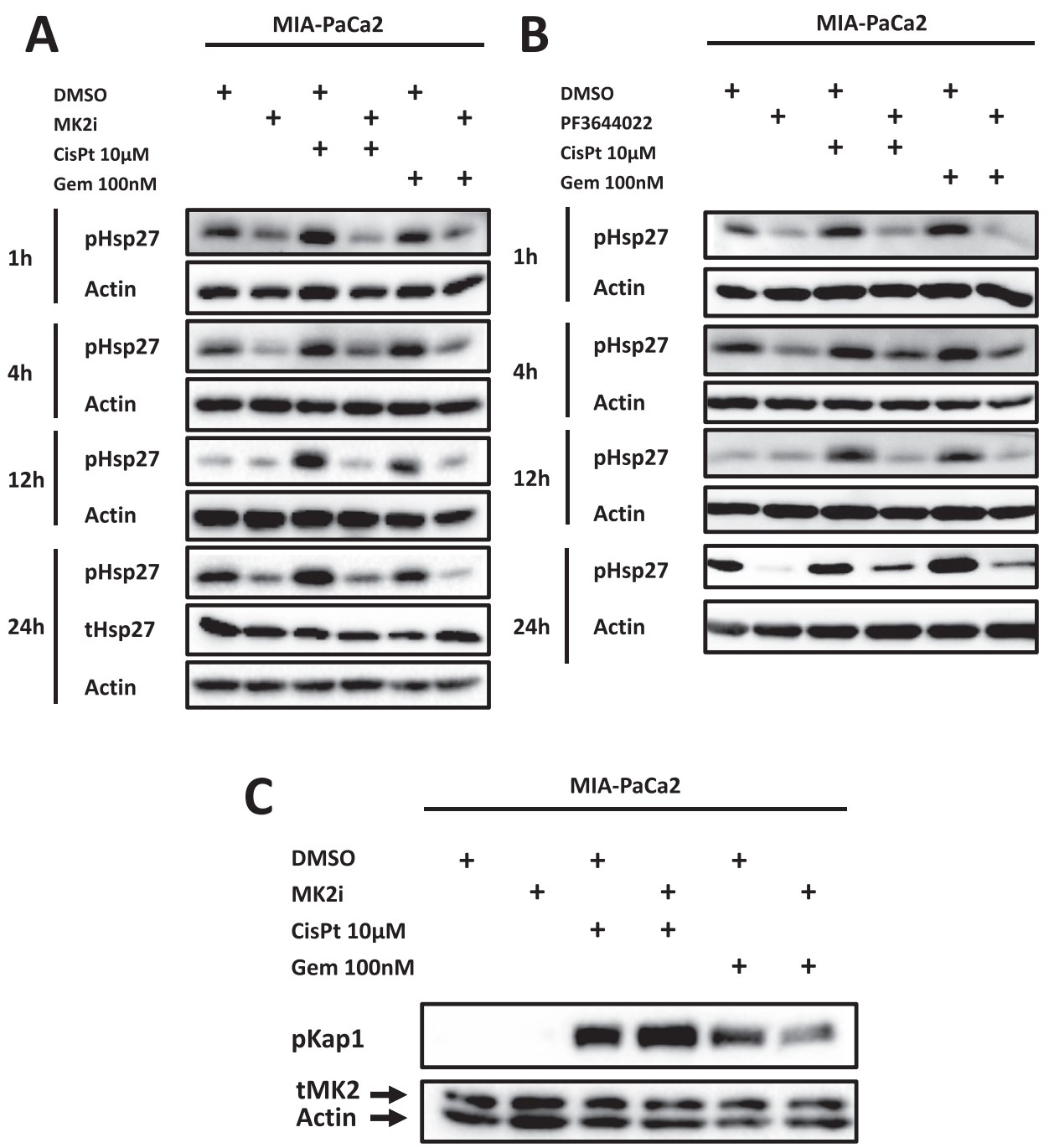

Fig. 2. MK2 activation by cisplatin as well as gemcitabine but differential impact of MK2 on the DNA damage response.

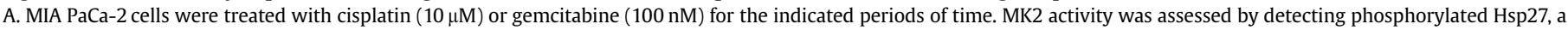

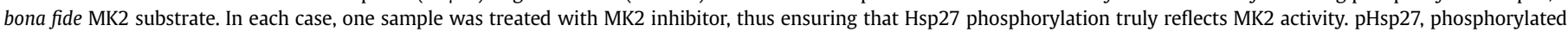

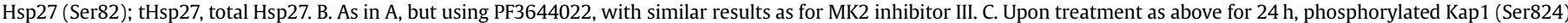

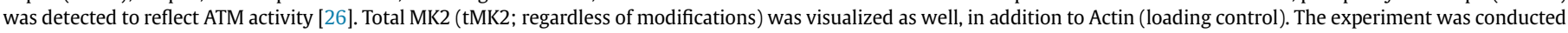
thrice, $\mathrm{n}=3$.

harvested and their DNA was spread on glass slides, followed by fluorescent detection of DNA that was synthesized during the labeling period. The length of labeled tracks on DNA fibers allowed us to determine the average speed by that replication forks moved along their template (Fig. 4B). As shown previously in other cell species [15], we found that gemcitabine reduced fork progression in pancreatic cancer cells. However, this was partially rescued by the addition of MK2 inhibitor (Fig. 4, B-E, Suppl. Fig. S3A and Suppl. Table S1), consistent with our previous results and pointing to a chemoprotective effect of MK2 inhibition [15,16]. Like MK2 inhibitor III, PF-3644022 enhanced DNA replication fork progression in the presence of gemcitabine (Fig. 4, F-G, Suppl. Fig. S3D and Suppl. Table S2).

Next we tested whether the same holds true in cisplatin-treated cells. Firstly, we found that only high amounts of cisplatin $(10 \mu \mathrm{M}$ but not $5 \mu \mathrm{M}$ for MK2 inhibitor III, and $50 \mu \mathrm{M}$ for PF3644022) for $24 \mathrm{~h}$ compromised DNA replication to an extent that could be readily observed by DNA fiber assays (Suppl. Fig. S3, cf. B and C). To explain this, it should be noted that commonly used amounts of cisplatin cause relatively few DNA interstrand crosslinks within the genome, roughly 1000 per cell when using $1 \mu \mathrm{M}$ cisplatin [28] on a total DNA content of $2 \times 3 \times 10^{9}$ bases. We assume that DNA replication at these few sites is virtually impossible, since DNA strands cannot be separated there. However, the majority of DNA regions appear to remain in a state that allows unperturbed replication. Based on these considerations, we were using high concentrations of cisplatin $(10 \mu \mathrm{M})$ for $24 \mathrm{~h}$ and indeed observed impaired DNA replication by reduced track length in fiber assays. Importantly, however, this reduction in fork progression was not ameliorated by MK2 inhibitor III (Fig. 5, A-D, Suppl. Fig. S3C and Suppl. Table S1) nor by PF3644022 (Fig. 5, E-F, Suppl. Fig. S3E and Suppl. Table S2).

We conclude that the protective effect of MK2 inhibitors on the processivity of DNA replication applies to a nucleoside analogue but not to a DNA-crosslinking agent such as cisplatin.

\section{Discussion}

Our results clarify the differential response of cancer cells to combinations of chemotherapy with MK2 inhibition. Rather than 


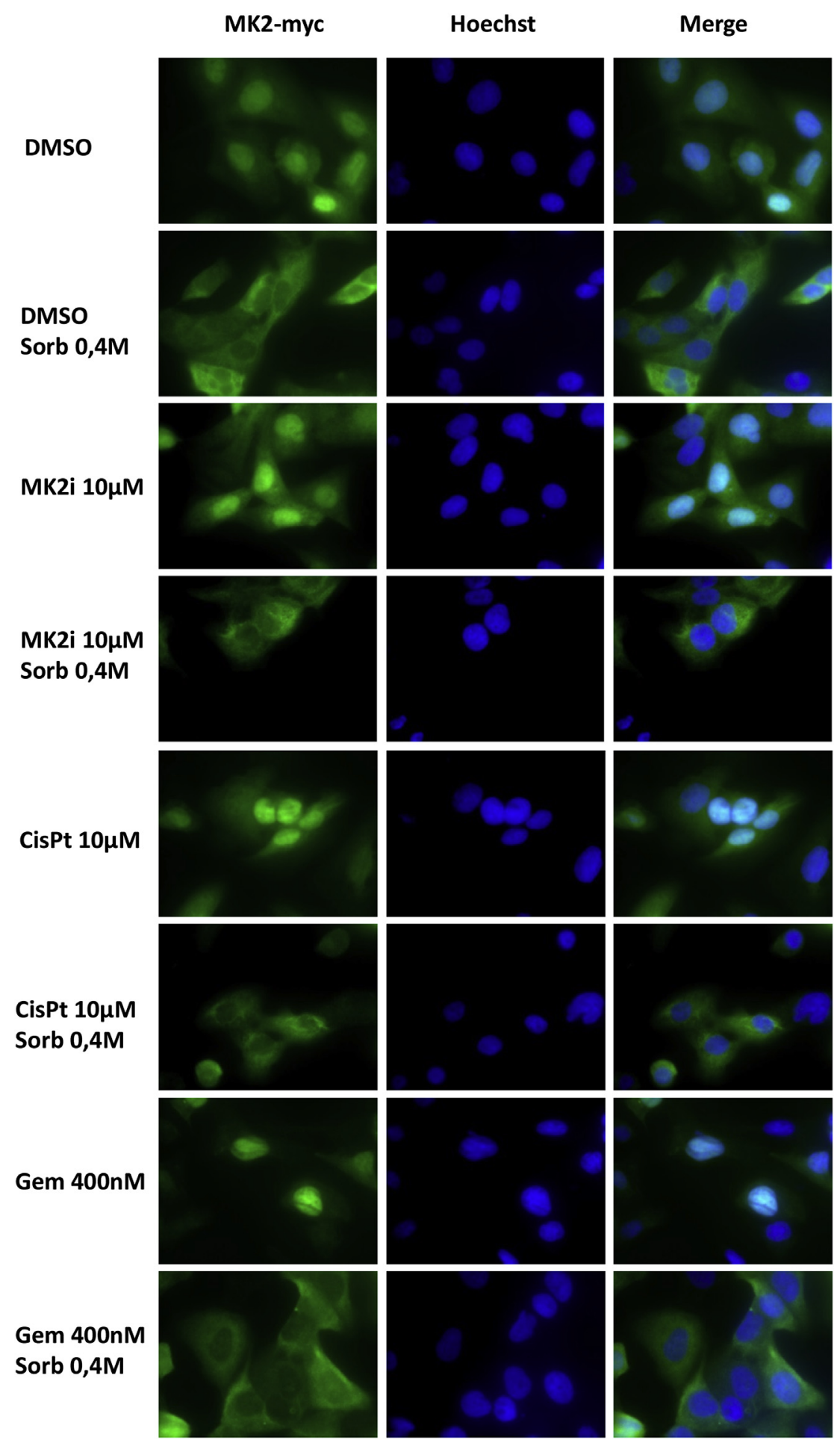

Fig. 3. Lack of change in MK2 location upon treatment with cisplatin or gemcitabine.

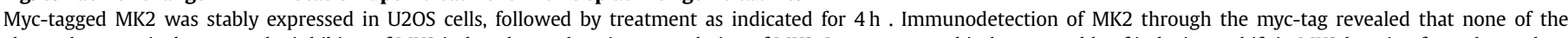

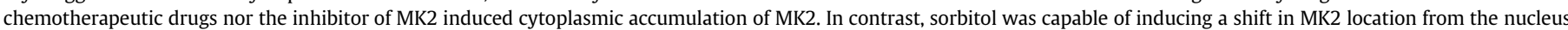

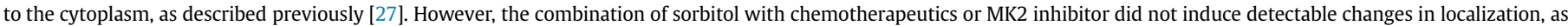
compared to sorbitol alone.

contradicting each other, the previously published results on such combinations are compatible. MK2 inhibition can sensitize or protect cancer cells of the same species, depending on the chemotherapeutic drug that the inhibitor is combined with. MK2 inhibition alleviates replicative stress imposed by a nucleoside analogue, gemcitabine but not when combined with cisplatin.

Inhibitors of MK2 represent promising candidates for clinically improving cancer treatment. Mice with a targeted disruption of the gene encoding MK2 are viable [29], strongly suggesting that specific MK2 inhibitors should have acceptable toxicities to a patient. 
A

DMSO

DMSO Gem100nM

DMSO Cisp10 $\mu \mathrm{M}$
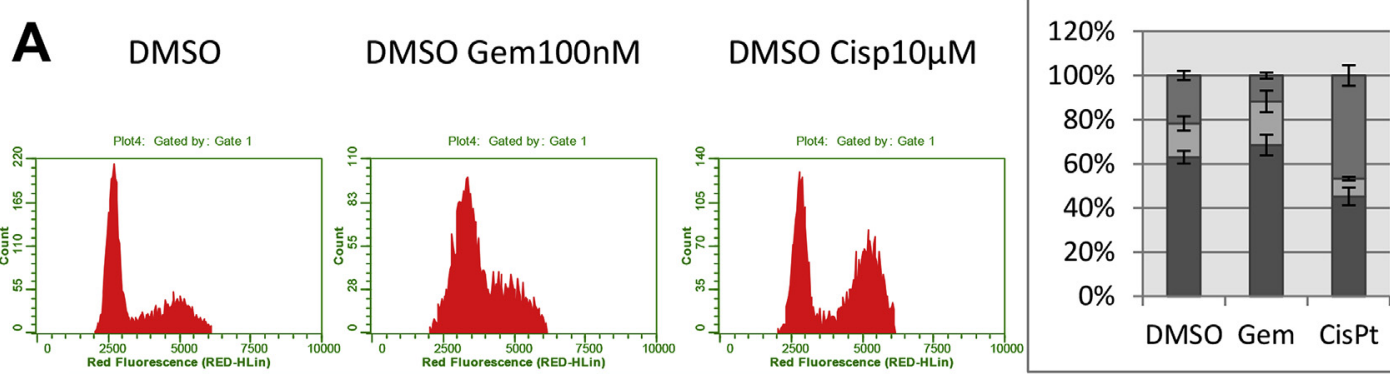

$\square \mathrm{G} 2 / \mathrm{M}$

$\square \mathrm{S}$

$\square \mathrm{G} 1$

B

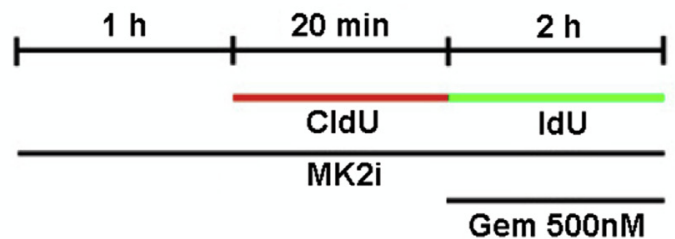

C

control

Gemcitabine 500nM

DMSO

MK2i
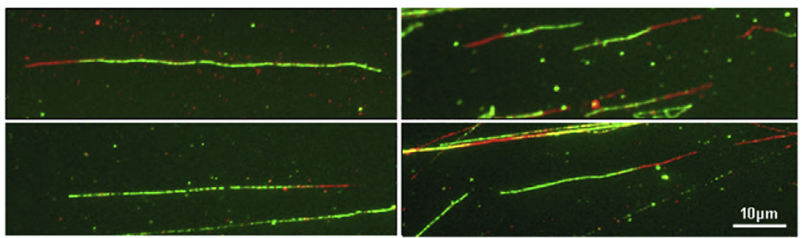

D
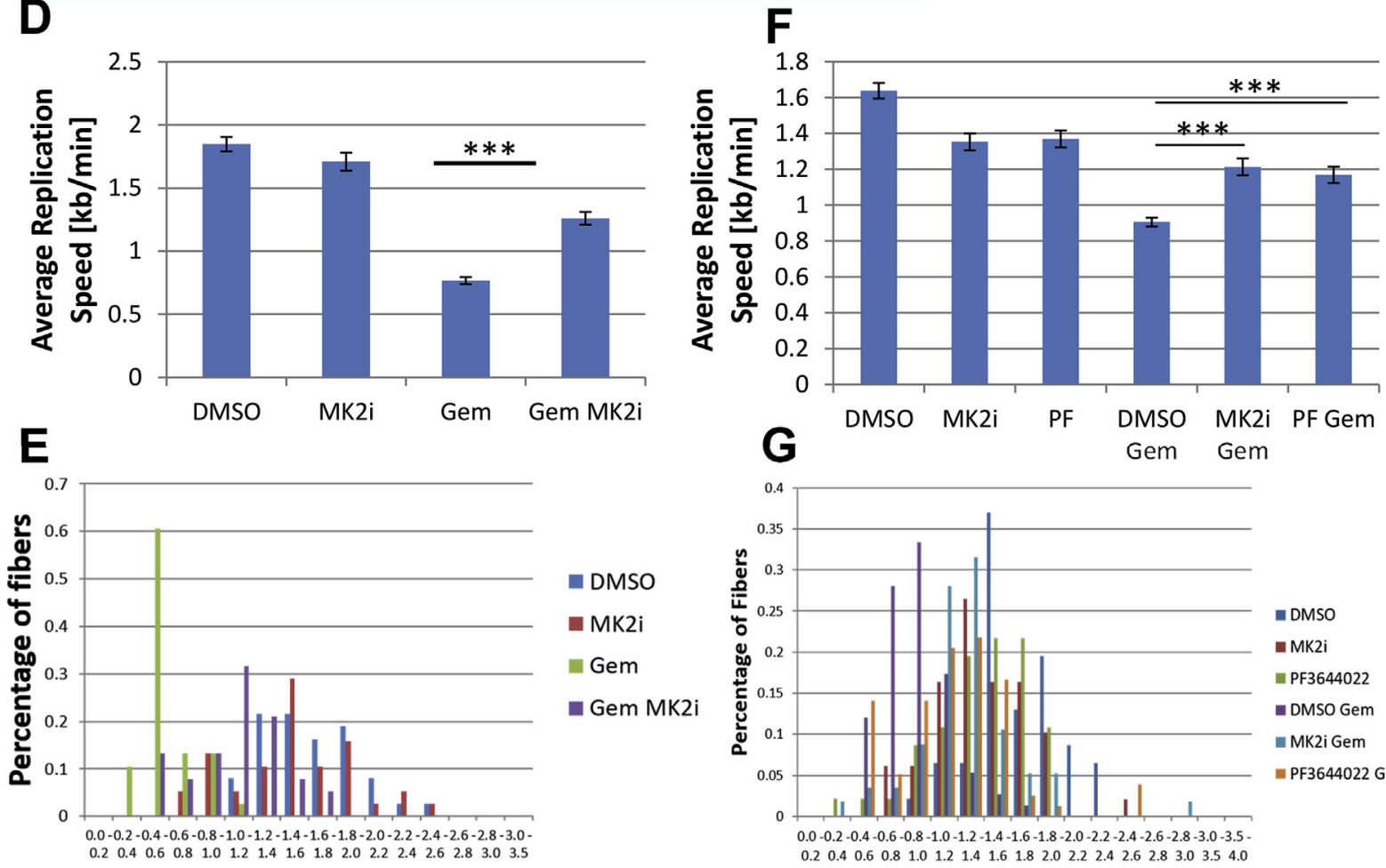

Replication Fork Speed [kb/min]

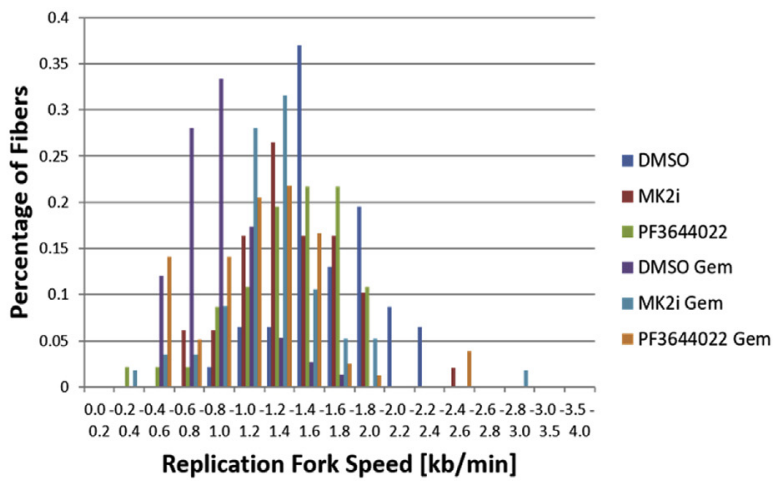

Fig. 4. Restored DNA replication by MK2 inhibition in the presence of gemcitabine.

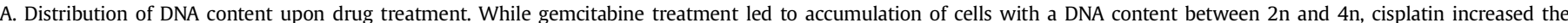

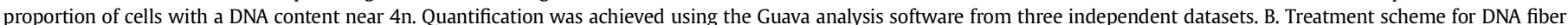

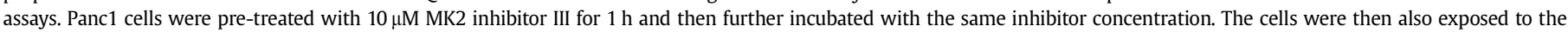

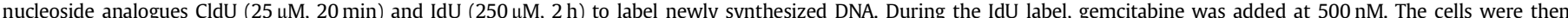

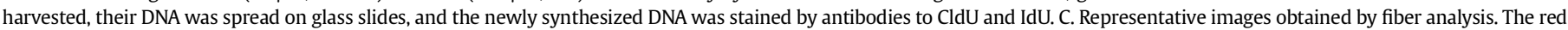

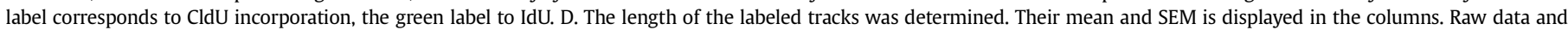

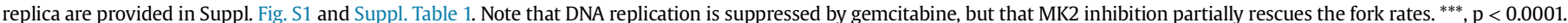

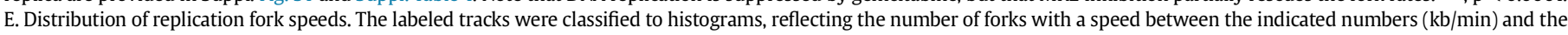

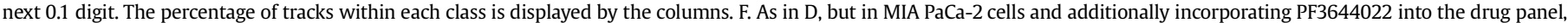
with similar results. G. Evaluation as in E. (For interpretation of the references to colour in this figure legend, the reader is referred to the Web version of this article.) 


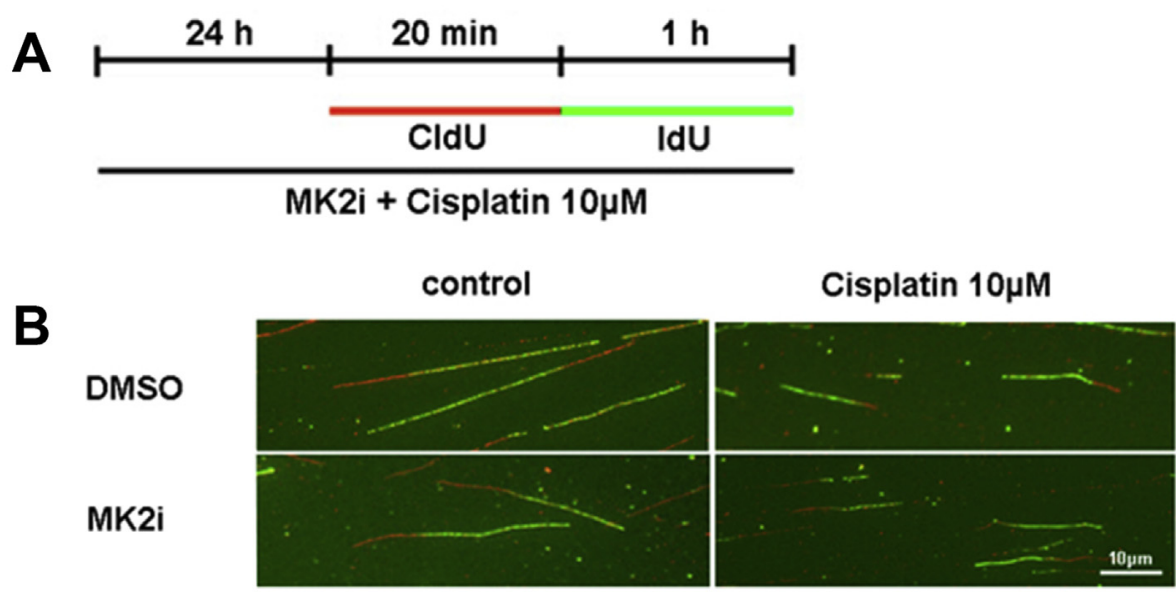

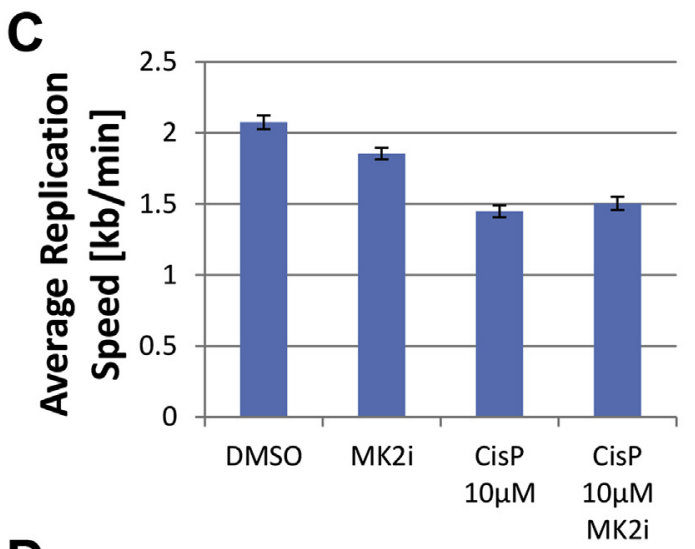

$\mathbf{D}$

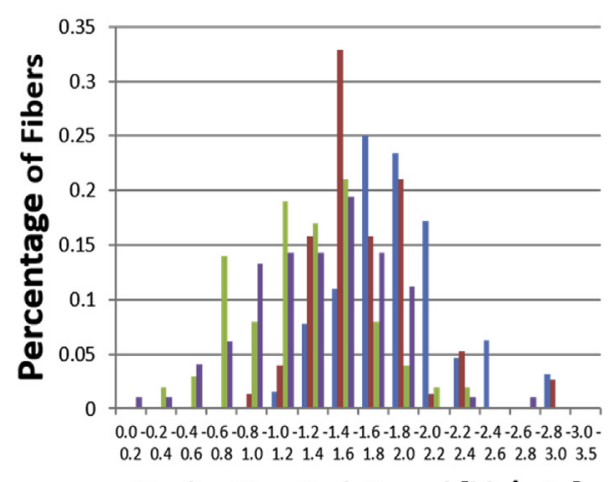

Replication Fork Speed [kb/min]

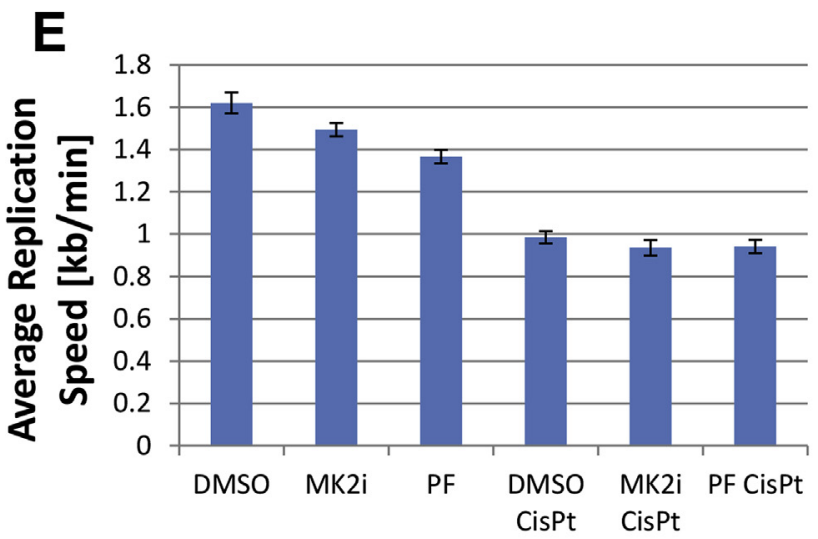

$\mathbf{F}$

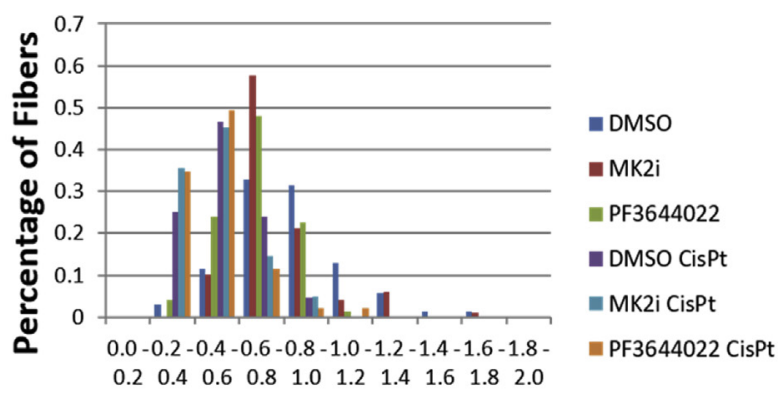

Replication Fork Speed [kb/min]

Fig. 5. Compromised DNA replication by high concentrations of cisplatin, but independent of MK2 inhibition.

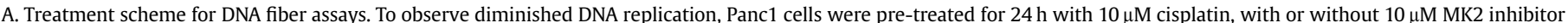

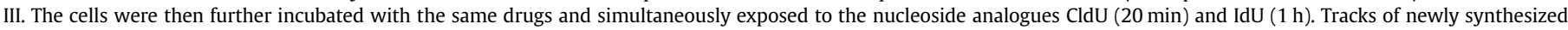

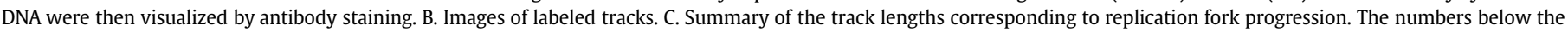

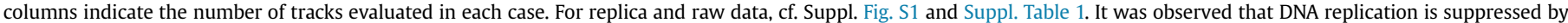

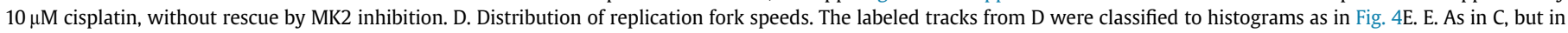
MIA PaCa-2 cells and additionally incorporating PF3644022 into the drug panel, with similar results using $50 \mu \mathrm{M}$ instead of $10 \mu \mathrm{M}$ cisplatin. F. Evaluation as in D.

The same holds true for mice that lack both MK2 and MK3 [30], raising the possibility that even inhibitors of both kinases should be tolerable. However, our results make it clear that care must be taken when choosing the particular chemotherapeutic drug to combine with MK2 inhibitors. This raises the question which drugs will cooperate with MK2 inhibitors, and in which cases the drugs will antagonize each other. Cooperation for increased cytotoxicity was reported for cisplatin, but also for the topoisomerase II inhibitor doxorubicin $[18,20]$. Moreover, MK2 can mediate resistance to gamma irradiation by phosphorylating ATDC/TRIM29 [31]. MK2 also confers resistance to oxidative stress [32]. These effects might be overcome by MK2 inhibition, leading to synergistic cytotoxicity. On the other hand, we have previously observed cytoprotection by MK2 inhibitors during treatment with gemcitabine [15,16], ultraviolet irradiation [15], and treatment with a Chk1 inhibitor [15]. Thus, it appears that drugs and DNA damage that 
mostly interfere with DNA replication can be antagonized by MK2 inhibition, whereas other drugs can cooperate with the MK2 inhibitors. However, in the case of topoisomerase inhibitors, this distinction is difficult to make in a sharp manner, since topoisomerases are essential during DNA replication but also required for DNA integrity during other phases of the cell cycle [33].

When combining Chk1 inhibitors with MK2 inhibitors, another interesting difference arises with respect to the tumor genotype. It was reported that tumor cells with a KRAS mutation specifically lose viability in response to the simultaneous inhibition of both kinases [34]; this is in contrast to our observations in U2OS cells, where the two drugs antagonize each other [15]. Thus, and perhaps not surprisingly, the tumor cell genotype also needs to be taken into account when evaluating these drug combinations.

Additional reasons for differential sensitization of cancer cells towards chemotherapeutics may also consist in the specific requirements of DNA repair machineries. For gemcitabine, we have previously found that translesion synthesis polymerases contribute to resistance in an MK2-dependent manner [15]. In the case of cisplatin, however, the Fanconi anemia pathway is of particular importance for repair, and its targeting by HSP90 inhibition sensitizes cancer cells towards platinum compounds [8]. Thus, MK2 activity may affect different repair mechanisms in different ways.

Most other chemotherapeutics have not been evaluated in combination with MK2 inhibitors. Since accurate predictions are difficult, we propose that any other cytotoxic drug needs to be carefully tested as to its cooperation or antagonism with MK2 inhibitors, before taking such drug combinations to the clinics. Mechanistically, the impact of such drugs on DNA replication may serve as a guideline for such evaluations.

If MK2 inhibitors can be tolerated by the body, why would cancer cells respond by cell death, even when cisplatin is applied in addition? It was proposed that the absence of the tumor suppressor p53 determines the response of cells towards the combination [18]. Indeed, the cells that were employed in the present study lack wild type $\mathrm{p} 53$, thereby reflecting the majority of pancreatic carcinomas. It is very possible that the absence of functional p53 fortifies the response observed in our study. For instance, p53 is known to promote the expression of the phosphatase DUSP1/MKP1, an antagonist to p38 signaling [35]. Active p53 may also suppress the accumulation of reactive oxygen species [36]. Thus, the combination of MK2 inhibitor and platinum drugs conceivably takes advantage of a therapeutic window set up by the mutation of p53 in tumor cells.

Inhibitors of p38 are already in clinical trials. For instance, LY2228820 is being tested according to clinicaltrials.gov with the IDs: NCT02322853, NCT02364206, NCT01663857, NCT01393990, NCT02860780. MK2 inhibitors are in preclinical development [24]. Despite the strong potential of these compounds as chemosensitizers, their use in combination therapies requires preevaluation with each particular chemotherapeutic drug to achieve synergisms rather than negative interference.

\section{Author contributions}

YL and MD conceived the project and designed experiments. YL conducted the experiments. MD drafted the manuscript. YL and MD revised the manuscript.

\section{Conflicts of interest}

The authors declare no conflict of interest.

\section{Acknowledgments}

We thank Antje Dickmanns and Cathrin Bierwirth for expert technical assistance. Our work was supported by the Deutsche Krebshilfe 111615, the Wilhelm Sander-Stiftung 2016.143.1, the Deutsche José Carreras Leukämie-Stiftung DJCLS R 11/14, and the Else Kröner-Fresenius-Stiftung 2014-A141.

\section{Appendix A. Supplementary data}

Supplementary data related to this article can be found at https://doi.org/10.1016/j.canlet.2018.04.030.

\section{References}

[1] M. Dobbelstein, U. Moll, Targeting tumour-supportive cellular machineries in anticancer drug development, Nat. Rev. Drug Discov. 13 (2014) 179-196.

[2] I. Garrido-Laguna, M. Hidalgo, Pancreatic cancer: from state-of-the-art treatments to promising novel therapies, Nat. Rev. Clin. Oncol. 12 (2015) 319-334.

[3] E.F. Wagner, A.R. Nebreda, Signal integration by JNK and p38 MAPK pathways in cancer development, Nat. Rev. Canc. 9 (2009) 537-549.

[4] D.S. Gesto, N.M. Cerqueira, P.A. Fernandes, M.J. Ramos, Gemcitabine: a critical nucleoside for cancer therapy, Curr. Med. Chem. 19 (2012) 1076-1087.

[5] V. Heinemann, D. Quietzsch, F. Gieseler, M. Gonnermann, H. Schonekas, A. Rost, H. Neuhaus, C. Haag, M. Clemens, B. Heinrich, U. Vehling-Kaiser, M. Fuchs, D. Fleckenstein, W. Gesierich, D. Uthgenannt, H. Einsele, A. Holstege, A. Hinke, A. Schalhorn, R. Wilkowski, Randomized phase III trial of gemcitabine plus cisplatin compared with gemcitabine alone in advanced pancreatic cancer, J. Clin. Oncol. 24 (2006) 3946-3952.

[6] D. Wang, S.J. Lippard, Cellular processing of platinum anticancer drugs, Nat. Rev. Drug Discov. 4 (2005) 307-320.

[7] A.J. Deans, S.C. West, DNA interstrand crosslink repair and cancer, Nat. Rev. Canc. 11 (2011) 467-480.

[8] D. Kramer, N. Stark, R. Schulz-Heddergott, N. Erytch, S. Edmunds, L. Rossmann, H. Bastians, N. Concin, U.M. Moll, M. Dobbelstein, Strong antitumor synergy between DNA crosslinking and HSP90 inhibition causes massive premitotic DNA fragmentation in ovarian cancer cells, Cell Death Differ. 24 (2) (2017) $300-316$.

[9] M. Dobbelstein, C.S. Sorensen, Exploiting replicative stress to treat cancer, Nat. Rev. Drug Discov. 14 (2015) 405-423.

[10] D. Kranz, M. Dobbelstein, Nongenotoxic p53 activation protects cells against S-phase-specific chemotherapy, Canc. Res. 66 (2006) 10274-10280.

[11] D. Kranz, C. Dohmesen, M. Dobbelstein, BRCA1 and Tip60 determine the cellular response to ultraviolet irradiation through distinct pathways, J. Cell Biol. 182 (2008) 197-213.

[12] E.M. Alexandrova, A.R. Yallowitz, D. Li, S. Xu, R. Schulz, D.A. Proia, G. Lozano, M. Dobbelstein, U.M. Moll, Improving survival by exploiting tumour dependence on stabilized mutant p53 for treatment, Nature 523 (2015) 352-356.

[13] I. Klusmann, S. Rodewald, L. Muller, M. Friedrich, M. Wienken, Y. Li, R. SchulzHeddergott, M. Dobbelstein, p53 activity results in DNA replication fork processivity, Cell Rep. 17 (2016) 1845-1857.

[14] D.R. Anderson, M.J. Meyers, W.F. Vernier, M.W. Mahoney, R.G. Kurumbail, N. Caspers, G.I. Poda, J.F. Schindler, D.B. Reitz, R.J. Mourey, Pyrrolopyridine inhibitors of mitogen-activated protein kinase-activated protein kinase 2 (MK-2), J. Med. Chem. 50 (2007) 2647-2654.

[15] F. Kopper, C. Bierwirth, M. Schon, M. Kunze, I. Elvers, D. Kranz, P. Saini, M.B. Menon, D. Walter, C.S. Sorensen, M. Gaestel, T. Helleday, M.P. Schon, M. Dobbelstein, Damage-induced DNA replication stalling relies on MAPKactivated protein kinase 2 activity, Proc. Natl. Acad. Sci. U. S. A. 110 (2013) $16856-16861$.

[16] F. Kopper, A.M. Binkowski, C. Bierwirth, M. Dobbelstein, The MAPK-activated protein kinase 2 mediates gemcitabine sensitivity in pancreatic cancer cells, Cell Cycle 13 (2014) 884-889.

[17] I.G. Cannell, Y.W. Kong, S.J. Johnston, M.L. Chen, H.M. Collins, H.C. Dobbyn, A. Elia, T.R. Kress, M. Dickens, M.J. Clemens, D.M. Heery, M. Gaestel, M. Eilers, A.E. Willis, M. Bushell, p38 MAPK/MK2-mediated induction of miR-34c following DNA damage prevents Myc-dependent DNA replication, Proc. Natl. Acad. Sci. U. S. A. 107 (2010) 5375-5380.

[18] H.C. Reinhardt, A.S. Aslanian, J.A. Lees, M.B. Yaffe, p53-deficient cells rely on ATM- and ATR-mediated checkpoint signaling through the p38MAPK/MK2 pathway for survival after DNA damage, Canc. Cell 11 (2007) 175-189.

[19] H.C. Reinhardt, I.G. Cannell, S. Morandell, M.B. Yaffe, Is post-transcriptional stabilization, splicing and translation of selective mRNAs a key to the DNA damage response? Cell Cycle 10 (2011) 23-27.

[20] H.C. Reinhardt, P. Hasskamp, I. Schmedding, S. Morandell, M.A. van Vugt, X. Wang, R. Linding, S.E. Ong, D. Weaver, S.A. Carr, M.B. Yaffe, DNA damage activates a spatially distinct late cytoplasmic cell-cycle checkpoint network controlled by MK2-mediated RNA stabilization, Mol. Cell 40 (2010) 34-49.

[21] S. Morandell, H.C. Reinhardt, I.G. Cannell, J.S. Kim, D.M. Ruf, T. Mitra, A.D. Couvillon, T. Jacks, M.B. Yaffe, A reversible gene-targeting strategy 
identifies synthetic lethal interactions between MK2 and p53 in the DNA damage response in vivo, Cell Rep. 5 (2013) 868-877.

[22] E.L. Deer, J. Gonzalez-Hernandez, J.D. Coursen, J.E. Shea, J. Ngatia, C.L. Scaife, M.A. Firpo, S.J. Mulvihill, Phenotype and genotype of pancreatic cancer cell lines, Pancreas 39 (2010) 425-435.

[23] R.J. Mourey, B.L. Burnette, S.J. Brustkern, J.S. Daniels, J.L. Hirsch, W.F. Hood, M.J. Meyers, S.J. Mnich, B.S. Pierce, M.J. Saabye, J.F. Schindler, S.A. South, E.G. Webb, J. Zhang, D.R. Anderson, A benzothiophene inhibitor of mitogenactivated protein kinase-activated protein kinase 2 inhibits tumor necrosis factor alpha production and has oral anti-inflammatory efficacy in acute and chronic models of inflammation, J. Pharmacol. Exp. Therapeut. 333 (2010) 797-807.

[24] M. Fiore, S. Forli, F. Manetti, Targeting mitogen-activated protein kinaseactivated protein kinase 2 (MAPKAPK2, MK2): medicinal chemistry efforts to lead small molecule inhibitors to clinical trials, J. Med. Chem. 59 (2016) 3609-3634.

[25] F.M. Gurgis, W. Ziaziaris, L. Munoz, Mitogen-activated protein kinaseactivated protein kinase 2 in neuroinflammation, heat shock protein 27 phosphorylation, and cell cycle: role and targeting, Mol. Pharmacol. 85 (2014) 345-356.

[26] A.A. Goodarzi, A.T. Noon, D. Deckbar, Y. Ziv, Y. Shiloh, M. Lobrich, P.A. Jeggo, ATM signaling facilitates repair of DNA double-strand breaks associated with heterochromatin, Mol. Cell 31 (2008) 167-177.

[27] K. Engel, A. Kotlyarov, M. Gaestel, Leptomycin B-sensitive nuclear export of MAPKAP kinase 2 is regulated by phosphorylation, EMBO J. 17 (1998) 3363-3371.

[28] J.J. Roberts, F. Friedlos, Quantitative estimation of cisplatin-induced DNA interstrand cross-links and their repair in mammalian cells: relationship to toxicity, Pharmacol. Ther. 34 (1987) 215-246.

[29] A. Kotlyarov, Y. Yannoni, S. Fritz, K. Laass, J.B. Telliez, D. Pitman, L.L. Lin,
M. Gaestel, Distinct cellular functions of MK2, Mol. Cell Biol. 22 (2002) 4827-4835.

[30] N. Ronkina, A. Kotlyarov, O. Dittrich-Breiholz, M. Kracht, E. Hitti, K. Milarski, R. Askew, S. Marusic, L.L. Lin, M. Gaestel, J.B. Telliez, The mitogen-activated protein kinase (MAPK)-activated protein kinases MK2 and MK3 cooperate in stimulation of tumor necrosis factor biosynthesis and stabilization of p38 MAPK, Mol. Cell Biol. 27 (2007) 170-181.

[31] L. Wang, H. Yang, P.L. Palmbos, G. Ney, T.A. Detzler, D. Coleman, J. Leflein, M. Davis, M. Zhang, W. Tang, J.K. Hicks, C.M. Helchowski, J. Prasad, T.S. Lawrence, L. Xu, X. Yu, C.E. Canman, M. Ljungman, D.M. Simeone, ATDC/ TRIM29 phosphorylation by ATM/MAPKAP kinase 2 mediates radioresistance in pancreatic cancer cells, Canc. Res. 74 (2014) 1778-1788.

[32] W. Cai, J.L. Rudolph, S.M. Harrison, L. Jin, A.L. Frantz, D.A. Harrison, D.A. Andres, An evolutionarily conserved Rit GTPase-p38 MAPK signaling pathway mediates oxidative stress resistance, Mol. Biol. Cell 22 (2011) 3231-3241.

[33] D.A.N.,B. Gabrielli, Topoisomerase II inhibitors and poisons, and the influence of cell cycle checkpoints, Curr. Med. Chem. 24 (2017) 1504-1519.

[34] F. Dietlein, B. Kalb, M. Jokic, E.M. Noll, A. Strong, L. Tharun, L. Ozretic H. Kunstlinger, K. Kambartel, W.J. Randerath, C. Jungst, A. Schmitt, A. Torgovnick, A. Richters, D. Rauh, F. Siedek, T. Persigehl, C. Mauch, J. Bartkova, A. Bradley, M.R. Sprick, A. Trumpp, R. Rad, D. Saur, J. Bartek, J. Wolf R. Buttner, R.K. Thomas, H.C. Reinhardt, A synergistic interaction between Chk1- and MK2 inhibitors in KRAS-mutant cancer, Cell 162 (2015) 146-159.

[35] Y.X. Liu, J. Wang, J. Guo, J. Wu, H.B. Lieberman, Y. Yin, DUSP1 is controlled by p53 during the cellular response to oxidative stress, Mol. Canc. Res. 6 (2008) 624-633.

[36] A.A. Sablina, A.V. Budanov, G.V. Ilyinskaya, L.S. Agapova, J.E. Kravchenko P.M. Chumakov, The antioxidant function of the p53 tumor suppressor, Nat. Med. 11 (2005) 1306-1313. 


\section{Manuscript II}

\subsection{A two-step bio-orthogonal reaction enables specific targeting of $\mathrm{p} 53-$ mutant cells via Nutlin-3a mediated protection of p53-wildtype cells}

Yizhu Li ${ }^{1}$, Morten Loehr ${ }^{2}$, Nathan Luedtke ${ }^{2}$ and Matthias Dobbelstein ${ }^{1}$

1) Institute of Molecular Oncology, Göttingen Center of Molecular Biosciences (GZMB), University Medical Center Göttingen, D-37077 Göttingen, Germany

2) Department of Chemistry, McGill University, 845 Sherbrooke St W, Montreal, Quebec H3A 0G4, Canada

\section{Abstract:}

Over $50 \%$ of all cancers carry a mutation in the p53 tumor suppressor gene, yet no chemotherapeutic drug specifically targeting this group of mutations is established in the clinical routine. One approach to exploit p53 mutations consists in the concept of cyclotherapy. Accordingly, a low dose of a p53 activator arrests the cell cycle in all non-transformed cells of the organism, whereas the p53-mutated cancer cells remain sensitive to chemotherapeutics active in S-phase and mitosis. Here, we have combined cyclotherapy with a pretargeting approach, meaning the temporal uncoupling of a target-specific compound from its cytotoxic component. In our strategy, pretargeting comprises a bio-orthogonal reaction between the nucleoside analogue 5-Vinyl-2'-deoxyuridine (5-VdU) and a genotoxic partner molecule, compound $\mathrm{B}$, via the tetrazine-alkene ligation reaction. In our setup, this reaction specifically targets p53 mutated cells, since pre-treatment with the MDM2 antagonist Nutlin-3a activated p53 and thus prevented the incorporation of 5-VdU into DNA. The combination of $5-\mathrm{VdU}$ and compound B induced DNA damage and profoundly interfered with the proliferation of cultured cells. Moreover, it reduced the progression of DNA replication forks and arrested cells in mitosis. Pre-treatment with Nutlin prevented the toxicity of $5-\mathrm{VdU}$ and compound $\mathrm{B}$ in p53-proficient cells. Taken together, the bio-orthogonal combination of $5-\mathrm{VdU}$ and compound $\mathrm{B}$ presents itself as a powerful combination to treat p53 mutated cancer cells in a pretargeting approach, whereas p53 activation enables cyclotherapy and thus specificity to this strategy. Put in a bigger picture, pretargeting with nucleosides, which at the same time act as bioorthogonal reaction partners, may serve as a modular platform for chemotherapy. 


\subsubsection{Introduction}

The transcription factor p53 is mutated in over $50 \%$ of all cancers, making it the most important tumor suppressor protein and a therapeutic target for human malignant disease of the highest priority ${ }^{106,107}$. Cellular stressors, such as DNA damage, trigger stabilization and activation of p53, which lead to gene expression to promote cell cycle arrest, DNA repair and ultimately apoptosis ${ }^{107}$. The levels of p53 protein in the cell are controlled by the E3 ubiquitin ligase MDM2 through a negative feedback loop. MDM2 is a transcriptional target of p53 and promotes its proteasomal degradation through ubiquitination $^{108}$. The chemical inhibition of MDM2 stabilizes the p53 protein and promotes cell cycle arrest and apoptosis. Such inhibitors have been already implicated in preclinical research ${ }^{81}$ and clinical trials ${ }^{82,109}$, however they have not yet been approved for the clinical routine. Adverse effects of MDM2 small molecule antagonists include gastrointestinal and hematological toxicity, with the most severe being neutropenia and thrombocytopenia ${ }^{110}$. Another way to utilize these p53 stabilizing compounds is the concept of cyclotherapy, in which only a low dosage of the drug is administered for a short term to arrest the cell cycle in non-cancerous cells of the patient, this protects them from chemotherapeutics that act during replication or mitosis, and allows specific targeting of p53 mutant cells ${ }^{93}$. The low dose regimen would also decrease the onset of adverse effects of p53 activating drugs ${ }^{110}$.

The "Click-Chemistry" is a highly specific reaction, which was originally designed as the Copper catalyzed Azide-Alkyne Click (CuAAC) reaction ${ }^{94}$. Such bio-orthogonal reactions, meaning artificially introduced compounds specifically react with each other and not with naturally occurring cellular molecules, have been widely applied in biomedical research ${ }^{95}$, in which they have enabled researchers to study specific macromolecules in situ ${ }^{96}$. As copper is cytotoxic, live cell applications were only made possible through the discovery of copper-free bioconjugations ${ }^{97}$, most importantly the Strain-promoted Azide-Alkyne Click Chemistry (SPAAC) reaction ${ }^{98}$ and the tetrazinealkene ligation ${ }^{99}$. They have led to the endeavor to develop bio-orthogonal reactions in clinical diagnostics and tumor targeted therapy ${ }^{100}$. Bio-orthogonal reactions can also be utilized for the concept of pretargeting, which uncouples the targeting compound from the cytotoxic agent to enhance their therapeutic index, meaning the ratio of drug toxicities to drug therapeutic effects ${ }^{105}$. In addition, researchers have successfully 
generated copper free clickable nucleosides, i.e. nucleoside analogues, to target live cell DNA for diagnostics ${ }^{111,112,113,101}$ and therapy ${ }^{114}$. Copper dependent clickable nucleosides, notably Bromodesoxyuridine (BrdU) and 5-Ethynyl-2'-deoxyuridine (EdU), have already been widely applied for DNA research ${ }^{115}$. Copper free nucleosideanalogues include 5-Vinyl-2'-deoxyuridine $\quad(5-\mathrm{VdU})^{101}, \quad$ 5-(Azidomethyl)-2'deoxyuridine (AmdU) $)^{111}$ and its enhanced version $5^{\prime}$-bispivaloyloxymethyl (POM)AmdU112,114, both substances visualize DNA in living cells, while POM-AmdU is able to generate toxic DNA-DNA interstrand crosslinks $(\mathrm{ICL})$ reacting with the Sondheimer diyne derivative DiMOC ${ }^{114}$ and can visualize nuclei in vivo ${ }^{112}$ (Danio rerio). The in vivo activity and the potential use in pretargeting render these novel compounds potential candidates for drug discovery.

In this manuscript, we present the synergistic cytotoxic effects of a novel bioorthogonal compound (compound B) in cultured cells. It acts as a DNA intercalator, within a previously described tetrazine-alkene ligation reaction ${ }^{111}$ with the nucleoside analogue $5-\mathrm{VdU}$. We further incorporated the strong cytotoxic effects of the chemical combination of $5-\mathrm{VdU}$ and compound B within a cyclotherapy approach. Dependent on the p53 mutation status, Nutlin-3a acted cytoprotective against the combination. In conclusion, this treatment scheme, once applied in vivo, would allow specific targeting of tumor suppressor mutated cancers, while protecting the non-transformed cells of the host.

\subsection{Materials and Methods}

\subsubsection{Cell culture and treatment}

H1299 and HCT116 p53 +/+ and HCT116 p53 -/- cells were obtained from the German Collection of Cell lines (DSMZ, Braunschweig), mouse pancreatic cancer cells (KPC) were a kind gift of Dr. Elisabeth Hessmann. The cultures were maintained in Dulbecco's modified Eagle's medium (DMEM) supplemented with $10 \%$ fetal bovine serum (FBS), L-Arginine and antibiotics, at $37^{\circ} \mathrm{C}$ in a humidified atmosphere with $5 \%$ $\mathrm{CO}_{2}$. For treatment, $5-\mathrm{VdU}$ and compound B (both synthesized in Nathan Luedtke lab) or Nutlin-3a (Sigma), were diluted in pre-warmed medium and added to the cells for the indicated periods of time. 


\subsubsection{Assessment of cell proliferation}

Cells were seeded at a density of 5000 cells/well in 96 -well plates. $24 \mathrm{~h}$ later, the cells were treated with the drugs at the indicated concentrations, for $24 \mathrm{~h}$, and then incubated with another drug for $24 \mathrm{~h}$ or with fresh media again. Subsequently, the percentage of cell confluence was determined every $24 \mathrm{~h}$ by bright-field microscopy using a Celigo Adherent Cell Cytometer (Nexcelom). Media was exchanged every 48 h. Cell proliferation was calculated from the increase in plate confluence using the Celigo software and evaluating three biological replicates at each time point.

\subsubsection{DNA fiber assays}

DNA fiber assays to analyze replication fork progression was essentially carried out as described previously ${ }^{62}$. The cells were treated with $5-\mathrm{VdU}$ for $24 \mathrm{~h}$ and then with compound B for $24 \mathrm{~h}$. They were then pulse-labeled with $25 \mu \mathrm{M}$ 5-chloro- 2'deoxyuridine (CldU) for $20 \mathrm{~min}$, followed by $250 \mu \mathrm{M}$ 5-iodo-2'-deoxyuridine (IdU; both from Sigma-Aldrich) for $1 \mathrm{~h}$. The cells were harvested, and DNA fibers were spread on glass slides. After hydrochloric acid treatment, CldU- and IdU-labeled tracts were detected by $1 \mathrm{~h}$ incubation at $37^{\circ} \mathrm{C}$ with rat anti-BrdU antibody (dilution 1:500 detects BrdU and CldU; AbD Serotec) and mouse anti-BrdU antibody (1:500, detects BrdU and IdU; Becton Dickinson). Slides were fixed in 4\% paraformaldehyde/PBS and incubated for $2 \mathrm{~h}$ at room temperature with Alexa Fluor 555-conjugated goat anti-rat antibody (dilution 1:250) or Alexa Fluor 488-conjugated goat anti-mouse antibody (dilution 1:250; both from Molecular Probes/Thermofisher). Samples were mounted in Vectashield (Vector Laboratories). Fiber images were acquired by fluorescence microscopy. The lengths of CldU- (red) and IdU- (green) labeled fibers were measured by using the Fiji software in pixels, converted to micrometers and subsequently converted to $\mathrm{kb}$ using the conversion factor $1 \mu \mathrm{m}=2.59 \mathrm{~kb}$. Replication structures were quantified by using the Cell Counter Plug-in for Fiji (Kurt De Vos, University of Sheffield, Sheffield, United Kingdom). 


\subsubsection{Immunoblot analysis}

Cells were harvested in protein lysis buffer $(20 \mathrm{mM}$ TRIS-HCl pH 7.5, 150mM NaCl, $1 \mathrm{mM}$ Na2EDTA, 1mM EGTA, 1mM beta-glycerophosphate, 2M urea, protease inhibitor cocktail, Roche). After 10min lysis on ice, the samples were briefly sonicated to disrupt DNA-protein complexes. Total protein concentration was measured using a Pierce BCA Protein assay kit (Thermo Scientific Fisher). After boiling the samples in Laemmli buffer at $95^{\circ} \mathrm{C}$ for $5 \mathrm{~min}$, equal amounts of protein samples were separated by SDS-PAGE, transferred onto nitrocellulose, and visualized with the following antibodies, followed by peroxidase-coupled secondary antibodies and chemiluminescence: phosphorylated Ser 139 H2AX (05-636, Millipore), phosphorylated Ser 317 Chk1 (2344, Cell Signaling Technology), PARP1 (9542, Cell Signaling Technology), beta-Actin (ab8227 Abcam), Ser 10 H3 (D2C8-XP, Cell Signaling Technology).

\subsubsection{Flow cytometry}

For cell cycle analysis, cells were fixed in ethanol and washed with $0.05 \%$ Triton-X in PBS. Subsequently, the cells were resuspended in $1 \mathrm{mg} / \mathrm{ml}$ RNAse A solution in PBS and incubated for $30 \mathrm{~min}$ at $37^{\circ} \mathrm{C}$, and then with propidium iodide (final concentration: $30 \mu \mathrm{g} / \mathrm{ml}$ ). Flow cytometry was performed using the Guava PCA-96 Base System (Millipore), and the distribution of DNA contents was determined using the Guava Express Pro software.

\subsubsection{Fluorescence microscopy}

Pretreated cells in 8 chamber slide wells (nunc labtek, 177445) were incubated with Hoechst DNA stain (Thermo Fisher Scientific) at a concentration of $2 \mu \mathrm{g} / \mathrm{ml}$ for 15 mins and then mounted in PBS for microscopy. Images were obtained by fluorescent microscopy Zeiss Axioscope A1, ZEN 2 software. 


\subsection{Results}

\subsubsection{The combination of 5-VdU and compound B exhibits synergistic lethality in human and mouse cancer cell lines}

To evaluate a possible synergistic effect between $5-\mathrm{VdU}$ and compound $\mathrm{B}$, we treated H1299 cells, a human non-small cell lung carcinoma (NSCLC) cell line, and cells of the murine KPC model, which is K-Ras and p53 mutated and contains a pancreasspecific promoter to express the Cre-recombinase ${ }^{116}$, with the indicated drugs. Cells were treated with $5-\mathrm{VdU}$ for $24 \mathrm{~h}$ and subsequently $24 \mathrm{~h}$ with compound $\mathrm{B}$ (see Fig. $8 \mathrm{E})$. They were then either further observed with live cell confluency measurements or lysed for Western Blot analysis. Both H1299 cells (Fig. 8A \& 8C) and KPC cells (Fig. 8B and 8D) exhibited a strong synergistic effect upon the combination of 5-VdU and compound B. Cell viability was drastically decreased in the cell confluency assays upon treatment with the combination, whereas $5-\mathrm{VdU}$ or compound $B$ alone exhibited almost no toxicities by themselves (Fig. 8A \& B). In the Western Blot analyses a strong amplification of the DNA damage marker $\mathrm{yH} 2 \mathrm{AX}$ was detected upon treatment with the combination, while $5-\mathrm{VdU}$ and compound $\mathrm{B}$ only lead to a small increase when compared with the DMSO control (Fig. $8 \mathrm{C}$ and $8 \mathrm{D}$ ). Furthermore, the activating phosphorylation of the DNA damage sensor kinase Chk1 on Ser317 was increased in $\mathrm{H} 1299$ cells upon treatment with the combination when compared to the single drugs alone (Fig. 8C). In KPC cells the cleavage of the apoptosis marker PARP was augmented in the combination (Fig. 8D), implying an activation of the apoptotic pathway. Taken together, the combination of $5-\mathrm{VdU}$ and compound $\mathrm{B}$ acts synergistically to decrease cell viability in a live cell confluency assay and activates DNA damage and apoptosis markers in the Western Blot analysis. 
Fig. 8A

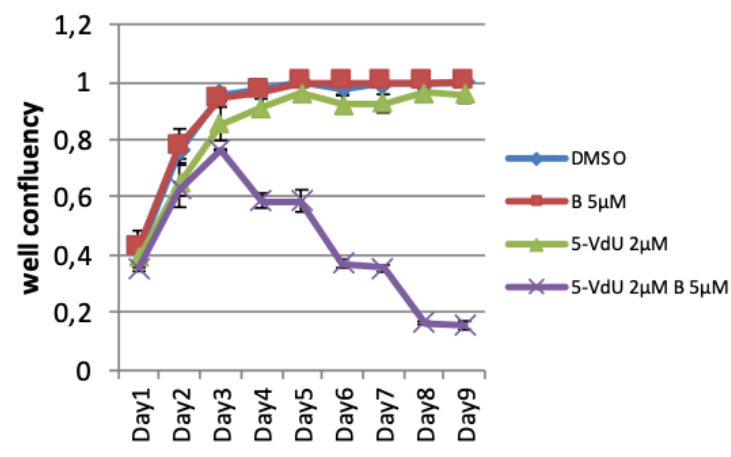

C

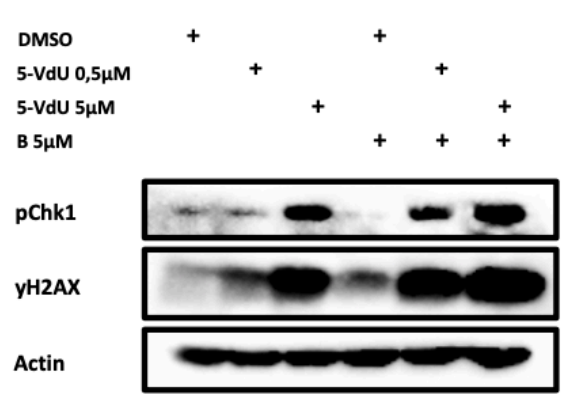

E

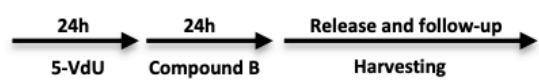

B

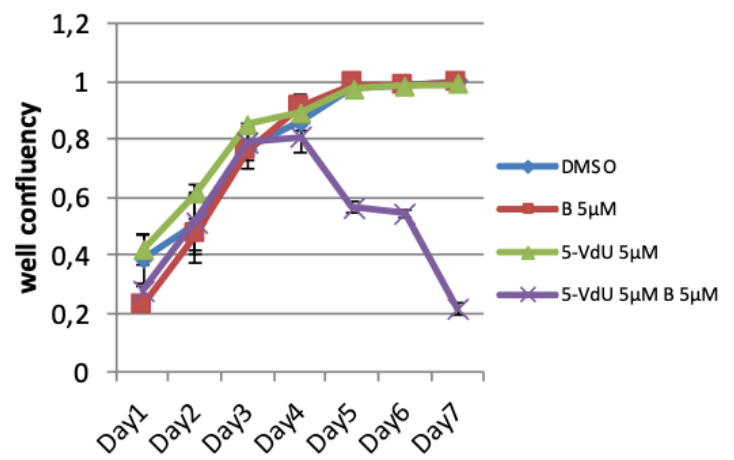

D

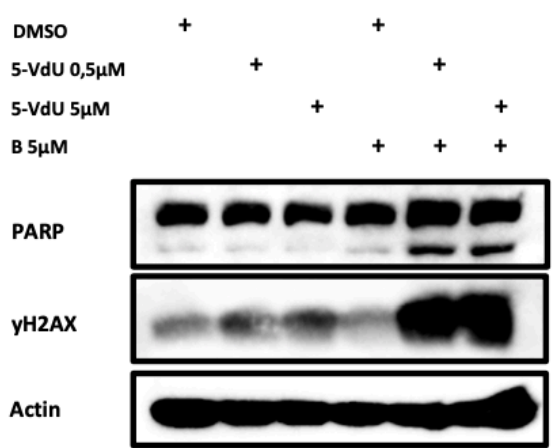

Figure 8: Synergistic lethality of 5-VdU and compound B. Cell confluency upon treatment with the drugs was measured daily using (A) H1299 cells and (B) mouse KPC cells. Western Blot analysis reveals synergistic effects of $5-\mathrm{VdU}$ and compound B on markers of DNA damage and cell death (C) H1299 cells and (D) mouse KPC cells. (E) Treatment scheme. 


\subsubsection{5-VdU is incorporated into the cellular DNA, binds compound B and can}

be visualized in live cells

To rule out DNA independent effects of the combination of 5-VdU and compound $B$, we have used fluorescence microscopy to visualize compound $B$, which is supposed to be excitable at $555 \mathrm{~nm}$. Live cell nuclei can be imaged using the Hoechst 33342 stain ${ }^{117}$. Cultured H1299 cells were treated with $5-\mathrm{VdU}$ for $24 \mathrm{~h}$ and subsequently with compound B for $24 \mathrm{~h}$, treated with Hoechst stain and then directly mounted for fluorescence microscopy (Fig. 9B). And indeed, compound B can be imaged at the indicated wavelength and the signal colocalizes with the Hoechst nuclear stain (Fig. 9A). This result suggests, that the cytotoxic and DNA damaging effects of the combination of $5-\mathrm{VdU}$ and compound $\mathrm{B}$ are due to specific interaction of the two drugs at the cellular DNA and not elsewhere in the cell.

Fig. 9A
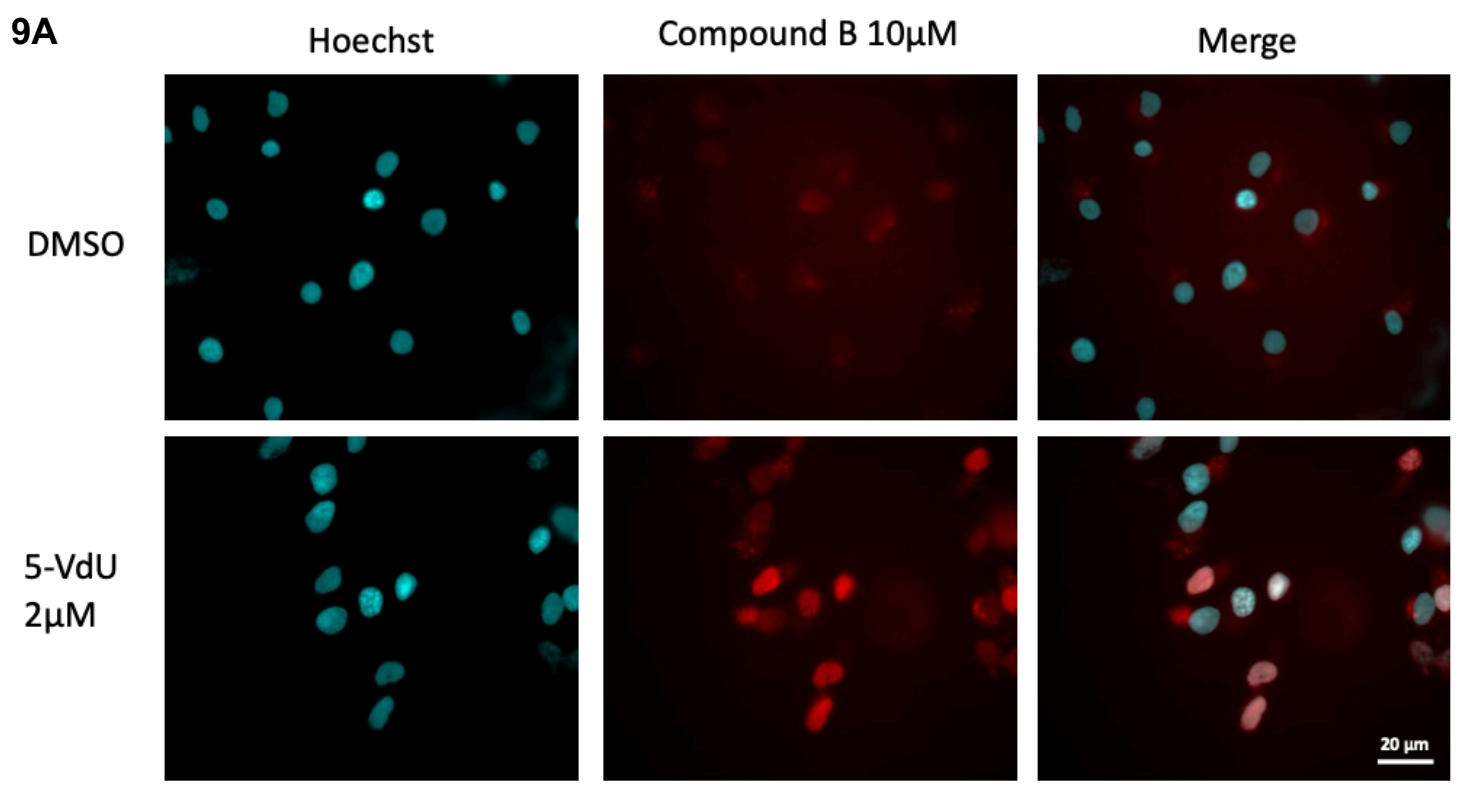

B

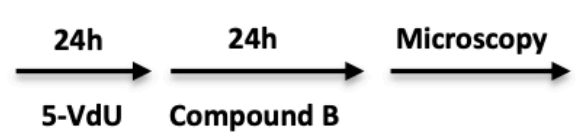

Figure 9: (A) Nuclear localization of the compound B signal shown by co-localization with the Hoechst nuclear stain in living H1299 cells using fluorescence microscopy. (B) Treatment scheme. 


\subsubsection{The combination of 5-VdU and compound B impedes the progression of DNA replication forks and leads to accumulation of cells in mitosis}

To unravel the mechanism of cytotoxicity conveyed by the combination of 5-VdU and compound $\mathrm{B}$, we have conducted a cell cycle analysis via flow cytometry (Fig. 10). $\mathrm{H} 1299$ cells were treated with $5-\mathrm{VdU}$ for $24 \mathrm{~h}$ and subsequently with compound $\mathrm{B}$ for $24 \mathrm{~h}$ (Fig. 10B). $48 \mathrm{~h}$ after the start of treatment, cells were halted in S-phase in the combination treatment condition and after $72 \mathrm{~h}$ cells accumulated at the G2/M cell cycle boundary (Fig. 10A). Furthermore, some cells progressed through mitosis after $96 \mathrm{~h}$, which is implied by a larger population of G1 phase cells, but at the same time an increase in sub-G1 cells can be observed. We therefore hypothesized that the combination is inducing cell death via DNA damage impacting mitosis, this is supported by the observation that cells start dying in the cell confluency assay only 72 h after start of treatment (Fig. 8A \& 8B). To visualize the possible effects on replication, a DNA fiber assay was conducted, cells were treated with 5-VdU for $24 \mathrm{~h}$, subsequently with compound B for $24 \mathrm{~h}$ and then labelled for the DNA fiber assay (Fig. 11D). Compound $B$ decreases the replication fork speed by itself, but it is even further reduced by the combination treatment (Fig. 11A, 11B \& 11C). We can therefore show that the combination of $5-\mathrm{VdU}$ and compound $\mathrm{B}$ indeed slows down DNA replication, which explains the accumulation of cells in S-phase in the flow cytometry experiment (Fig. 10A). Furthermore, a Western Blot analysis of $\mathrm{H} 1299$ cells $24 \mathrm{~h}$ post compound $B$ treatment (Fig. 11E \& 11F) shows an immense accumulation of phospho-histone 3 at Ser $10(\mathrm{pH} 3)^{118}$, which indicates cells in M-phase, this observation also fits with the cell cycle profile at $72 \mathrm{~h}$ after start of treatment.

As a sub-G1 cell population was observed after the mitotic arrest at $96 \mathrm{~h}$ post start of treatment, we wanted to observe the cell nuclear morphology $72 \mathrm{~h}$ post start of treatment (Fig. 12). Live cells were treated with Hoechst nuclear stain at the indicated time point (Fig. 12E) and then observed with fluorescence microscopy (Fig. 12A). While the treatment conditions of $5-\mathrm{VdU}$ and compound $\mathrm{B}$ alone looked comparable to the DMSO control, strong morphological aberrations could be observed in the combination treatment condition. For one, nuclei in metaphase were far more abundant than in the controls (Fig. 12B \& 12D), furthermore the nuclei were in average larger in the combination treatment condition (Fig. 12C). From these findings we 
hypothesize, that the DNA damage inflicted by the combination of $5-\mathrm{VdU}$ and compound B most likely impact cells in mitosis, which then leads to cell death.

Fig. 10A

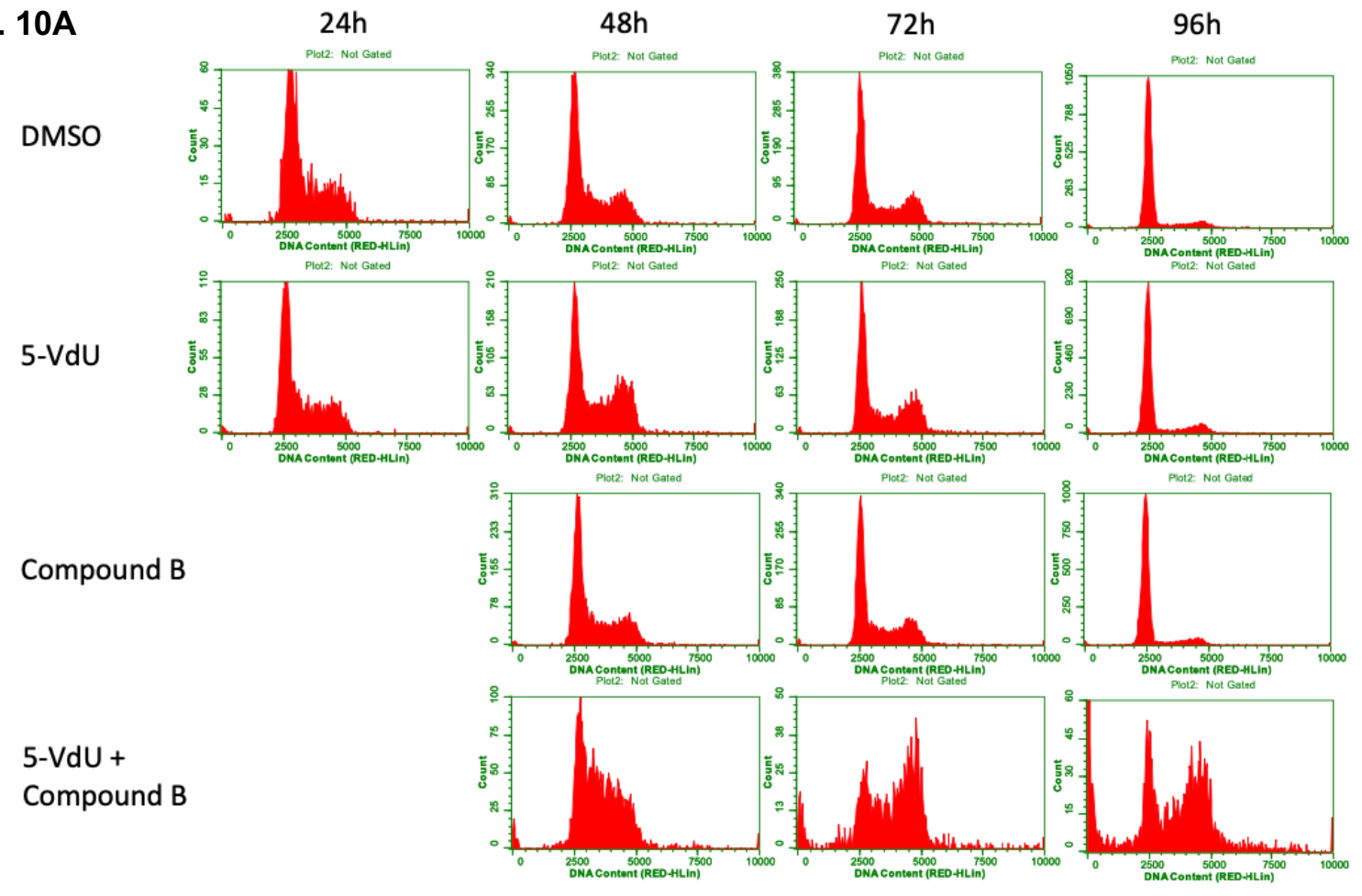

B

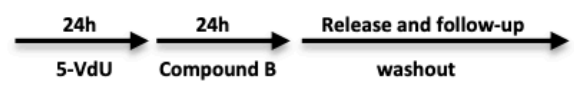

Figure 10: (A) Cell cycle analyses of H1299 cells show mostly unperturbed cell cycle profiles upon treatment with $0,5 \mu \mathrm{M} 5-\mathrm{VdU}$ or $5 \mu \mathrm{M}$ compound $\mathrm{B}$ alone for the indicated periods of time. The combination of the two drugs leads to the accumulation of cells in S-phase at $24 \mathrm{~h}$, near the G2/M boundary at $72 \mathrm{~h}$ and $96 \mathrm{~h}$, and additionally in a subG1 fraction at 96h. (B) Treatment scheme. 
Fig. 11A
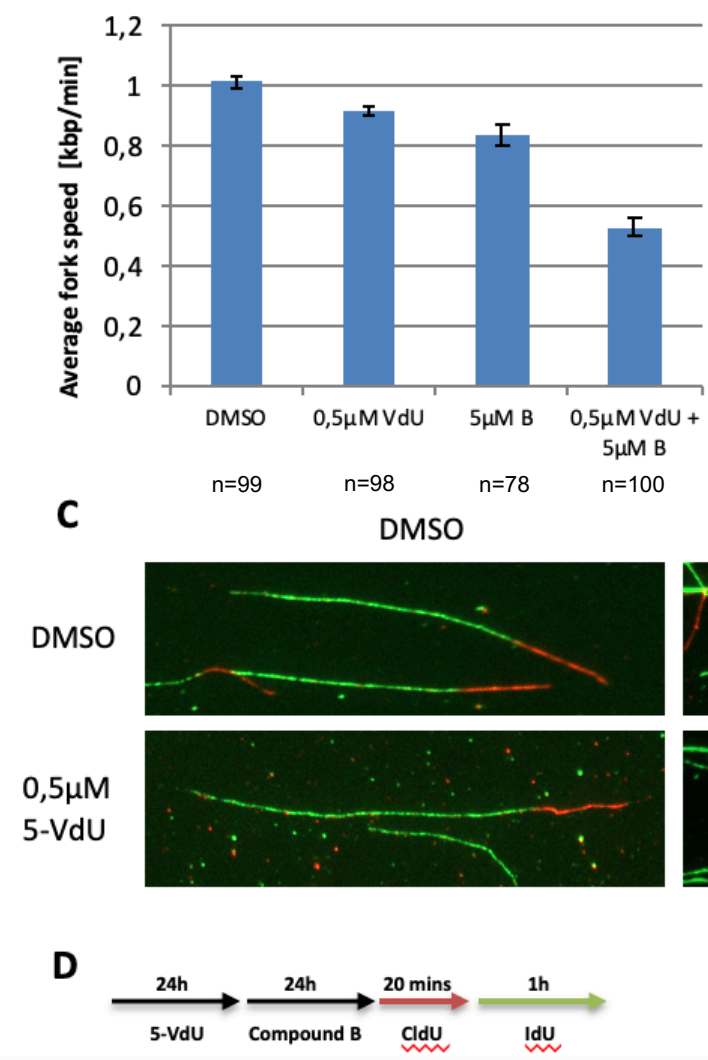

E

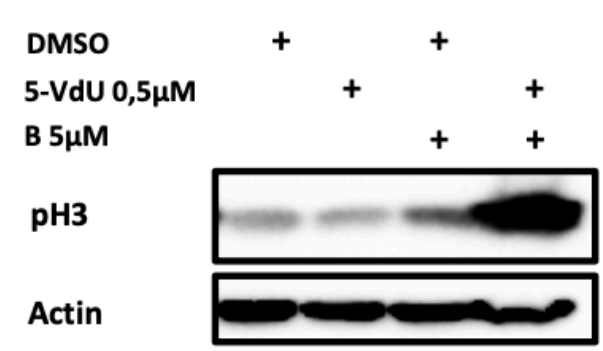

\section{B}

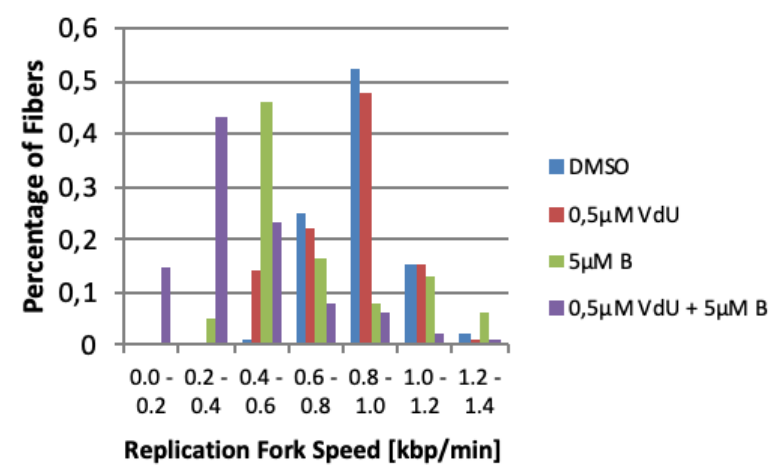

$5 \mu \mathrm{M} \mathrm{B}$

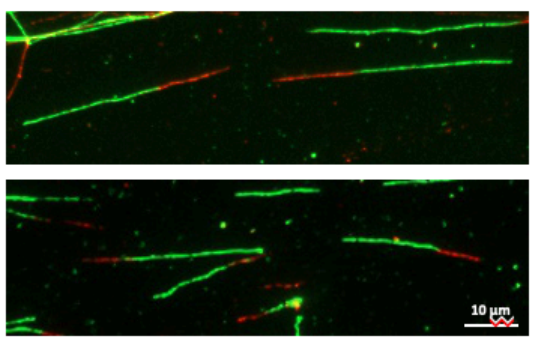

$10 \mathrm{Hm}$

$\mathbf{F}$

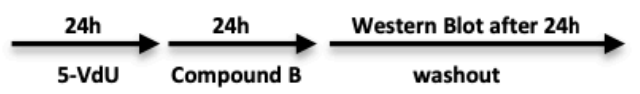

Figure 11: (A) H1299 cells were subjected to the DNA fiber assay after $24 \mathrm{~h}$ of 5-VdU and $24 \mathrm{~h}$ of compound B treatment. (B) Distribution of replication fork speeds. The labelled tracks were classified to histograms, reflecting the number of forks with a speed between the indicated numbers $(\mathrm{kb} / \mathrm{min})$ and the next 0.1 digit. The percentage of tracks within each class is displayed by the columns. (C) Representative images of DNA fibers in the experiment. (D) Treatment scheme. (E) Western Blot analysis of H1299 cells 24 h post compound B treatment. (F) Treatment scheme of 4E. 
Fig. 12A
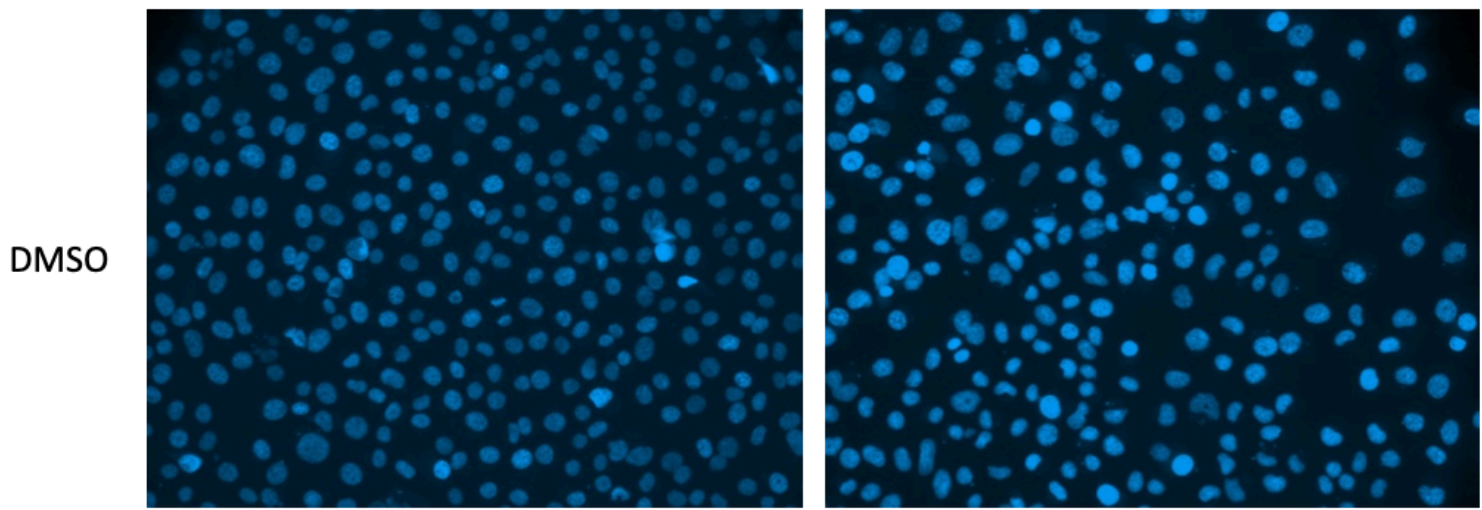

$5 \mu \mathrm{MB}$
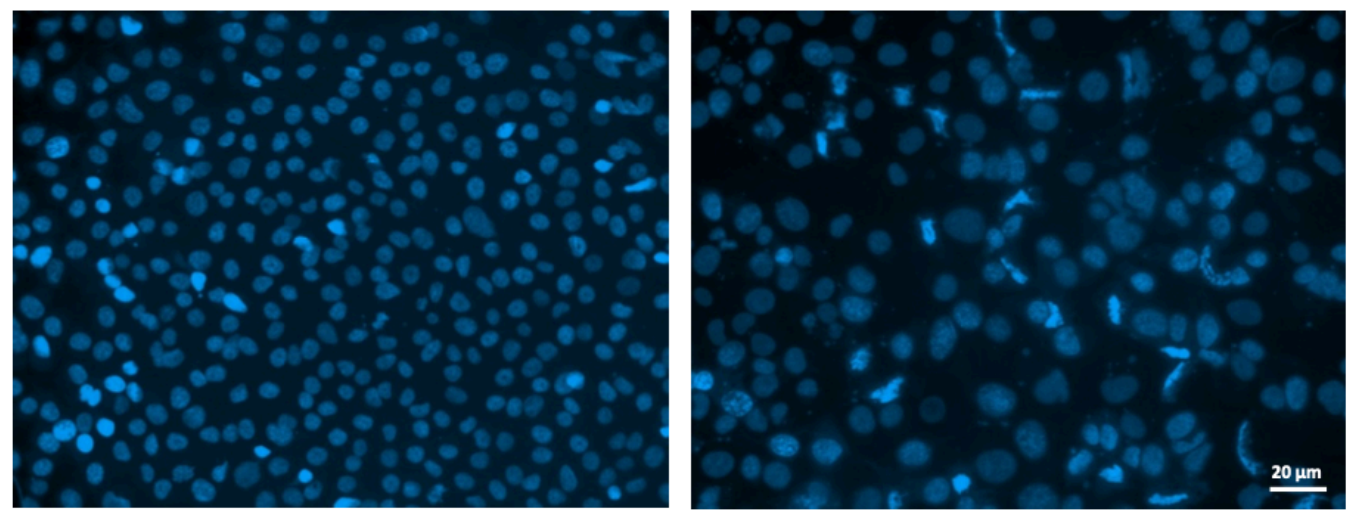

B
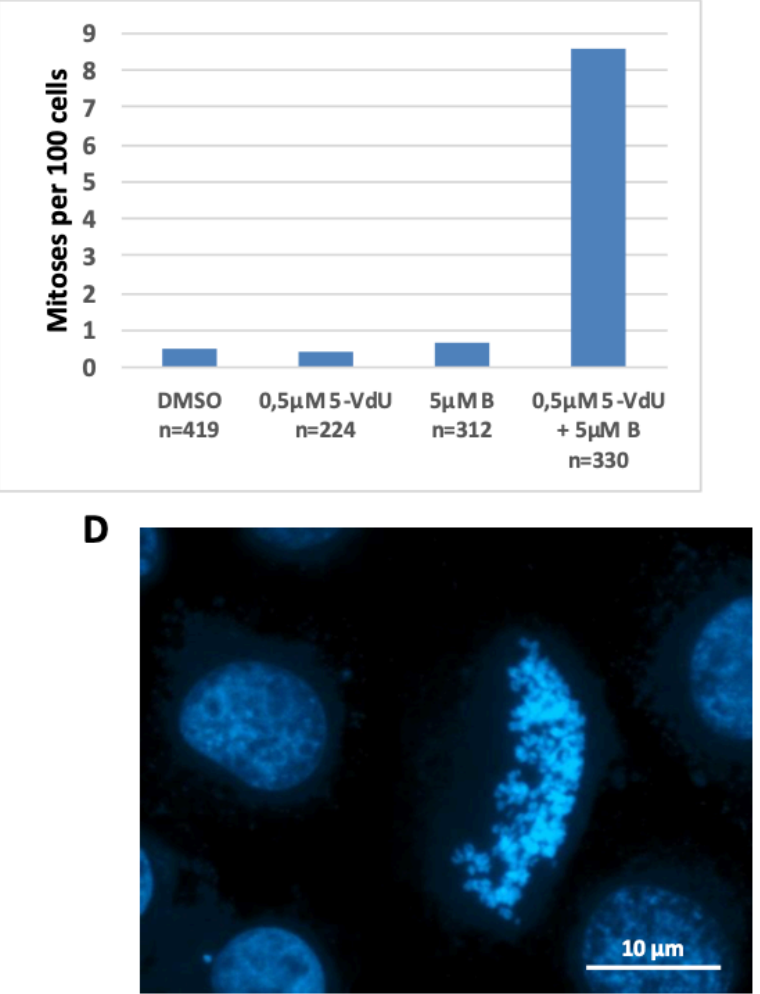

C

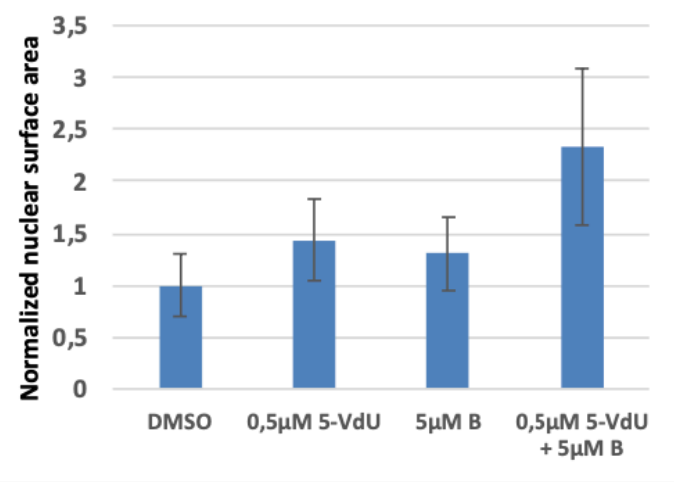

E

$\underset{5-\mathrm{VdU}}{\stackrel{24 \mathrm{~h}}{\longrightarrow}} \underset{\text { Compound B }}{\stackrel{24 \mathrm{~h}}{\longrightarrow}} \underset{\text { washout }}{\stackrel{\text { Release 24h }}{\longrightarrow}} \stackrel{\text { Microscopy }}{\longrightarrow}$ 


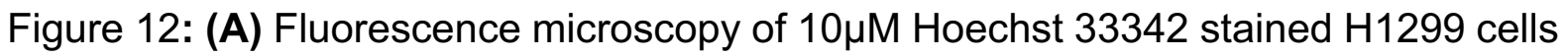
treated for $24 \mathrm{~h}$ with $5-\mathrm{VdU}$ and $24 \mathrm{~h}$ with compound $\mathrm{B}$ and further incubated without drugs for another 24h. (B) Mitoses per 100 cells, measured using cell counter in ImageJ. (C) Normalized nuclear surface area, measured using ROI manager in Image J. (D) Cells treated with 5-VdU and compound B, a disturbed metaphase cell is visible. (E) Treatment scheme.

\subsubsection{Nutlin-3a selectively protects cultured cells against the combination of 5- VdU and compound B based on the p53 mutation status}

To implement the bio-orthogonal reaction of $5-\mathrm{VdU}$ and compound $\mathrm{B}$ into a cyclotherapy approach, we have pretreated HCT116 p53 +/+ cells with Nutlin-3a for $24 \mathrm{~h}$ prior to the combination treatment (Fig. 13A \& 13D). All Nutlin-3a pretreated cells were temporarily impaired in cell proliferation, but the chemical did protect against the combination of 5-VdU and compound B (Fig. 13A). To test the dependency on p53 protein functionality of this effect, we used the isogenic p53 -/- HCT116 cell line for the same experimental setup, and as a result, Nutlin-3a pretreatment failed to protect p53 $-/$ - cells against the combination of $5-\mathrm{VdU}$ and compound B (Fig. 13B). We have further conducted Western Blot analyses to visualize the impact of Nutlin-3a mediated protection on DNA damage markers in these isogenic cell lines (Fig. 13C). As expected, the phosphorylation of Chk1 (pChk1) was reduced and the phosphorylation of $\mathrm{yH} 2 \mathrm{AX}$ was strongly reduced in Nutlin-3a pretreated conditions in the $\mathrm{p} 53+/+$ cell line. Furthermore, this signal reduction could not be observed for the HCT116 p53 -/cell line, the signals for pChk1 and $\mathrm{yH} 2 \mathrm{AX}$ were even intensified in the Nutlin-3a pretreated conditions. In conclusion, the protection via Nutlin-3a against the combination of $5-\mathrm{VdU}$ and compound $\mathrm{B}$ is strictly dependent on the p53 mutation status. 
Fig. 13A

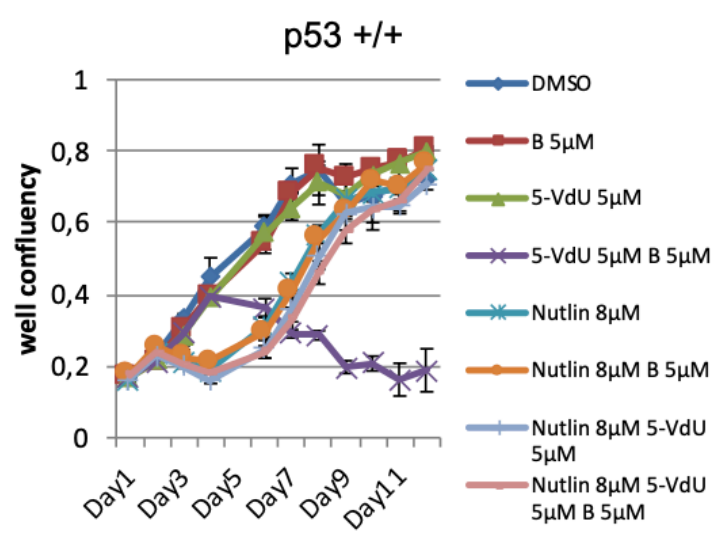

B

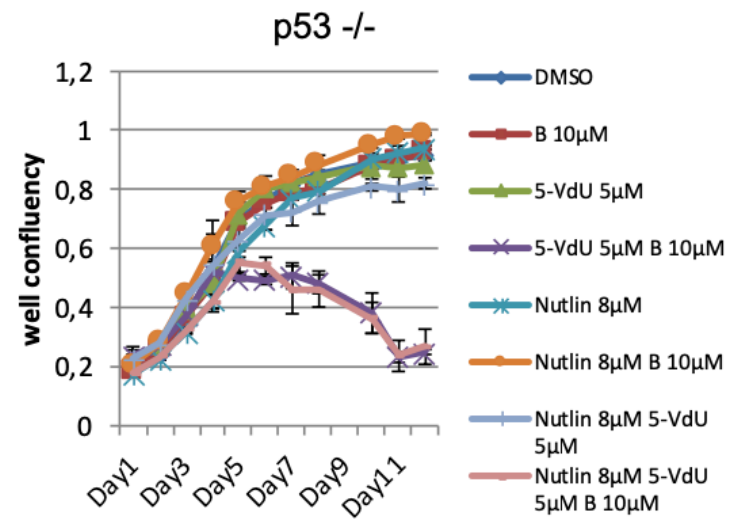

C
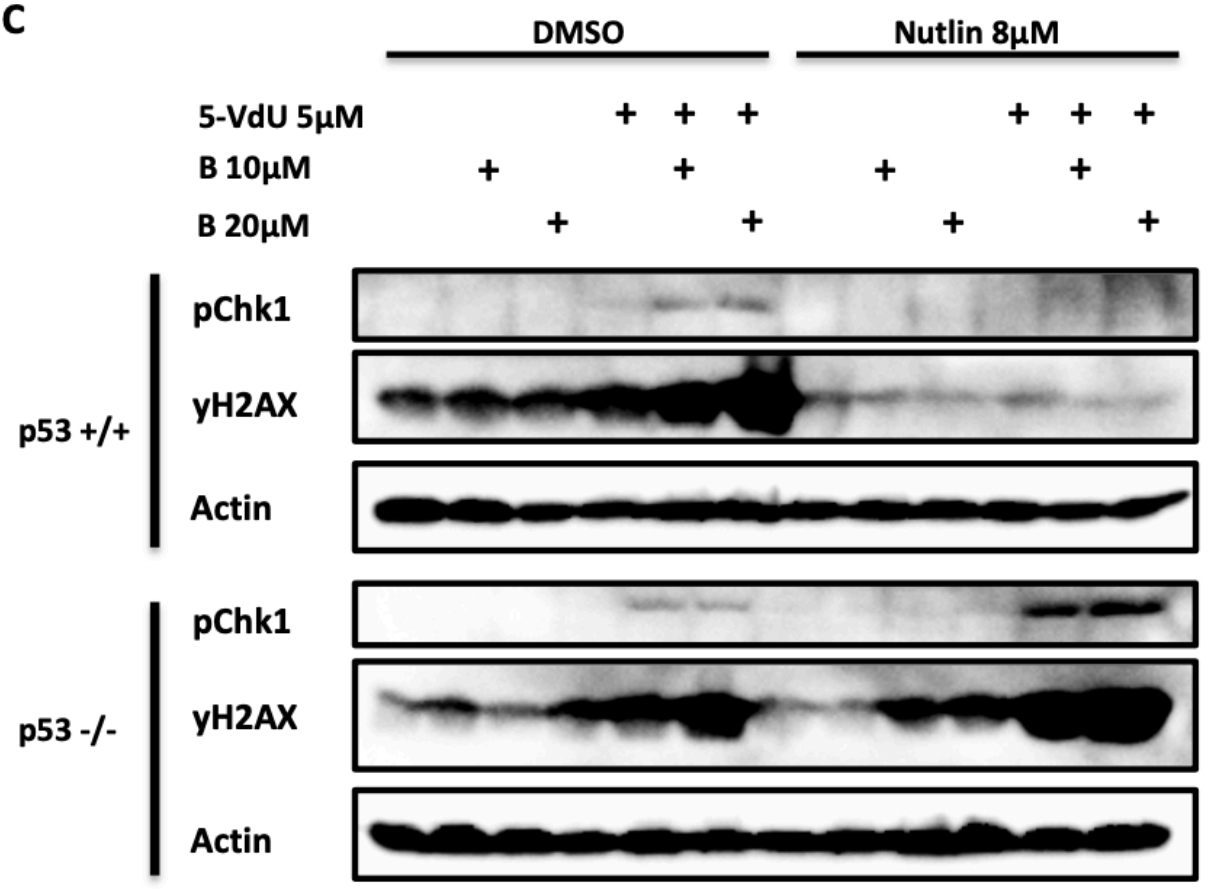

D

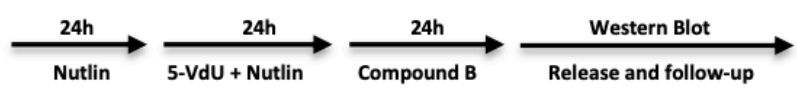

Figure 13: Pharmacological protection against the combination of 5-VdU / Compound B via Nutlin-3a in a p53 status dependent manner: (A) Pre- and co-treatment with Nutlin-3a protects HCT116 p53 +/+ cells against 5-VdU / Compound B induced synthetic lethality, but fails to do so in (B) the isogenic HCT116 p53 -/- cell line. (C) Western Blot analysis shows that Nutlin-3a pre-treatment prevents phospho-Chk1 and yH2AX accumulation in HCT116 p53 +/+ cells, but not in HCT116 p53-/- cells. (D) Treatment scheme. 


\subsection{Discussion}

Our data provide insight to a potent pretargeting strategy with the combination of 5VdU and compound B, which can be incorporated into a cyclotherapy approach, via Nutilin-3a pretreatment, to target p53 mutated cells specifically. We believe the combination of $5-\mathrm{VdU}$ and compound $\mathrm{B}$ to be more powerful than Gemcitabine in this setup, as the latter induces a cell cycle arrest in targeted cells ${ }^{87,119}$. In contrast, 5-VdU incorporates throughout the genome, providing a much larger target surface, on which compound B could be applied with an otherwise cell cycle arrest inducing high dose concentration. Furthermore, the entire setup is modular, as $5-\mathrm{VdU}$ could serve as a reaction partner for any tetrazine-coupled molecule.

Bio-orthogonal synthetic lethality has been previously described with the combination of POM-AmdU and DiMOC ${ }^{114}$. Put into perspective, the combination of $5-\mathrm{VdU}$ and compound B presents itself as the superior combination, as lower concentrations of either compound is needed to induce a stronger cytotoxic effect. Furthermore, compound B can be directly detected via fluorescence microscopy in living cells. This characteristic might be utilized for tumor localization in cancer surgery. Such an approach is already established in neurosurgery using the compound 5-Aminolevulinic Acid $(5-A L A)^{120,121}$ and in clinical trials for intraoperative detection of Carcinoembryonic Antigen (CEA) using monoclonal fluorescent antibodies against $\mathrm{CEA}^{122}$. Cancer surgery conducted in this way might be beneficial due to better evaluation of safety distances and detection of micro-metastases.

Our promising results legitimize the experimental evaluation in a mouse model. We are planning to use the KPC cells as a xenograft. However, a recent study has reported that Nutlin drugs might not have the same potency in mice as in humans ${ }^{123}$. As an alternative, the retinoblastoma protein $(\mathrm{pRb})$ mutation might serve as a potential target, as it can be indirectly targeted through CDK4/6 inhibitors ${ }^{124}$. Such inhibitors are already used in the clinical routine for treatment of advanced and metastatic breast cancers $^{125}$, in which they halt tumor progression by cell cycle arrest induction. Small cell lung cancer is a suitable tumor entity to study the effects of the bio-orthogonal combination regimen, as these cancers most commonly lose both $\mathrm{pRb}$ and $\mathrm{p} 53^{126}$. 
The concept of pretargeting has already been extensively investigated in radiotherapy ${ }^{105}$. Due to the modular nature of the pretargeting approach, a bioorthogonal reaction between a nucleoside analogue and a radionuclide would also be possible. The prerequisite for the functionality would be the nuclear localization of the radionuclide, which should be short-range acting. The most suitable high energy particles for such a purpose are Auger electrons which are formed after electron capture from a higher energy level. Most of the excess energy is emitted as X-ray energy, but some is released as kinetic energy given to another electron, then called Auger electron, which is emitted ${ }^{127}$. The most common Auger-electron-emitters are iodine isotopes, which are frequently used in nuclear medicine clinical routine. The nuclear targeting of such a drug has been of great interest in the targeted radionuclide therapy (TRT) community, as the induced DNA damage would be most intense with a nuclear localized radionuclide ${ }^{128}$. Furthermore, it would be similarly beneficial to couple a radiosensitizer to DNA of cancer cells ${ }^{129,130}$, which might improve the therapeutic index for radiation therapy. Taken together, the incorporation of a radionuclide or a radiosensitizer into the cyclotherapy and pretargeting regimen might be effective for treating tumor suppressor mutated cells in cancer patients.

The advances of nanotechnology prompt the idea to bio-orthogonally attach nanomaterials to DNA-incorporated nucleosides. They can, as an example, be utilized for thermal ablation ${ }^{131}$ or any other designable purpose ${ }^{132}$. The attachment of an enzymatic compound on the DNA, which activates a DNA damaging compound, would be of great interest to target tumor suppressor mutated cancer cells specifically ${ }^{133}$.

In summary, the bio-orthogonal combination of $5-\mathrm{VdU}$ and compound B presents itself as a powerful combination to treat p53 mutated cancer cells in a pretargeting, Nutlin3a mediated cyclotherapy approach. Put in a bigger picture, the pretargeting with nucleosides, which at the same time act as a bio-orthogonal reaction partners, may serve as a modular platform for chemotherapy, cancer surgery, radiotherapy and beyond. It is the current mission to find functional compounds with the desired effects in vivo. 


\section{Discussion}

DNA stands at the center of cancer disease and therapy. In our work, we have shown the context related modulation of established DNA damaging chemotherapeutic drugs with novel compounds, i.e. Gemcitabine or cisplatin in combination with MK2 inhibitors. The different outcomes of the drugs are based on the different effects MK2 inhibition has on the DNA damage response, DNA repair and cell cycle regulation. The modulation of DNA damage pathways therefore represents an opportunity for finding novel chemotherapeutic targets for clinical cancer treatment, although these findings will be specifically context related. The correct identification of the specific context and application of the suitable treatment will be solved by the onset and establishment of personalized medicine patient big data. In another part of this dissertation, we have successfully applied the concept of cyclotherapy with a high potency in vitro, prompting application in an experimental mouse model. This will be a difficult task to accomplish, as the in vivo application of cyclotherapy will demand a careful titration and timing of the treatments given. We will discuss current synthetic lethality drug regimens and the up to date knowledge on tumor suppressor pharmacological activators in the upcoming sections.

\subsection{Drug combinations and synthetic lethality}

The aim of novel combinations between established chemotherapeutics and newly discovered compounds is the exacerbation of cytotoxicity. We were able to show in the same biological system, that MK2 pharmacological inhibition protects cells against the S-phase drug Gemcitabine, but sensitizes against cisplatin, which mainly impacts mitosis $^{134}$. Possible applications of MK2 inhibitors in the clinics are therefore strictly context related. It has been recently reported that the p38-MK2 axis plays an important role in RNA metabolism upon the DNA damage response to UV-light irradiation ${ }^{135}$. In more detail, p38 and MK2 mediate the removal of Negative Elongation Factor E (NELFE) from chromatin through 14-3-3 protein binding, by phosphorylation at Ser115, which ensures the elongation of transcription. Ongoing transcription can be beneficial or detrimental for the $D D R^{136}$. Our group has previously reported the protective effects of MK2 loss of function against UV-light irradiation in vivo, MK2/MK3 deficient mice showed less induction of apoptosis in skin keratinocytes upon UV-light 
irradiation as compared to control animals ${ }^{62}$, this might hint at a cellular protective role of MK2 inhibition in the context of UV-light irradiation. Our results and the current literature exemplify the specific context relatedness in the application of novel targeted compounds for personalized medicine.

\subsubsection{PARP inhibition}

The onset of personalized medicine, i.e. the large scale and high-throughput sequencing of patient DNA, RNA and protein sample data, will help to put novel chemotherapeutic drugs into the correct biological context ${ }^{137}$. The concept of synthetic lethality, meaning the identification of vulnerable targets upon a specific cancer cell mutation $^{138}$, is a very promising direction for DDR and DNA repair pathway related drug development. The beauty of the system is that only cancerous cells would be susceptible to the treatment, whereas non-transformed cells would not be affected to the same degree. One success story of synthetic lethality is the development of PolyADP-ribose polymerase (PARP) inhibitors, which are now routinely applied to patients with breast and ovarian cancers ${ }^{139}$. PARP mediated attachment of ADP-ribose is crucial for the recognition and repair of DNA SSBs, which will, if unrepaired, progress into highly cytotoxic DNA DSBs ${ }^{33}$. As a consequence, if DSB repair is impaired in a cell, a window for synthetic lethality therapeutic options opens. This is the case for breast and ovarian cancers that carry Breast Cancer gene (BRCA) 1/2 mutations, as BRCA proteins play a central role in DSB repair ${ }^{140,141}$. The generation of DSB through PARP inhibition exacerbates DNA damage in BRCA mutant cells that fail to undergo DNA DSB repair. Furthermore, other mutations in the DSB repair pathway mimic BRCA mutations and would similarly respond to PARP inhibition, this phenomenon has been termed "BRCAness" and significantly broadens the clinical indications for PARP inhibitors ${ }^{142}$. Due to the firm establishment of PARP inhibitors in clinical oncology, numerous mechanisms of drug resistance have also been elucidated, one of them being the dysregulation of DNA repair pathway choice. DNA DSBs are repaired by a careful equilibrium between homologous recombination (HR) and nonhomologous end joining (NHEJ). The loss of BRCA proteins tilt the balance towards

NHEJ, which is error-prone and can lead to catastrophic chromosomal rearrangements. While BRCA proteins control HR, 53BP1 mediates NHEJ repair of DSB, an additional 53BP1 loss in a BRCA mutant background therefore inactivates 
NHEJ and restores HR, rendering the cell less susceptible towards PARP inhibition ${ }^{143}$. The successful clinical application of PARP inhibitors show the importance of understanding the DDR and DNA repair pathways in molecular detail. Further research could reveal even more potent drug combinations and possibilities to overcome mechanisms of drug resistance.

\subsubsection{DNA damage pathways and checkpoint inhibitors}

A recent breakthrough in clinical cancer therapy was the successful application of checkpoint inhibitors, which are therapeutic antibodies against the immunological epitopes Cytotoxic T-Lymphocyte-Associated protein 4 (CTLA4), Programmed cell Death protein 1 (PD-1) and PD-Ligand 1 (PD-L1) ${ }^{144}$. These factors are able to dampen the immune response upon an immunologic stimulus. CTLA4 and PD-1 are transmembrane receptors expressed on activated T-cell membranes, whereas PD-L1 is the corresponding ligand for PD-1 expressed on a target cell surface, leading to its veiling from the immune system. CTLA4 mainly acts on T-cell activation in lymphatic tissue, while PD-1/PD-L1 mediates the inhibition of effector T-cells and NK cells in peripheral tissues ${ }^{145}$. As a subgroup of cancers utilize these checkpoint factors to protect themselves from the patient immune system, checkpoint inhibitor therapy can overcome this protection and restore immune function, rendering these tumors vulnerable again. Most interestingly, a recent intracellular signalosome has revealed ATM and ATR as interaction partners of PD-L1, most likely in the nucleus ${ }^{146,147}$, suggesting that ATM/ATR co-inhibition could potentiate checkpoint inhibitor blockades and help overcome mechanisms of resistance ${ }^{148,149,150}$. Furthermore, multiple DNA repair pathways have been implicated in PD-L1 regulation, such as DNA mismatch repair (MMR) $)^{151,152}$, DNA DSB repair ${ }^{153}$ and DNA base excision repair (BER) ${ }^{154}$. For instance, DSB signaling through ATR/Chk1 activate the STAT1/3-IRF1 pathway, with IRF1 directly upregulating PD-L1 mRNA transcription ${ }^{153,155}$. Currently, the study of checkpoint protein interactions with DDR and DNA repair, as well as the evaluation of possible biomarkers from these pathways, are promising approaches to complement the already powerful impact of checkpoint inhibitors in clinics. 


\subsection{Tumor suppressor activating drugs revisited}

The discovery of p53 activating drugs was at first met with great excitement, as the successful targeting of such an important protein would revolutionize cancer medicine ${ }^{156}$. p53 proficient cancer cells are often dysregulated in the p53 pathway, pharmacological activation would therefore strongly reactivate p53 functions independently from other factors. Such treatment would mediate arrest of the cell cycle and apoptosis, severely impacting cancer cell survival. And indeed, preclinical testing revealed Nutlin-3a induced cytotoxicity in p53 proficient cell lines and in mouse xenografts ${ }^{85}$, with MDM2 overexpressing cancer cells being the most vulnerable to the treatment. The p53-activating drug RG7112 was then cleared for clinical trials, using a 20 patient cohort suffering from liposarcoma, which commonly exhibits an MDM2 amplification ${ }^{110}$. The outcome was disappointing. Not only was the response limited to 1 partial response and 14 stable disease patients, but the array of side effects ranged from severe to life threatening, with 6 patients suffering from neutropenia and 3 patients from thrombocytopenia. Taken together, the results were not as expected and would limit the clinical applications of p53 stabilizing drugs. The interest in RG7112 was lost, however, a more potent Nutlin-3a analogue with superior potency and selectivity, RG7388 or Idasanutlin ${ }^{157}$, currently has 15 entries on the ClinicalTrials.gov website, the clinical trials were designed for targeting various hematological malignancies and solid tumors. Next generation Nutlins might therefore really find their way into the clinical routine.

The application of p53 activators for the cyclotherapy approach remains of great interest. The use of an analogue with great potency and selectivity, such as Idasanutlin, would be favorable for this purpose. However, the final proof of principle in vivo has not yet been provided, as such animal experiments are very sophisticated, the careful titration and timing in a whole organism is not easily done. Another important factor is the chemotherapeutic drug, which should be protected against. Only a very suitable and effective candidate would justify such an intricate experimental mouse model. We hope to have provided evidence for such a promising candidate in the combination of 5-VdU and Compound B. Aggravating the matter, a recent report has revealed a difference in effectivity of MDM2 antagonists between human and murine cell lines, the difference being larger if the Nutlin is more specific 
and potent in human cell lines, i.e. the difference in Idasanutlin effectivity would be larger than the Nutlin-3a effectivity difference ${ }^{123}$. Paving the way to cyclotherapy clinical trials through an experimental mouse model using Idasanutlin might therefore be even more complicated as anticipated. As an alternative, upon a pRB mutation, the Cdk4/6 inhibitor Palbociclib (Ibrance $®$ ) could be utilized as a tumor suppressor activating drug for the cyclotherapy regimen ${ }^{124}$. Palbociclib is already routinely given to patients with advanced and metastatic breast cancers to induce tumor cell cycle arrest ${ }^{125}$, it can be taken orally and is in average well tolerated, with one daily dose over a course of 21 days ${ }^{158}$. The possible application for Palbociclib in a cyclotherapy experimental setup would be feasible in a small cell lung cancer model, as these cancers are very aggressive and commonly lose both $\mathrm{pRb}$ and $\mathrm{p} 53^{126}$. In summary, the final proof of principle for cyclotherapy is yet to be provided in vivo and the discovery of more pharmacological activators of tumor suppressor proteins could be further utilized for this concept.
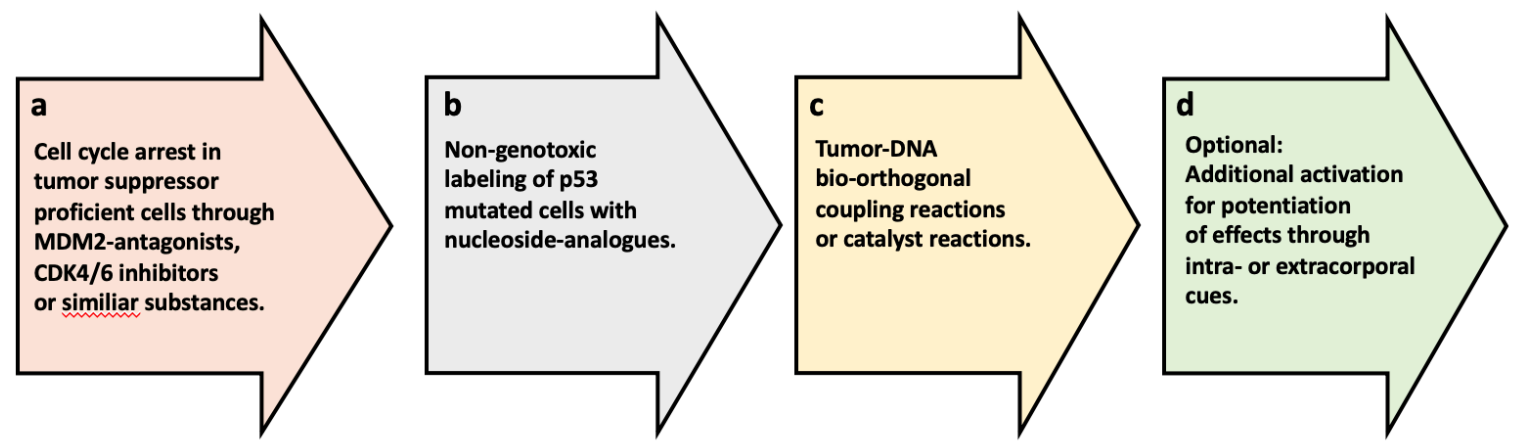

Figure 14: Obligatory chronological order of treatment events in the cyclotherapypretargeting scheme. 


\subsection{Specific targeting of cancer cells with tumor suppressor mutations}

\subsubsection{Improvement of the current cyclotherapy model}

The combination of the cyclotherapy approach with the pretargeting model is superior to cyclotherapy without pretargeting due to a number of reasons: Without pretargeting, the use of a DNA replication toxin, such as Gemcitabine, would arrest the cell cycle in tumor suppressor mutated cells after initial exposure to the substance ${ }^{119}$. Furthermore, a higher dosage of Gemcitabine would arrest the cell cycle faster. As a consequence, both of these effects limit the effective drug concentration in the cancer cell nucleus. Pretargeting solves both these problems. For one, non-genotoxic incorporation of a nucleoside analogue does not arrest the cell cycle and labels most of the genome. In addition, the nucleoside analogue can be given at a low concentration, whereas the partner drug can be upscaled to a high concentration, as p53 proficient cells would have not incorporated the nucleoside analogue and arrested their cell cycle, rendering them insusceptible to the second drug. This ensures the entire p53 mutant cancer cell genome to be targeted by a high dose of the cytotoxic pretargeting component. Furthermore, a potentiation of the effects could be accomplished by applying additional substances or extracorporal factors. As an example, certain nanoparticles attached to DNA could be activated by magnetism or ultrasound to produce heat for tumor thermal ablation ${ }^{131}$. Also, the attachment of nanozymes to DNA could turnover a non-toxic substrate into a cytotoxic product ${ }^{159}$. The success of this type of strategies will depend on the possible introduction of such metal-ion-catalyst bearing nanostructures. 


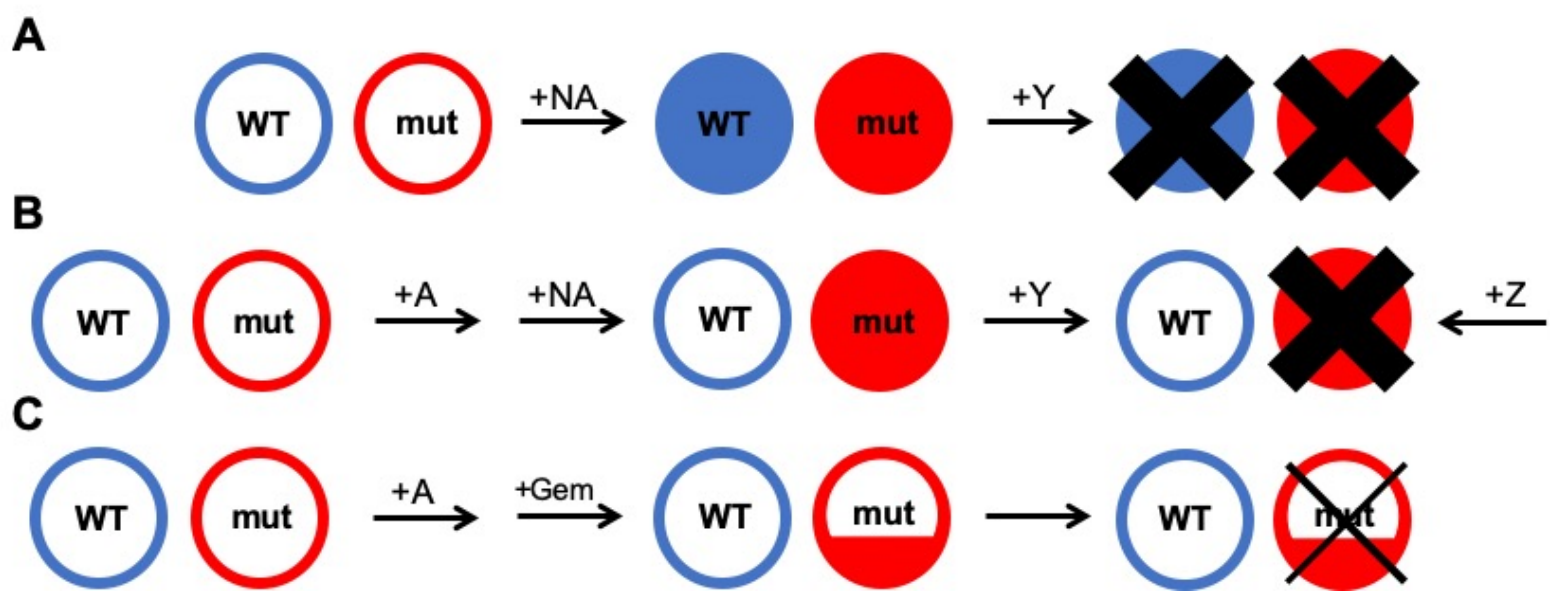

Figure 15: Schematic representation of the labeling extent of treated cell nuclei: WT = tumor suppressor wild type, mut = tumor suppressor mutated, $A=$ tumor suppressor activating drug, $N A=$ nucleoside analogon compatible for Click Chemistry reaction, Gem $=$ Gemcitabine, $Y=$ cytotoxic drug component, $Z$ = additional cues, such as magnetism or ultrasound for thermal ablation. (A) Without cyclotherapy, WT and mut cells are both labeled with the NA and suffer severe cytotoxic effects upon the addition of $Y$. (B) Upon the activation of the tumor suppressor, only mut cells incorporate the NA and are subsequently susceptible for $Y$ and subsequently $Z$, while WT cells remain unharmed due to an arrested cell cycle. (C) In comparison, cyclotherapy with Gemcitabine offers a smaller DNA target surface, as the genome will only be partially impacted due to a genotoxic drug induced cell cycle arrest.

\subsubsection{A versatile tool for cancer therapy}

Our findings suggest the possibility of specifically targeting the DNA of tumor suppressor mutated cancer cells in a patient. Multiple benefits arise from this model. For one, the induction of cytotoxicity, only in cancer cells, strongly reduces chemotherapeutic side effects ${ }^{93}$. Furthermore, p53 mutations arise late in carcinogenesis and are correlated with aggressive behavior of the cancer ${ }^{160}$. Targeting these cells should provide a large therapeutic benefit for the patient. Most importantly, with the DNA being of pivotal importance for a cancer cell, the direct targeting of DNA provides multiple advantages to impede tumor growth and survival ${ }^{29}$. Classical DNA damaging approaches, such as chemotherapy and radiotherapy, could 
be augmented in our model. The incorporated nucleoside analogue provides a multimodal platform for the reaction with various compounds of interest. Novel and established chemotherapeutics could be crosslinked with DNA and therefore enriched in the tumor suppressor mutated cancer cell nucleus. The DNA could be intra- and interstrand-crosslinked through a modulator and a catalyst (Fig. 9B and 11B). For radiotherapy, the crosslinking of established radiosensitizers ${ }^{161}$ and oxygen enriching substances ${ }^{162}$ would potently and specifically enhance the effects of therapeutic irradiation. The use of the pretargeting cyclotherapy scheme in nuclear medicine would give rise to different perspectives. For one, the incorporation of radioactive emitters ${ }^{127}$ could already damage cancer cells specifically, but the provided activation energy also sets the stage for switchable compounds ${ }^{163}$. A recent report shows such an activation of a photo-switchable chemotherapeutic by a radioemitter. The drug was specifically delivered into cancer cells by targeted nanomicelles, with a radiopharmaceutical circulating in the bloodstream in vivo ${ }^{133}$, suggesting that a switchable compound on the incorporated nucleoside analogue could be activated in a similar manner. Furthermore, incorporated radioemitters could be used for imaging ${ }^{164}$, whereas fluorescent substances could find their application in intrasurgical in situ tumor detection, similar to 5-Aminolevulinic Acid (5-ALA) in neurosurgery ${ }^{120}$. The successful proof of principle of the cyclotherapy-pretargeting combined approach would give rise to a versatile theranostics tool for specifically targeting tumor suppressor mutated cells in a cancer patient. 
A

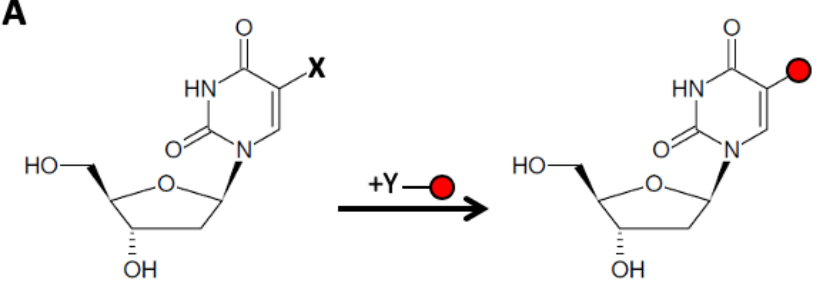

B

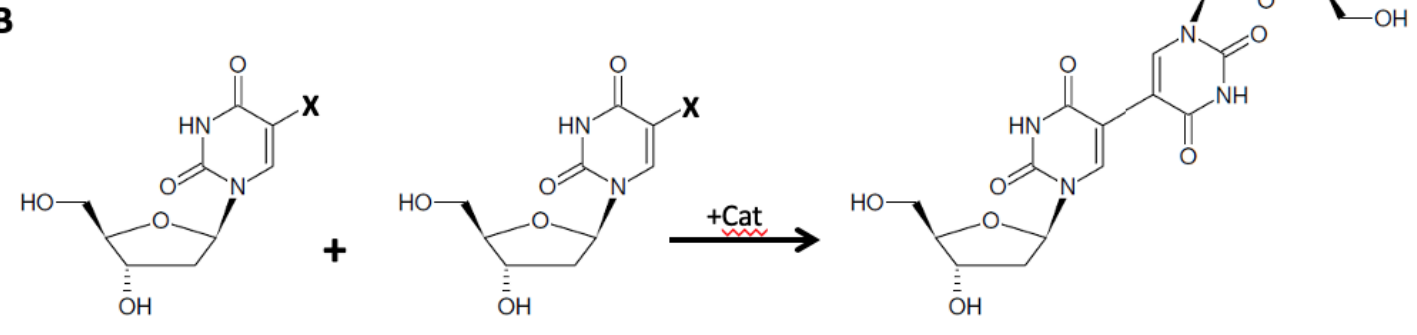

Figure 16: Reactions on nucleoside analogues: $X=$ Click chemistry reaction partner $1, Y=$ Click chemistry reaction partner 2 , Cat $=$ catalyst. (A) Bioconjugation at nucleoside analogue. (B) Dimerisation of nucleoside analogues.
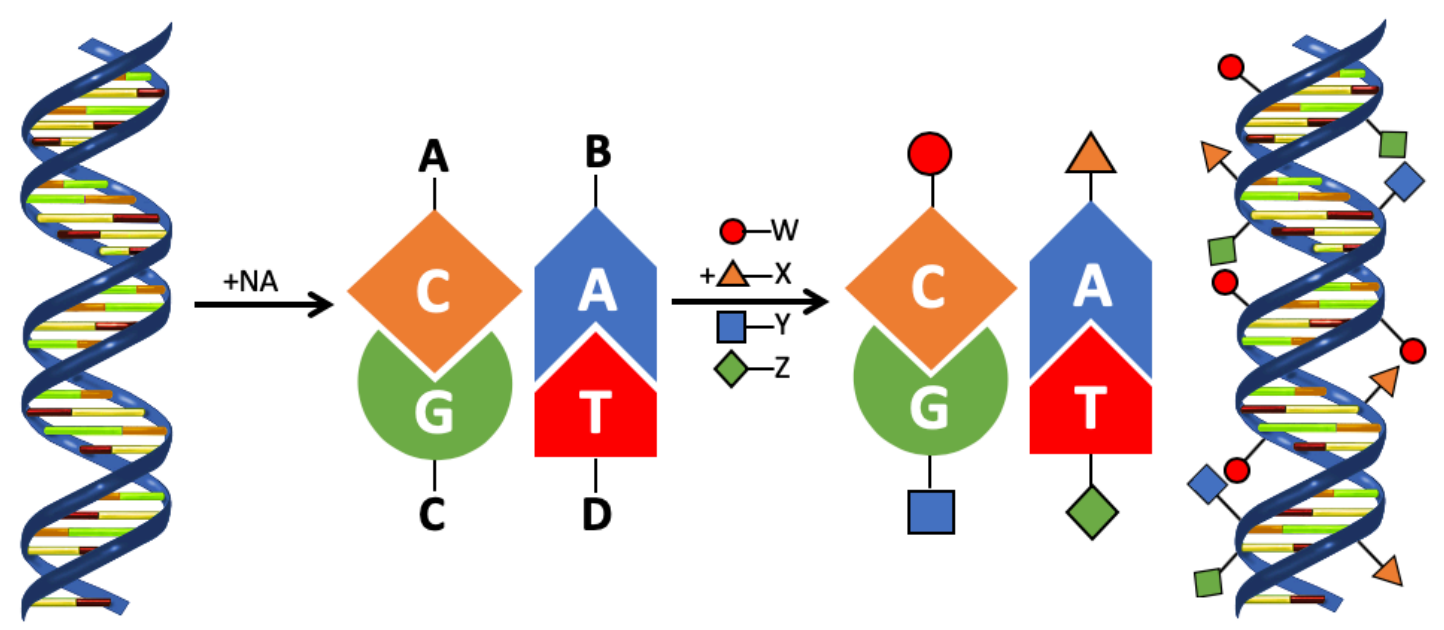

Figure 17: Schematic of the possibility to simultaneously apply up to 4 different nucleoside analogues with their specific reaction partners. 
A
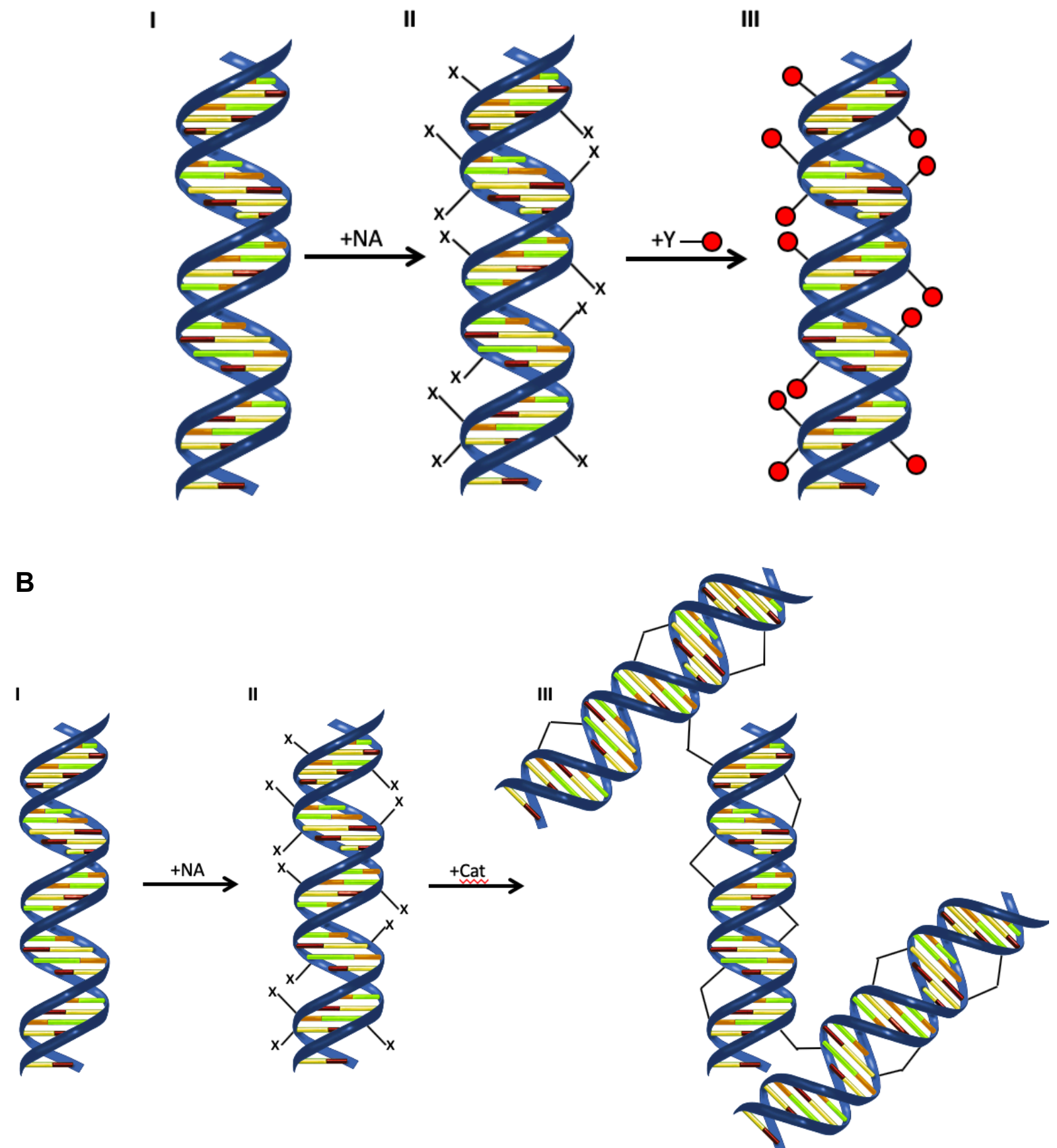

Figure 18: (A) Schematic reaction from Figure 16A. (B) Schematic reaction from Figure 16B, intra- and interstrand crosslink formation after catalytic reaction. 


\section{Bibliography}

1. Watson, J. D. \& Crick, F. H. The structure of DNA. Cold Spring Harb. Symp. Quant. Biol. 18, 123-131 (1953).

2. Crick, F. H. On protein synthesis. Symp. Soc. Exp. Biol. 12, 138-163 (1958).

3. Meselson, M. \& Stahl, F. W. THE REPLICATION OF DNA IN ESCHERICHIA COLI. Proc. Natl. Acad. Sci. U. S. A. 44, 671-682 (1958).

4. Olins, A. L. \& Olins, D. E. Spheroid chromatin units (v bodies). Science 183, 330-332 (1974).

5. Burgers, P. M. J. \& Kunkel, T. A. Eukaryotic DNA Replication Fork. Annu. Rev. Biochem. 86, 417-438 (2017).

6. Hoeijmakers, J. H. J. DNA damage, aging, and cancer. N. Engl. J. Med. 361, 1475-1485 (2009).

7. Mahdieh, N. \& Rabbani, B. An overview of mutation detection methods in genetic disorders. Iran. J. Pediatr. 23, 375-388 (2013).

8. Hakem, R. DNA-damage repair; the good, the bad, and the ugly. EMBO J. 27, 589-605 (2008).

9. Phillips, D. H. Mutational spectra and mutational signatures: Insights into cancer aetiology and mechanisms of DNA damage and repair. DNA Repair 71, 6-11 (2018).

10. Chabner, B. A. \& Roberts, T. G. Timeline: Chemotherapy and the war on cancer. Nat. Rev. Cancer 5, 65-72 (2005).

11. Herrlich, P., Karin, M. \& Weiss, C. Supreme EnLIGHTenment: damage recognition and signaling in the mammalian UV response. Mol. Cell 29, 279-290 (2008). 
12. De Bont, R. \& van Larebeke, N. Endogenous DNA damage in humans: a review of quantitative data. Mutagenesis 19, 169-185 (2004).

13. Lindahl, T. Molecular biology: ensuring error-free DNA repair. Nature 427, 598 (2004).

14. Xia, J. et al. Bacteria-to-Human Protein Networks Reveal Origins of Endogenous DNA Damage. Cell 176, 127-143.e24 (2019).

15. Lindahl, T. Instability and decay of the primary structure of DNA. Nature 362, 709715 (1993).

16. DNA repair processes: from the third annual workshop sponsored by the Institute for Medical Research and the National Institute on Aging. (Symposia Specialists, 1977).

17. Handbook of the biology of aging. (Van Nostrand Reinhold, 1985).

18. Vilenchik, M. M. \& Knudson, A. G. Endogenous DNA double-strand breaks: production, fidelity of repair, and induction of cancer. Proc. Natl. Acad. Sci. U. S. A. 100, 12871-12876 (2003).

19. Helbock, H. J. et al. DNA oxidation matters: the HPLC-electrochemical detection assay of 8-oxo-deoxyguanosine and 8-oxo-guanine. Proc. Natl. Acad. Sci. U. S. A. 95, 288293 (1998).

20. Nakamura, J. \& Swenberg, J. A. Endogenous apurinic/apyrimidinic sites in genomic DNA of mammalian tissues. Cancer Res. 59, 2522-2526 (1999).

21. Baskar, R., Lee, K. A., Yeo, R. \& Yeoh, K.-W. Cancer and radiation therapy: current advances and future directions. Int. J. Med. Sci. 9, 193-199 (2012).

22. Emadi, A., Jones, R. J. \& Brodsky, R. A. Cyclophosphamide and cancer: golden anniversary. Nat. Rev. Clin. Oncol. 6, 638-647 (2009). 
23. Hall, A. G. \& Tilby, M. J. Mechanisms of action of, and modes of resistance to, alkylating agents used in the treatment of haematological malignancies. Blood Rev. 6, 163-173 (1992).

24. Ghosh, S. Cisplatin: The first metal based anticancer drug. Bioorganic Chem. 88, 102925 (2019).

25. de Man, F. M., Goey, A. K. L., van Schaik, R. H. N., Mathijssen, R. H. J. \& Bins, S. Individualization of Irinotecan Treatment: A Review of Pharmacokinetics, Pharmacodynamics, and Pharmacogenetics. Clin. Pharmacokinet. 57, 1229-1254 (2018).

26. Henwood, J. M. \& Brogden, R. N. Etoposide. A review of its pharmacodynamic and pharmacokinetic properties, and therapeutic potential in combination chemotherapy of cancer. Drugs 39, 438-490 (1990).

27. Tacar, O., Sriamornsak, P. \& Dass, C. R. Doxorubicin: an update on anticancer molecular action, toxicity and novel drug delivery systems. J. Pharm. Pharmacol. 65, 157170 (2013).

28. Huang, P., Chubb, S., Hertel, L. W., Grindey, G. B. \& Plunkett, W. Action of 2', 2'difluorodeoxycytidine on DNA synthesis. Cancer Res. 51, 6110-6117 (1991).

29. Dobbelstein, M. \& Sørensen, C. S. Exploiting replicative stress to treat cancer. Nat. Rev. Drug Discov. 14, 405-423 (2015).

30. Froudarakis, M. et al. Revisiting bleomycin from pathophysiology to safe clinical use. Crit. Rev. Oncol. Hematol. 87, 90-100 (2013).

31. Ewald, B., Sampath, D. \& Plunkett, W. Nucleoside analogs: molecular mechanisms signaling cell death. Oncogene 27, 6522-6537 (2008).

32. Cortez, D. Preventing replication fork collapse to maintain genome integrity. DNA Repair 32, 149-157 (2015). 
33. Zeman, M. K. \& Cimprich, K. A. Causes and consequences of replication stress. Nat. Cell Biol. 16, 2-9 (2014).

34. Jackson, A. L. \& Loeb, L. A. The contribution of endogenous sources of DNA damage to the multiple mutations in cancer. Mutat. Res. 477, 7-21 (2001).

35. Wang, D. \& Lippard, S. J. Cellular processing of platinum anticancer drugs. Nat. Rev. Drug Discov. 4, 307-320 (2005).

36. Giunta, S. \& Jackson, S. P. Give me a break, but not in mitosis: the mitotic DNA damage response marks DNA double-strand breaks with early signaling events. Cell Cycle Georget. Tex 10, 1215-1221 (2011).

37. Noble, S. \& Goa, K. L. Gemcitabine. A review of its pharmacology and clinical potential in non-small cell lung cancer and pancreatic cancer. Drugs 54, 447-472 (1997).

38. Calvaro, S. of G. By Calvero. - Selfmade with ChemDraw., Public Domain, https://commons.wikimedia.org/w/index.php?curid=1593091.

39. Benrr101, S. of C. By Benrr101 - Own work, Public Domain, https://commons.wikimedia.org/w/index.php?curid=18871038.

40. Giglia-Mari, G., Zotter, A. \& Vermeulen, W. DNA damage response. Cold Spring Harb. Perspect. Biol. 3, a000745 (2011).

41. Matsuoka, S. et al. ATM and ATR substrate analysis reveals extensive protein networks responsive to DNA damage. Science 316, 1160-1166 (2007).

42. Zou, L. \& Elledge, S. J. Sensing DNA damage through ATRIP recognition of RPA-ssDNA complexes. Science 300, 1542-1548 (2003).

43. Liu, Q. et al. Chk1 is an essential kinase that is regulated by Atr and required for the G(2)/M DNA damage checkpoint. Genes Dev. 14, 1448-1459 (2000). 
44. Chen, Y. \& Poon, R. Y. C. The multiple checkpoint functions of CHK1 and CHK2 in maintenance of genome stability. Front. Biosci. J. Virtual Libr. 13, 5016-5029 (2008).

45. Smith, J., Tho, L. M., Xu, N. \& Gillespie, D. A. The ATM-Chk2 and ATR-Chk1 pathways in DNA damage signaling and cancer. Adv. Cancer Res. 108, 73-112 (2010).

46. Peng, C. Y. et al. Mitotic and G2 checkpoint control: regulation of 14-3-3 protein binding by phosphorylation of Cdc25C on serine-216. Science 277, 1501-1505 (1997).

47. Bakkenist, C. J. \& Kastan, M. B. DNA damage activates ATM through intermolecular autophosphorylation and dimer dissociation. Nature 421, 499-506 (2003).

48. Lee, J.-H. \& Paull, T. T. Activation and regulation of ATM kinase activity in response to DNA double-strand breaks. Oncogene 26, 7741-7748 (2007).

49. Buscemi, G. et al. Activation of ATM and Chk2 kinases in relation to the amount of DNA strand breaks. Oncogene 23, 7691-7700 (2004).

50. Huang, X. et al. Assessment of histone H2AX phosphorylation induced by DNA topoisomerase I and II inhibitors topotecan and mitoxantrone and by the DNA crosslinking agent cisplatin. Cytom. Part J. Int. Soc. Anal. Cytol. 58, 99-110 (2004).

51. Lou, Z. et al. MDC1 maintains genomic stability by participating in the amplification of ATM-dependent DNA damage signals. Mol. Cell 21, 187-200 (2006).

52. van Attikum, H. \& Gasser, S. M. Crosstalk between histone modifications during the DNA damage response. Trends Cell Biol. 19, 207-217 (2009).

53. Bouwman, P. \& Jonkers, J. The effects of deregulated DNA damage signalling on cancer chemotherapy response and resistance. Nat. Rev. Cancer 12, 587-598 (2012).

54. Engel, K., Plath, K. \& Gaestel, M. The MAP kinase-activated protein kinase 2 contains a proline-rich SH3-binding domain. FEBS Lett. 336, 143-147 (1993). 
55. Engel, K. et al. Constitutive activation of mitogen-activated protein kinase-activated protein kinase 2 by mutation of phosphorylation sites and an A-helix motif. J. Biol. Chem. 270, 27213-27221 (1995).

56. Engel, K., Kotlyarov, A. \& Gaestel, M. Leptomycin B-sensitive nuclear export of MAPKAP kinase 2 is regulated by phosphorylation. EMBO J. 17, 3363-3371 (1998).

57. Bulavin, D. V. et al. Initiation of a $\mathrm{G} 2 / \mathrm{M}$ checkpoint after ultraviolet radiation requires p38 kinase. Nature 411, 102-107 (2001).

58. Reinhardt, H. C., Aslanian, A. S., Lees, J. A. \& Yaffe, M. B. p53-deficient cells rely on ATM- and ATR-mediated checkpoint signaling through the p38MAPK/MK2 pathway for survival after DNA damage. Cancer Cell 11, 175-189 (2007).

59. Raman, M., Earnest, S., Zhang, K., Zhao, Y. \& Cobb, M. H. TAO kinases mediate activation of p38 in response to DNA damage. EMBO J. 26, 2005-2014 (2007).

60. Reinhardt, H. C. et al. DNA damage activates a spatially distinct late cytoplasmic cellcycle checkpoint network controlled by MK2-mediated RNA stabilization. Mol. Cell 40, 34-49 (2010).

61. Morandell, S. et al. A reversible gene-targeting strategy identifies synthetic lethal interactions between MK2 and p53 in the DNA damage response in vivo. Cell Rep. 5, 868877 (2013).

62. Köpper, F. et al. Damage-induced DNA replication stalling relies on MAPK-activated protein kinase 2 activity. Proc. Natl. Acad. Sci. U. S. A. 110, 16856-16861 (2013).

63. Bloom, J. \& Cross, F. R. Multiple levels of cyclin specificity in cell-cycle control. Nat. Rev. Mol. Cell Biol. 8, 149-160 (2007).

64. Malumbres, M. \& Barbacid, M. Cell cycle, CDKs and cancer: a changing paradigm. Nat. Rev. Cancer 9, 153-166 (2009). 
65. Lukas, J., Lukas, C. \& Bartek, J. Mammalian cell cycle checkpoints: signalling pathways and their organization in space and time. DNA Repair 3, 997-1007 (2004).

66. Uto, K., Inoue, D., Shimuta, K., Nakajo, N. \& Sagata, N. Chk1, but not Chk2, inhibits Cdc25 phosphatases by a novel common mechanism. EMBO J. 23, 3386-3396 (2004).

67. Gartel, A. L. \& Radhakrishnan, S. K. Lost in transcription: p21 repression, mechanisms, and consequences. Cancer Res. 65, 3980-3985 (2005).

68. Funk, J. O. et al. Inhibition of CDK activity and PCNA-dependent DNA replication by p21 is blocked by interaction with the HPV-16 E7 oncoprotein. Genes Dev. 11, 2090-2100 (1997).

69. Bartek, J. \& Lukas, J. Chk1 and Chk2 kinases in checkpoint control and cancer. Cancer Cell 3, 421-429 (2003).

70. Nevins, J. R. E2F: a link between the Rb tumor suppressor protein and viral oncoproteins. Science 258, 424-429 (1992).

71. Kastan, M. B. \& Bartek, J. Cell-cycle checkpoints and cancer. Nature 432, 316-323 (2004).

72. Taylor, W. R. \& Stark, G. R. Regulation of the G2/M transition by p53. Oncogene 20, 1803-1815 (2001).

73. Leemans, C. R., Braakhuis, B. J. M. \& Brakenhoff, R. H. The molecular biology of head and neck cancer. Nat. Rev. Cancer 11, 9-22 (2011).

74. Vogelstein, B., Lane, D. \& Levine, A. J. Surfing the p53 network. Nature 408, 307-310 (2000).

75. Meek, D. W. Mechanisms of switching on p53: a role for covalent modification? Oncogene 18, 7666-7675 (1999). 
76. Milczarek, G. J., Martinez, J. \& Bowden, G. T. p53 Phosphorylation: biochemical and functional consequences. Life Sci. 60, 1-11 (1997).

77. Michael, D. \& Oren, M. The p53-Mdm2 module and the ubiquitin system. Semin. Cancer Biol. 13, 49-58 (2003).

78. Valentine, J. M., Kumar, S. \& Moumen, A. A p53-independent role for the MDM2 antagonist Nutlin-3 in DNA damage response initiation. BMC Cancer 11, 79 (2011).

79. Tokino, T. \& Nakamura, Y. The role of p53-target genes in human cancer. Crit. Rev. Oncol. Hematol. 33, 1-6 (2000).

80. Bieging, K. T. \& Attardi, L. D. Deconstructing p53 transcriptional networks in tumor suppression. Trends Cell Biol. 22, 97-106 (2012).

81. Shen, H. \& G. Maki, C. Pharmacologic Activation of p53 by Small-Molecule MDM2 Antagonists. Curr. Pharm. Des. 17, 560-568 (2011).

82. Tisato, V., Voltan, R., Gonelli, A., Secchiero, P. \& Zauli, G. MDM2/X inhibitors under clinical evaluation: perspectives for the management of hematological malignancies and pediatric cancer. J. Hematol. Oncol.J Hematol Oncol 10, 133 (2017).

83. Miyachi, M. et al. Restoration of p53 pathway by nutlin-3 induces cell cycle arrest and apoptosis in human rhabdomyosarcoma cells. Clin. Cancer Res. Off. J. Am. Assoc. Cancer Res. 15, 4077-4084 (2009).

84. Khoo, K. H., Hoe, K. K., Verma, C. S. \& Lane, D. P. Drugging the p53 pathway: understanding the route to clinical efficacy. Nat. Rev. Drug Discov. 13, 217-236 (2014).

85. Vassilev, L. T. et al. In vivo activation of the p53 pathway by small-molecule antagonists of MDM2. Science 303, 844-848 (2004).

86. Carvajal, D. et al. Activation of $\mathrm{p} 53$ by $\mathrm{MDM} 2$ antagonists can protect proliferating cells from mitotic inhibitors. Cancer Res. 65, 1918-1924 (2005). 
87. Kranz, D. \& Dobbelstein, M. Nongenotoxic p53 activation protects cells against Sphase-specific chemotherapy. Cancer Res. 66, 10274-10280 (2006).

88. Blagosklonny, M. V. P53: an ubiquitous target of anticancer drugs. Int. J. Cancer 98, 161-166 (2002).

89. Blagosklonny, M. V. \& Pardee, A. B. Exploiting cancer cell cycling for selective protection of normal cells. Cancer Res. 61, 4301-4305 (2001).

90. van Leeuwen, I. M. M. Cyclotherapy: opening a therapeutic window in cancer treatment. Oncotarget 3, 596-600 (2012).

91. Sur, S. et al. A panel of isogenic human cancer cells suggests a therapeutic approach for cancers with inactivated p53. Proc. Natl. Acad. Sci. U. S. A. 106, 3964-3969 (2009).

92. Malhab, L. J. B., Descamps, S., Delaval, B. \& Xirodimas, D. P. The use of the NEDD8 inhibitor MLN4924 (Pevonedistat) in a cyclotherapy approach to protect wild-type p53 cells from MLN4924 induced toxicity. Sci. Rep. 6, 37775 (2016).

93. Rao, B., Lain, S. \& Thompson, A. M. p53-Based cyclotherapy: exploiting the 'guardian of the genome' to protect normal cells from cytotoxic therapy. Br. J. Cancer 109, 29542958 (2013).

94. Rostovtsev, V. V., Green, L. G., Fokin, V. V. \& Sharpless, K. B. A stepwise huisgen cycloaddition process: copper(I)-catalyzed regioselective 'ligation' of azides and terminal alkynes. Angew. Chem. Int. Ed Engl. 41, 2596-2599 (2002).

95. Nwe, K. \& Brechbiel, M. W. Growing Applications of "Click Chemistry" for Bioconjugation in Contemporary Biomedical Research. Cancer Biother. Radiopharm. 24, 289-302 (2009).

96. Lang, K. \& Chin, J. W. Cellular incorporation of unnatural amino acids and bioorthogonal labeling of proteins. Chem. Rev. 114, 4764-4806 (2014). 
97. Jewett, J. C., Sletten, E. M. \& Bertozzi, C. R. Rapid Cu-Free Click Chemistry with Readily Synthesized Biarylazacyclooctynones. J. Am. Chem. Soc. 132, 3688-3690 (2010).

98. Agard, N. J., Prescher, J. A. \& Bertozzi, C. R. A strain-promoted [3 + 2] azide-alkyne cycloaddition for covalent modification of biomolecules in living systems. J. Am. Chem. Soc. 126, 15046-15047 (2004).

99. Devaraj, N. K., Weissleder, R. \& Hilderbrand, S. A. Tetrazine-based cycloadditions: application to pretargeted live cell imaging. Bioconjug. Chem. 19, 2297-2299 (2008).

100. Rondon, A. \& Degoul, F. Antibody Pretargeting Based on Bioorthogonal Click Chemistry for Cancer Imaging and Targeted Radionuclide Therapy. Bioconjug. Chem. 31, 159-173 (2020).

101. Rieder, U. \& Luedtke, N. W. Alkene-Tetrazine Ligation for Imaging Cellular DNA. Angew. Chem. Int. Ed. 53, 9168-9172 (2014).

102. caymanchem.com, S. of N.-3a. https://www.caymanchem.com/images/catalog/screen/18585.png.

103. Jena Bioscience, S. of 5-V. https://www.jenabioscience.com/images/PDF/CLK050.0001.pdf.

104. Jena Bioscience, C. C. background info. https://www.jenabioscience.com/images/741d0cd7d0/20140306_Click_Chemistry_Backg round_information_pdf_creator.pdf.

105. Verhoeven, Seimbille \& Dalm. Therapeutic Applications of Pretargeting. Pharmaceutics 11, 434 (2019).

106. Lane, D. \& Levine, A. p53 Research: The Past Thirty Years and the Next Thirty Years. Cold Spring Harb. Perspect. Biol. 2, a000893-a000893 (2010). 
107. Joerger, A. C. \& Fersht, A. R. The p53 Pathway: Origins, Inactivation in Cancer, and Emerging Therapeutic Approaches. Annu. Rev. Biochem. 85, 375-404 (2016).

108. Wade, M., Li, Y.-C. \& Wahl, G. M. MDM2, MDMX and p53 in oncogenesis and cancer therapy. Nat. Rev. Cancer 13, 83-96 (2013).

109. Khurana, A. \& Shafer, D. A. MDM2 antagonists as a novel treatment option for acute myeloid leukemia: perspectives on the therapeutic potential of idasanutlin (RG7388). OncoTargets Ther. Volume 12, 2903-2910 (2019).

110. Ray-Coquard, I. et al. Effect of the MDM2 antagonist RG7112 on the P53 pathway in patients with MDM2-amplified, well-differentiated or dedifferentiated liposarcoma: an exploratory proof-of-mechanism study. Lancet Oncol. 13, 1133-1140 (2012).

111. Neef, A. B. \& Luedtke, N. W. An Azide-Modified Nucleoside for Metabolic Labeling of DNA. ChemBioChem 15, 789-793 (2014).

112. Tera, M., Glasauer, S. M. K. \& Luedtke, N. W. In Vivo Incorporation of Azide Groups into DNA by Using Membrane-Permeable Nucleotide Triesters. ChemBioChem 19, 19391943 (2018).

113. Tera, M. \& Luedtke, N. W. Three-Component Bioorthogonal Reactions on Cellular DNA and RNA. Bioconjug. Chem. 30, 2991-2997 (2019).

114. Tera, M., Harati Taji, Z. \& Luedtke, N. W. Intercalation-enhanced “Click” Crosslinking of DNA. Angew. Chem. Int. Ed. 57, 15405-15409 (2018).

115. Cavanagh, B. L., Walker, T., Norazit, A. \& Meedeniya, A. C. B. Thymidine analogues for tracking DNA synthesis. Mol. Basel Switz. 16, 7980-7993 (2011).

116. Lee, J. W., Komar, C. A., Bengsch, F., Graham, K. \& Beatty, G. L. Genetically Engineered Mouse Models of Pancreatic Cancer: The KPC Model (LSL-Kras(G12D/+) ;LSL- 
Trp53(R172H/+) ;Pdx-1-Cre), Its Variants, and Their Application in Immuno-oncology Drug Discovery. Curr. Protoc. Pharmacol. 73, 14.39.1-14.39.20 (2016).

117. Parrilla, I. et al. Hoechst 33342 stain and u.v. laser exposure do not induce genotoxic effects in flow-sorted boar spermatozoa. Reprod. Camb. Engl. 128, 615-621 (2004).

118. Pérez-Cadahía, B., Drobic, B. \& Davie, J. R. H3 phosphorylation: dual role in mitosis and interphase. Biochem. Cell Biol. Biochim. Biol. Cell. 87, 695-709 (2009).

119. Li, Y., Saini, P., Sriraman, A. \& Dobbelstein, M. Mdm2 inhibition confers protection of p53-proficient cells from the cytotoxic effects of Wee1 inhibitors. Oncotarget 6, 3233932352 (2015).

120. Hadjipanayis, C. G., Widhalm, G. \& Stummer, W. What is the Surgical Benefit of Utilizing 5-Aminolevulinic Acid for Fluorescence-Guided Surgery of Malignant Gliomas? Neurosurgery 77, 663-673 (2015).

121. Ferraro, N. et al. The role of 5-aminolevulinic acid in brain tumor surgery: a systematic review. Neurosurg. Rev. 39, 545-555 (2016).

122. Boogerd, L. S. F. et al. Safety and effectiveness of SGM-101, a fluorescent antibody targeting carcinoembryonic antigen, for intraoperative detection of colorectal cancer: a dose-escalation pilot study. Lancet Gastroenterol. Hepatol. 3, 181-191 (2018).

123. Chen, L. et al. Characterisation of the p53 pathway in cell lines established from THMYCN transgenic mouse tumours. Int. J. Oncol. 52, 967-977 (2018).

124. Goel, S., DeCristo, M. J., McAllister, S. S. \& Zhao, J. J. CDK4/6 Inhibition in Cancer: Beyond Cell Cycle Arrest. Trends Cell Biol. 28, 911-925 (2018).

125. Bui, T. B. V., Burgers, D. M., Agterof, M. J. \& van de Garde, E. M. Real-World Effectiveness of Palbociclib Versus Clinical Trial Results in Patients With 
Advanced/Metastatic Breast Cancer That Progressed on Previous Endocrine Therapy.

Breast Cancer Basic Clin. Res. 13, 1178223418823238 (2019).

126. George, J. et al. Comprehensive genomic profiles of small cell lung cancer. Nature 524, 47-53 (2015).

127. Cornelissen, B. \& Vallis, K. A. Targeting the nucleus: an overview of Auger-electron radionuclide therapy. Curr. Drug Discov. Technol. 7, 263-279 (2010).

128. Rosenkranz, A. A., Slastnikova, T. A., Georgiev, G. P., Zalutsky, M. R. \& Sobolev, A. S. Delivery systems exploiting natural cell transport processes of macromolecules for intracellular targeting of Auger electron emitters. Nucl. Med. Biol. 80-81, 45-56 (2020). 129. Sun, H., Wang, X. \& Zhai, S. The Rational Design and Biological Mechanisms of Nanoradiosensitizers. Nanomater. Basel Switz. 10, (2020).

130. Wang, H., Mu, X., He, H. \& Zhang, X.-D. Cancer Radiosensitizers. Trends Pharmacol. Sci. 39, 24-48 (2018).

131. Ashikbayeva, Z. et al. Application of Nanoparticles and Nanomaterials in Thermal Ablation Therapy of Cancer. Nanomater. Basel Switz. 9, (2019).

132. Zhang, R., Fan, K. \& Yan, X. Nanozymes: created by learning from nature. Sci. China Life Sci. (2020) doi:10.1007/s11427-019-1570-7.

133. Kotagiri, N. et al. Radionuclides transform chemotherapeutics into phototherapeutics for precise treatment of disseminated cancer. Nat. Commun. 9, 275 (2018).

134. Li, Y., Köpper, F. \& Dobbelstein, M. Inhibition of MAPKAPK2/MK2 facilitates DNA replication upon cancer cell treatment with gemcitabine but not cisplatin. Cancer Lett. 428, 45-54 (2018). 
135. Borisova, M. E. et al. p38-MK2 signaling axis regulates RNA metabolism after UVlight-induced DNA damage. Nat. Commun. 9, 1017 (2018).

136. D'Alessandro, G. \& d'Adda di Fagagna, F. Transcription and DNA Damage: Holding Hands or Crossing Swords? J. Mol. Biol. 429, 3215-3229 (2017).

137. Koulis, C. et al. Personalized Medicine-Current and Emerging Predictive and Prognostic Biomarkers in Colorectal Cancer. Cancers 12, (2020).

138. Huang, A., Garraway, L. A., Ashworth, A. \& Weber, B. Synthetic lethality as an engine for cancer drug target discovery. Nat. Rev. Drug Discov. 19, 23-38 (2020).

139. Patel, M., Nowsheen, S., Maraboyina, S. \& Xia, F. The role of poly(ADP-ribose) polymerase inhibitors in the treatment of cancer and methods to overcome resistance: a review. Cell Biosci. 10, 35 (2020).

140. Boussios, S. et al. Poly (ADP-Ribose) Polymerase Inhibitors: Talazoparib in Ovarian Cancer and Beyond. Drugs RD (2020) doi:10.1007/s40268-020-00301-8.

141. Jerez, Y. et al. Poly (ADP-ribose) Polymerase Inhibition in Patients with Breast Cancer and BRCA 1 and 2 Mutations. Drugs 80, 131-146 (2020).

142. Lord, C. J. \& Ashworth, A. BRCAness revisited. Nat. Rev. Cancer 16, 110-120 (2016).

143. Bunting, S. F. et al. 53BP1 inhibits homologous recombination in Brca1-deficient cells by blocking resection of DNA breaks. Cell 141, 243-254 (2010).

144. Pardoll, D. M. The blockade of immune checkpoints in cancer immunotherapy. Nat. Rev. Cancer 12, 252-264 (2012).

145. Rotte, A. Combination of CTLA-4 and PD-1 blockers for treatment of cancer. J. Exp. Clin. Cancer Res. CR 38, 255 (2019). 
146. Satelli, A. et al. Potential role of nuclear PD-L1 expression in cell-surface vimentin positive circulating tumor cells as a prognostic marker in cancer patients. Sci. Rep. $\mathbf{6}$, 28910 (2016).

147. Ghebeh, H. et al. Doxorubicin downregulates cell surface B7-H1 expression and upregulates its nuclear expression in breast cancer cells: role of B7-H1 as an antiapoptotic molecule. Breast Cancer Res. 12, R48 (2010).

148. Escors, D. et al. The intracellular signalosome of PD-L1 in cancer cells. Signal Transduct. Target. Ther. 3, 26 (2018).

149. Sun, L.-L. et al. Inhibition of ATR downregulates PD-L1 and sensitizes tumor cells to T cell-mediated killing. Am. J. Cancer Res. 8, 1307-1316 (2018).

150. Jin, M. H. et al. Therapeutic Co-targeting of WEE1 and ATM Downregulates PD-L1 Expression in Pancreatic Cancer. Cancer Res. Treat. Off. J. Korean Cancer Assoc. 52, 149166 (2020).

151. Le, D. T. et al. PD-1 Blockade in Tumors with Mismatch-Repair Deficiency. N. Engl. J. Med. 372, 2509-2520 (2015).

152. Llosa, N. J. et al. The vigorous immune microenvironment of microsatellite instable colon cancer is balanced by multiple counter-inhibitory checkpoints. Cancer Discov. 5, 43-51 (2015).

153. Sato, H. et al. DNA double-strand break repair pathway regulates PD-L1 expression in cancer cells. Nat. Commun. 8, 1751 (2017).

154. Permata, T. B. M. et al. Base excision repair regulates PD-L1 expression in cancer cells. Oncogene 38, 4452-4466 (2019).

155. Garcia-Diaz, A. et al. Interferon Receptor Signaling Pathways Regulating PD-L1 and PD-L2 Expression. Cell Rep. 19, 1189-1201 (2017). 
156. Brown, C. J., Lain, S., Verma, C. S., Fersht, A. R. \& Lane, D. P. Awakening guardian angels: drugging the p53 pathway. Nat. Rev. Cancer 9, 862-873 (2009).

157. Ding, Q. et al. Discovery of RG7388, a potent and selective p53-MDM2 inhibitor in clinical development. J. Med. Chem. 56, 5979-5983 (2013).

158. FDA, P., Ibrance.

https://www.accessdata.fda.gov/drugsatfda_docs/label/2019/207103s008lbl.pdf.

159. Zhang, J. \& Liu, J. Light-activated nanozymes: catalytic mechanisms and applications. Nanoscale 12, 2914-2923 (2020).

160. Robles, A. I., Jen, J. \& Harris, C. C. Clinical Outcomes of TP53 Mutations in Cancers. Cold Spring Harb. Perspect. Med. 6, (2016).

161. Lawrence, T. S., Blackstock, A. W. \& McGinn, C. The mechanism of action of radiosensitization of conventional chemotherapeutic agents. Semin. Radiat. Oncol. 13, $13-21(2003)$.

162. Harrison, L. B., Chadha, M., Hill, R. J., Hu, K. \& Shasha, D. Impact of tumor hypoxia and anemia on radiation therapy outcomes. The Oncologist 7, 492-508 (2002).

163. Hüll, K., Morstein, J. \& Trauner, D. In Vivo Photopharmacology. Chem. Rev. 118, 10710-10747 (2018).

164. Cheson, B. D. PET/CT in Lymphoma: Current Overview and Future Directions. Semin. Nucl. Med. 48, 76-81 (2018). 


\section{Supplemental information}

\subsection{Supplemental figures for manuscript I}

\section{Supplemental Figure S1}

Densitometry of pHsp27 normalized to Actin in MiaPaca-2 cells - $1 \mathrm{~h}$ timepoint

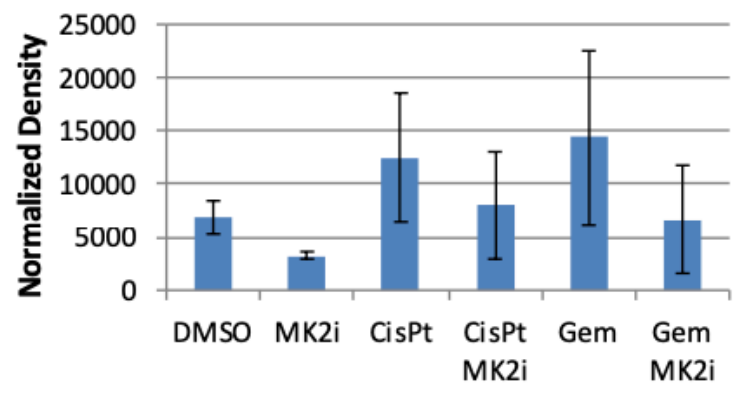

Densitometry of pHsp27 normalized to Actin in MiaPaca-2 cells - $4 \mathrm{~h}$ timepoint

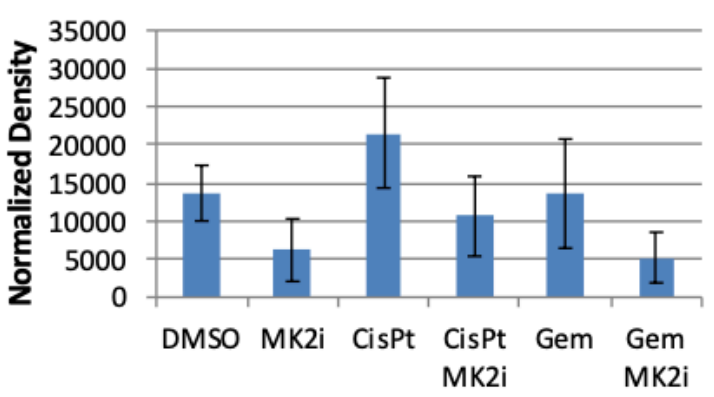

Densitometry of pHsp27 normalized to Actin in MiaPaca-2 cells - 12h timepoint

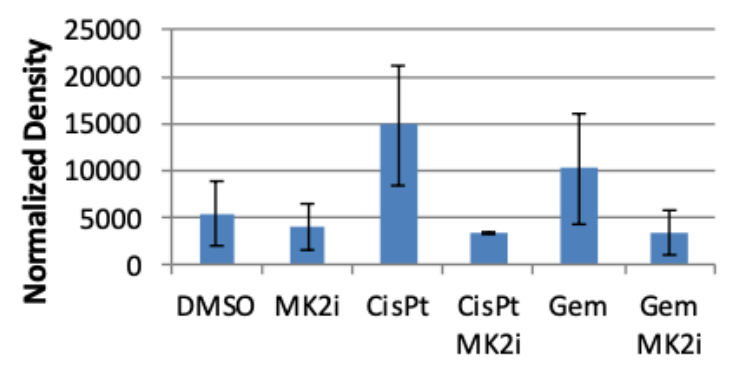

Densitometry of pHsp27 normalized to Actin in MiaPaca-2 cells - 24h timepoint

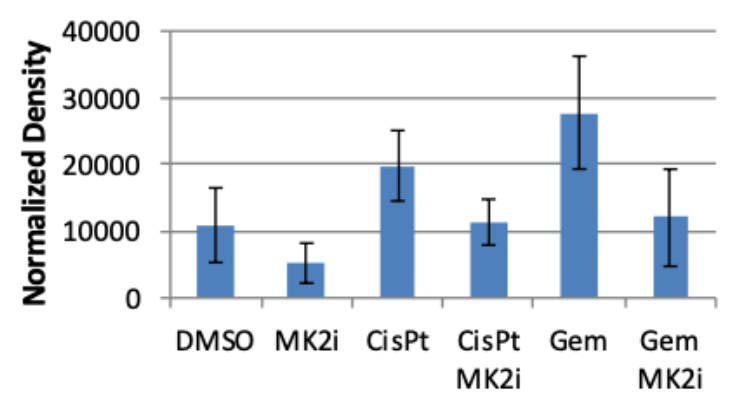

\section{Supplemental Figure S1:}

\section{Quantification of phospho-HSP27} normalized to Actin corresponding to figure $2 \mathrm{~A}$. Western blot band intensities of different time points were quantified using the Image J software. Error bars represent the standard error of 3 independent experiments. 


\section{Supplemental Figure S2}

A

\begin{tabular}{|l|r|r|}
\hline & nuclear & \multicolumn{2}{c|}{ cytoplasmic } \\
\hline DMSO & 30 & 0 \\
\hline DMSO + Sorb & 0 & 34 \\
\hline MK2i & 27 & 0 \\
\hline MK2i + Sorb & 0 & 21 \\
\hline CisPt & 26 & 0 \\
\hline CisPt + Sorb & 0 & 28 \\
\hline Gem & 24 & 0 \\
\hline Gem+Sorb & 0 & 35
\end{tabular}

B

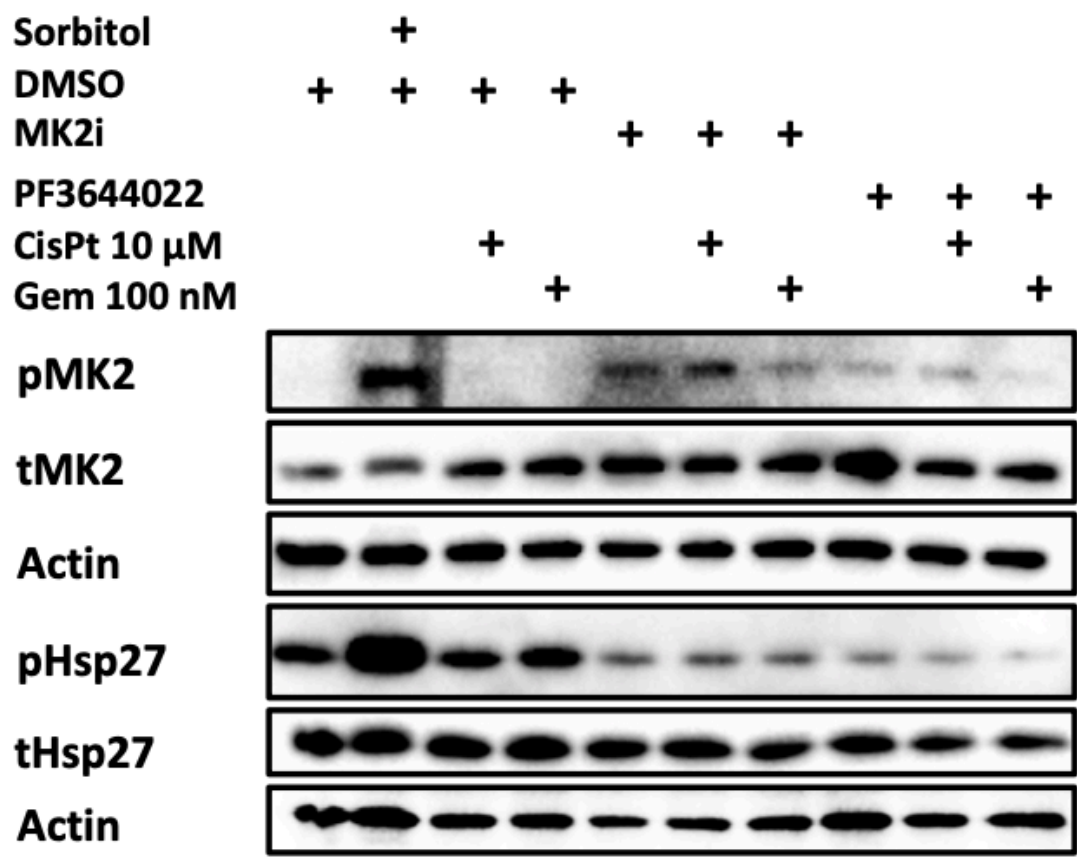

MiaPaca2 cell line, $4 \mathrm{~h}$ treatment

Supplemental Figure S2: Comparison of sorbitol with gemcitabine and cisplatin, regarding MK2 localization and activation. A. Quantification of nuclear or cytoplasmic localization of MK2-myc overexpressing cells corresponding to figure 3. B. Western Blot analysis corresponding to figure 3, adding PF3644022 to the drug panel. 


\section{Supplemental Figure S3}

A
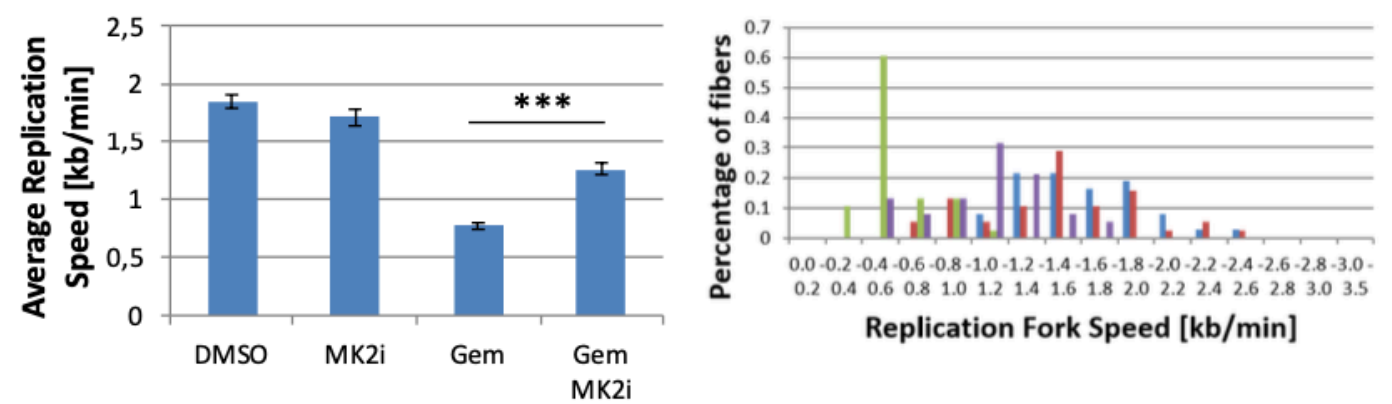

= DMSO

- MK2i

$=\mathrm{Gem}$

= Gem MK2i

Replication Fork Speed [kb/min]
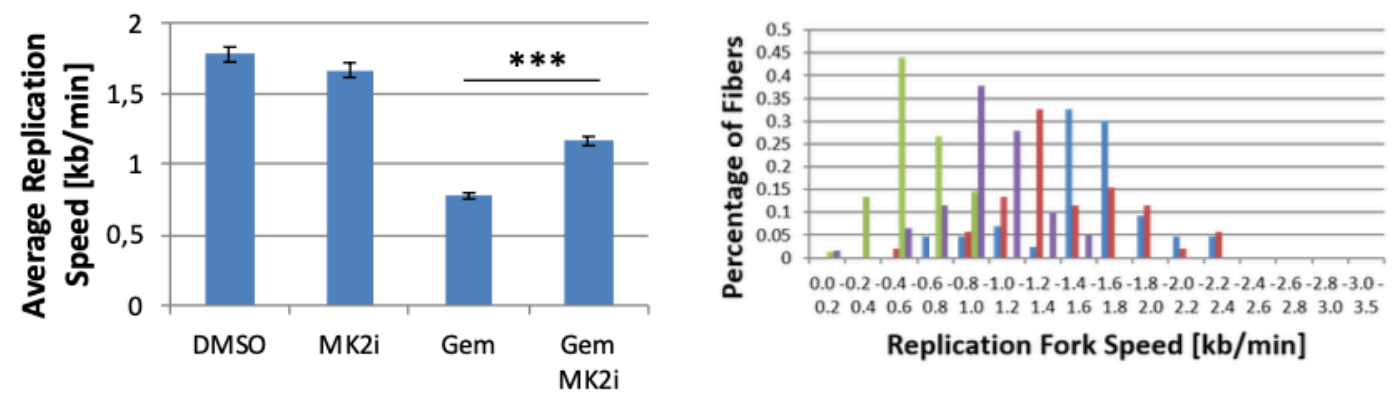

- DMSO

- MK2i

= Gem

= Gem MK2
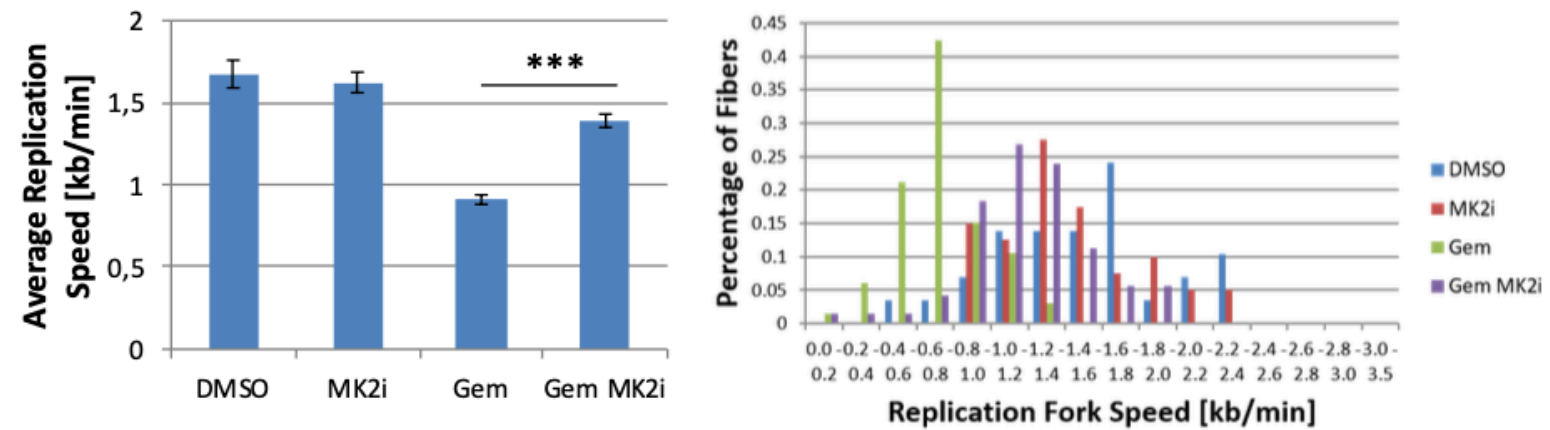
B
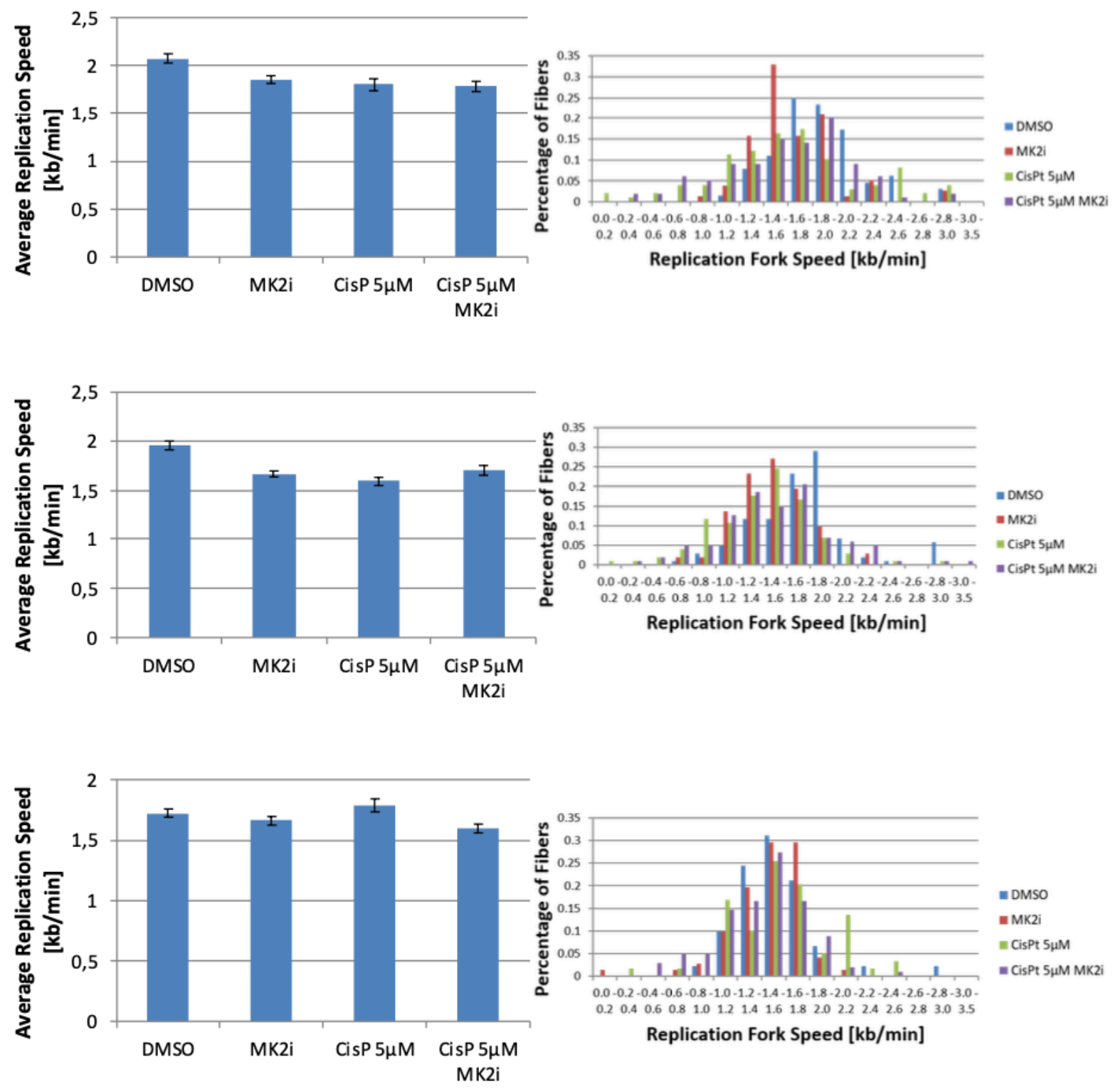
C
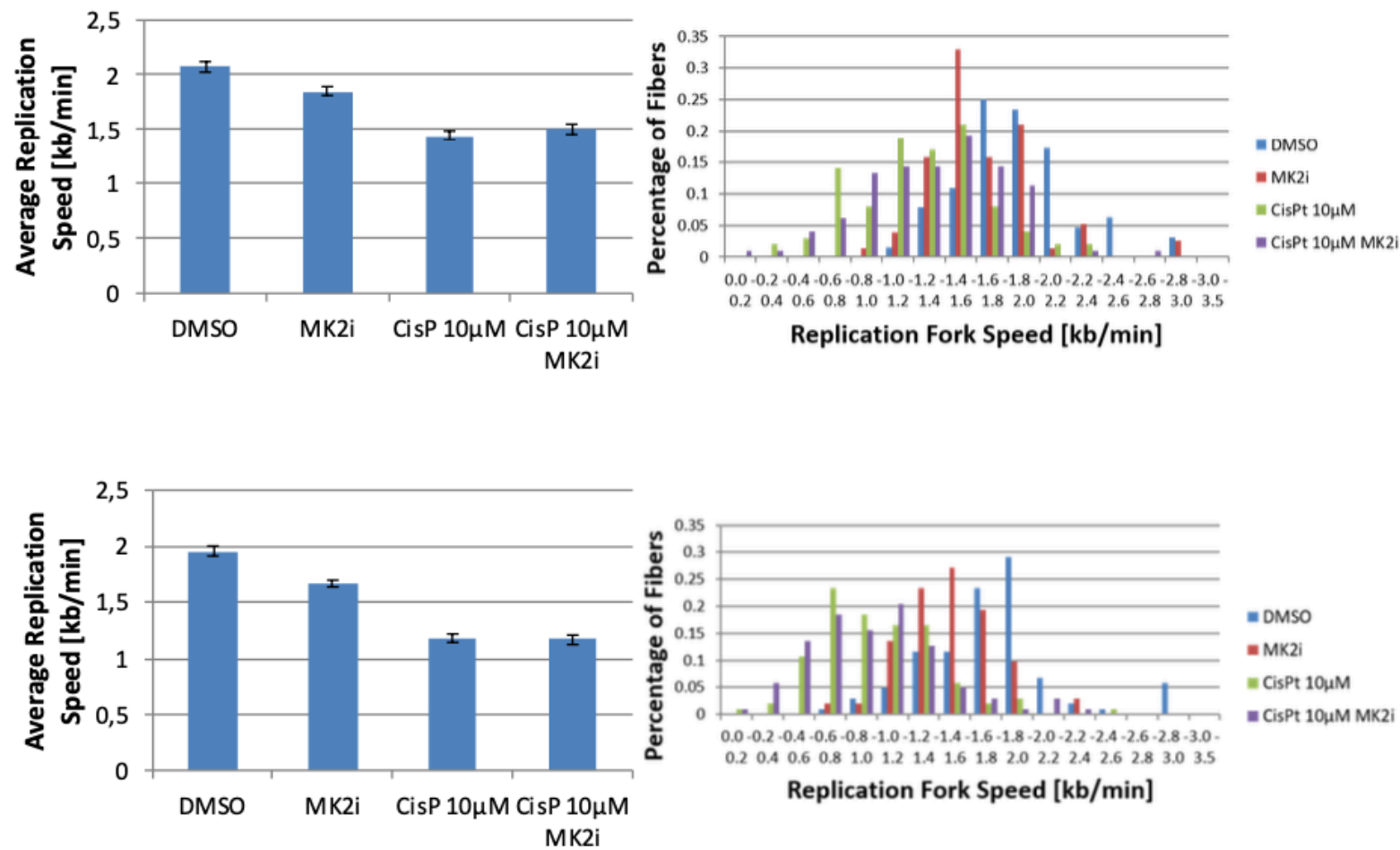

= DMSO

- MK2i

= Cispt 10uM

= Cispt 10uM MK2
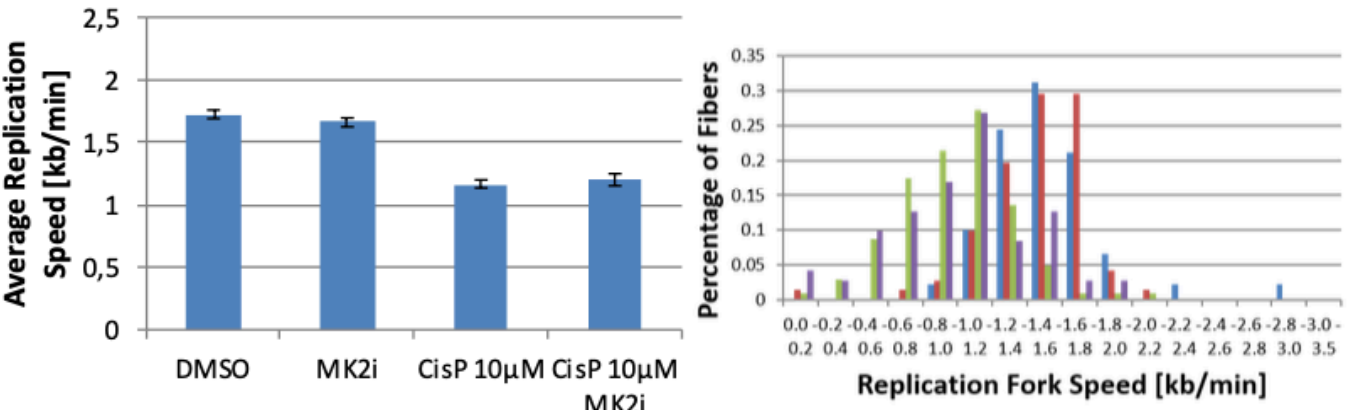

= DMSO

MK2i

- Cispt 10 $\mu \mathrm{M}$

- Cispt 10uM MK2

MK2i

Replication Fork Speed [kb/min] 
D
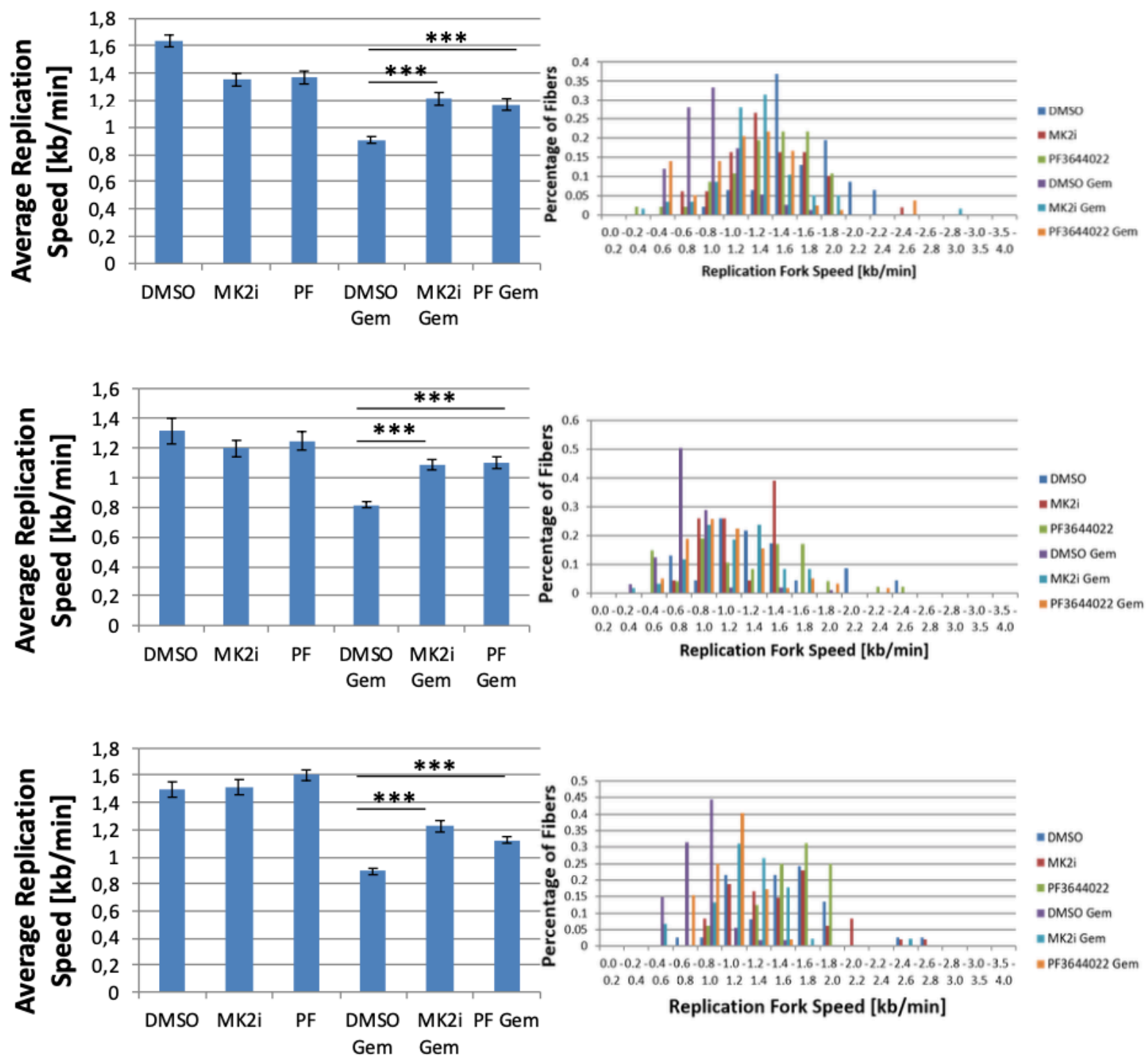
E
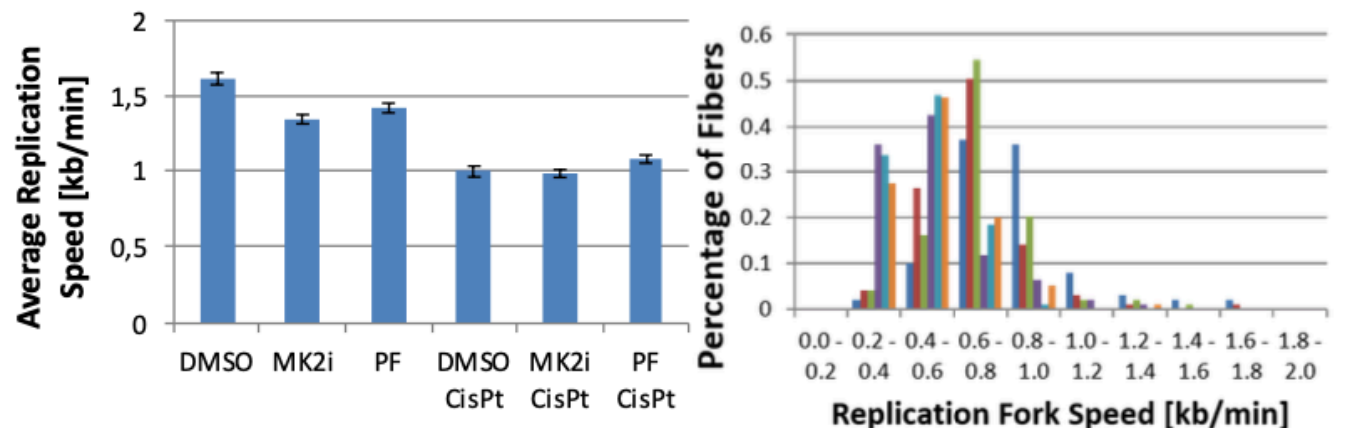

- DMSO

MK2 $\mathrm{i}$

- PF3644022

- DMSO CisPt

mK2i CisPt

= PF3644022 CisPt
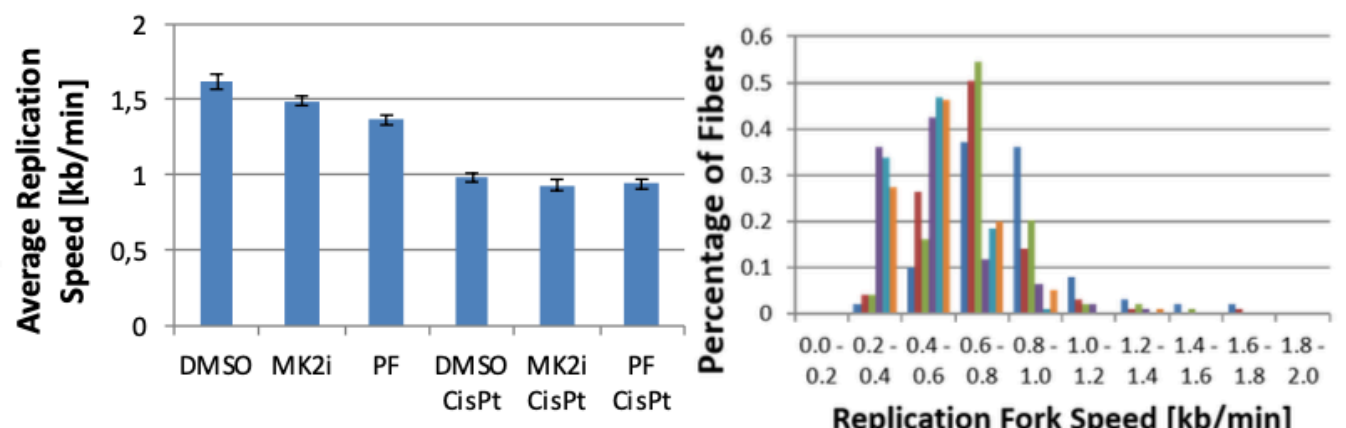

- DMSO

- MK2i

= PF3644022

DMSO CisPt

mK2i CisPt

n PF3644022 CisPt

Replication Fork Speed [kb/min]
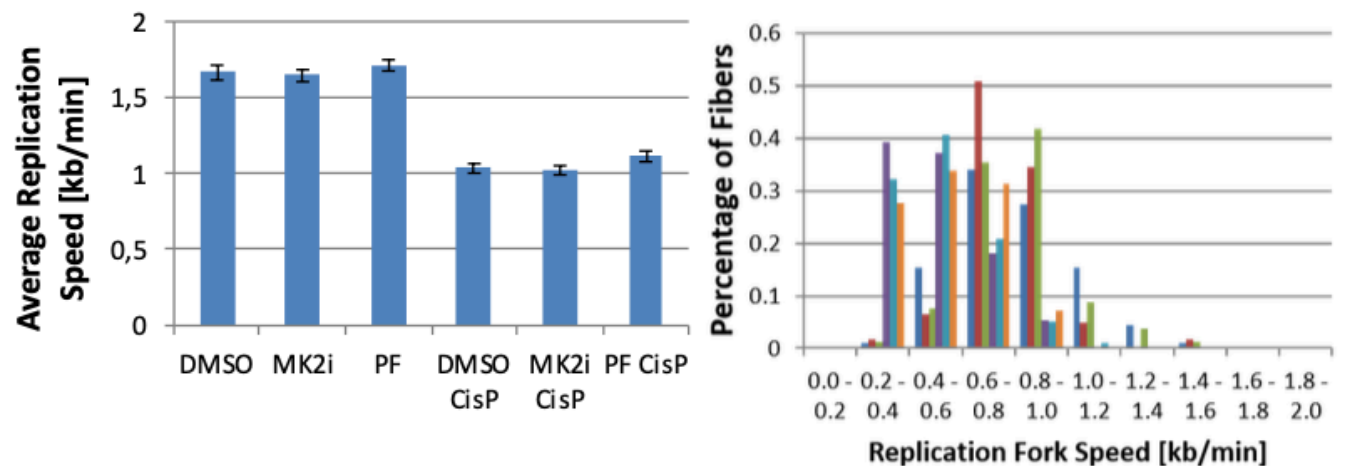

- DMSO

- MK2i

- PF3644022 - DMSO CisPt MK2i CisPt = PF3644022 CisPt Replication Fork Speed [kb/min] 
Supplemental Figure S3: Distribution of track lengths in all fiber assays, corresponding to figures $\mathbf{4}$ and $\mathbf{5}$. Three replica are shown for each condition, with the mean and SEM of the track lengths (left), along with the distribution of track lengths (right). A. Experiments conducted in Panc1 cells, treatment with gemcitabine and MK2 inhibitor as in Fig. 4, B-E. B. Experiments conducted in Panc1 cells, treatment with $5 \mu \mathrm{M}$ cisplatin and MK2 inhibitor for $24 \mathrm{~h}$. Note that this concentration of cisplatin, albeit far greater than the amount required for compromising cell viability $(0.5 \mu \mathrm{M}$, cf. Fig. 1 $B$ ), is still insufficient for detectable reduction in replication fork progression. C.

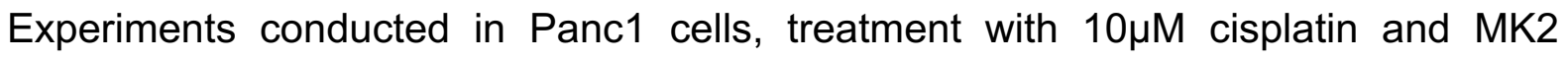
inhibitor III, as in Fig. 5. D. As in A, but experiment conducted in MIA PaCa-2 cells and adding PF3644022 to the drug panel. E. As in C, but experiment conducted in MIA PaCa-2 cells with $50 \mu \mathrm{M}$ instead of $10 \mu \mathrm{M}$ cisplatin and adding PF3644022 to the drug panel. 


\subsection{Supplemental figures for manuscript II}

\section{Supplemental figure SII-1}
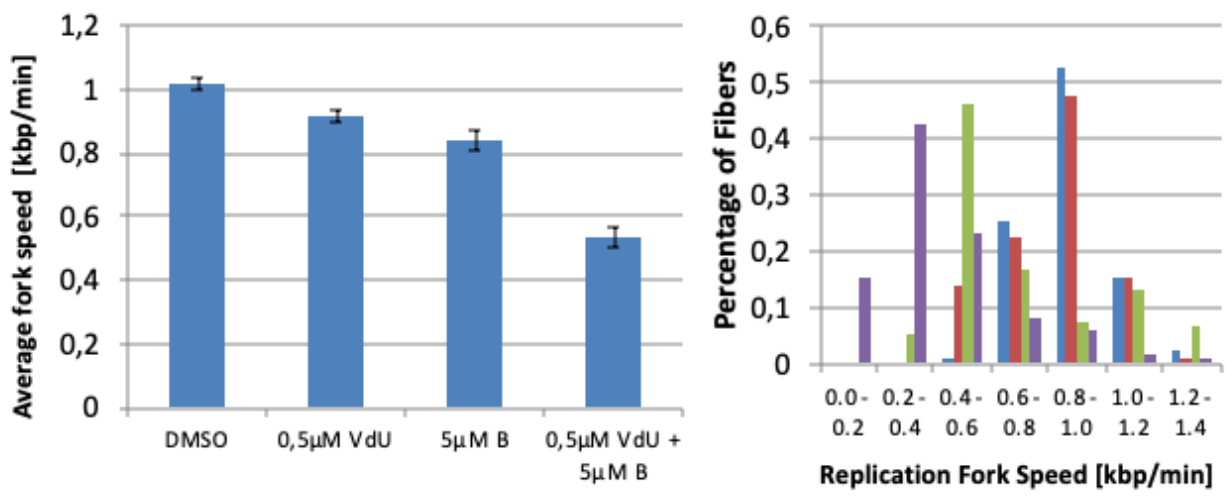

- DMSO

$0,5 \mu \mathrm{M}$ VdU

$\square 5 \mu \mathrm{MB}$

$=0,5 \mu \mathrm{M} V \mathrm{dU}+5 \mu \mathrm{MB}$
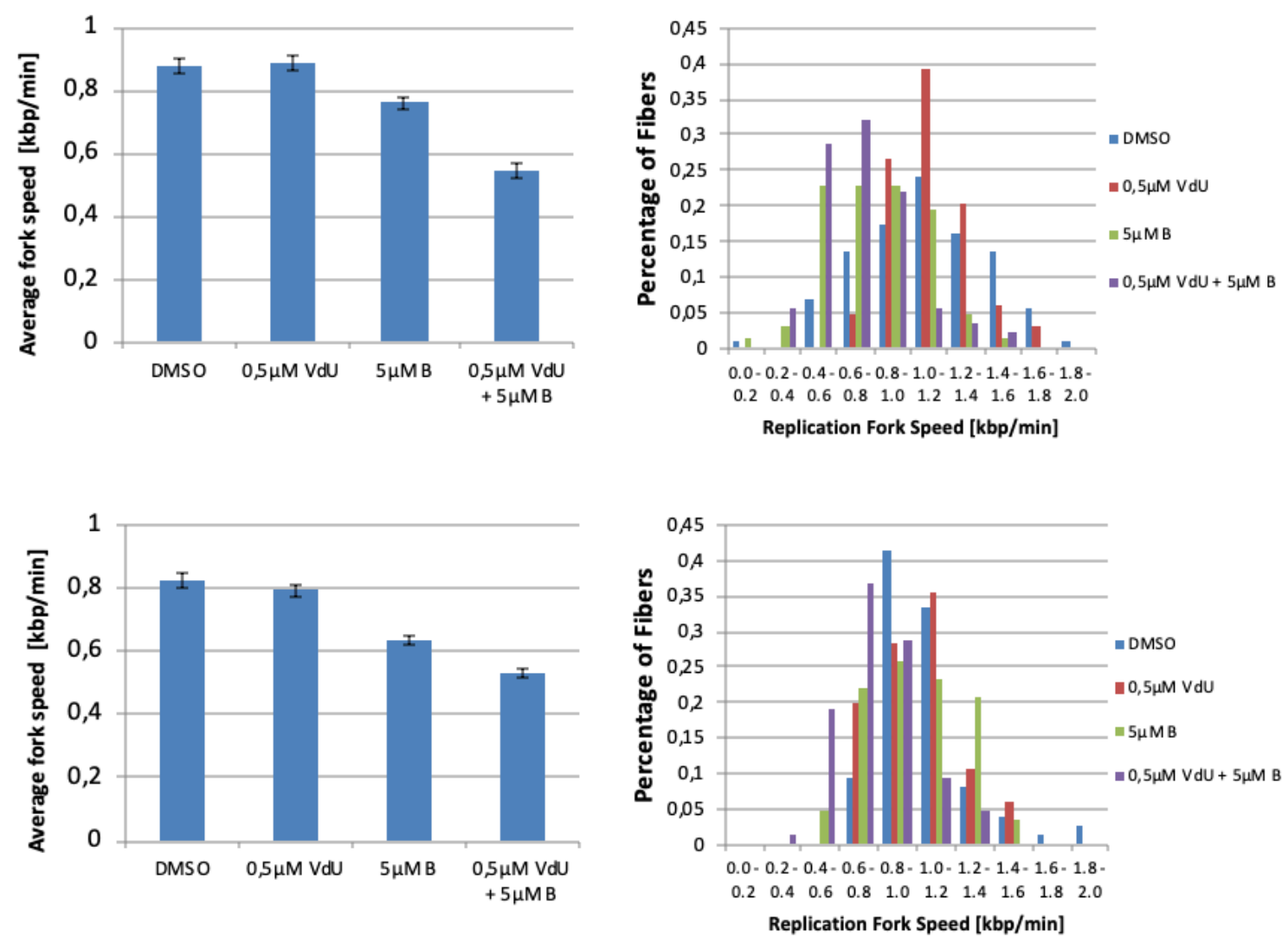

\section{Supplemental Figure SII-1: Distribution of track lengths fiber assays,}

corresponding to figure 4. Three replica are shown for each condition, with the mean and SEM of the track lengths (left), along with the distribution of track lengths (right). Experiments conducted in $\mathrm{H} 1299$ cells, treatment with 5-VdU and compound $B$ as in Fig. 4. 


\section{Abbreviations}

\begin{tabular}{|c|c|}
\hline${ }^{\circ} \mathrm{C}$ & Degree Celsius \\
\hline$\mu l$ & Microliter \\
\hline$\mu \mathrm{M}$ & Micromolar \\
\hline ATM & Ataxia telangiectasia mutated \\
\hline ATR & ATM and Rad3-related \\
\hline ATRIP & ATR interacting protein \\
\hline BRCA & Breast cancer gene \\
\hline BSA & Bovine serum albumin \\
\hline CAK & CDK-activating kinase \\
\hline CDK & Cyclin-dependent kinase \\
\hline Chk1 & Checkpoint kinase 1 \\
\hline Chk2 & Checkpoint kinase 2 \\
\hline CTLA4 & Cytotoxic T-Lymphocyte-Associated protein 4 \\
\hline CuAAC & Copper catalyzed Azide-Alkyne Click reaction \\
\hline dFCTP & 2',2'-difluorodeoxycytidine triphosphate \\
\hline DDR & DNA damage response \\
\hline DMSO & Dimethylsulphoxide \\
\hline DNA & Deoxyribonucleic acid \\
\hline dsDNA & Double stranded DNA \\
\hline DSB & Double stranded DNA break \\
\hline H2AX & Histone variant $2 \mathrm{AX}$ \\
\hline $\mathrm{H}_{2} \mathrm{O}$ & Water \\
\hline HR & homologous recombination \\
\hline $\mathrm{kDa}$ & Kilodalton \\
\hline M & Molar \\
\hline MAPK & Mitogen activated protein kinase \\
\hline MDM2 & Mouse double minute 2 \\
\hline $\mathrm{mg}$ & milligram \\
\hline $\min$ & minute \\
\hline $\mathrm{ml}$ & milliliter \\
\hline $\mathrm{mM}$ & milimolar \\
\hline MRN & MRE/Rad50/NBS1 \\
\hline
\end{tabular}




\begin{tabular}{|c|c|}
\hline mRNA & messenger RNA \\
\hline NHEJ & non-homologous end joining \\
\hline NER & nucleotide excision repair \\
\hline PARP & Poly-ADP-Ribose-Polymerase \\
\hline PBS & phosphate buffered saline \\
\hline PCNA & proliferating cell nuclear antigen \\
\hline PD-1 & Programmed cell Death protein 1 \\
\hline PD-L1 & PD-Ligand 1 \\
\hline PI & Propidium lodide \\
\hline $\mathrm{pRb}$ & retinoblastoma protein \\
\hline ROS & Reactive oxygen species \\
\hline RNA & ribonucleic acid \\
\hline RPA & replication protein $A$ \\
\hline SDS & sodium dodecyl sulfate \\
\hline SDS-PAGE & SDS polyacrylamide gel electrophoresis \\
\hline SPAAC & Strain-promoted Azide-Alkyne Click reaction \\
\hline SSB & Single stranded DNA break \\
\hline ssDNA & single stranded DNA \\
\hline TBST & Tris buffered saline + Tween 20 \\
\hline Tris & Trisamine \\
\hline UV & Ultraviolet \\
\hline V & Volt \\
\hline VdU & 5-Vinyl-2'-deoxyuridine \\
\hline $\mathrm{yH} 2 \mathrm{AX}$ & Gamma-H2AX \\
\hline
\end{tabular}




\section{Table of Figures}

Figure 1: Chemical structures of Gemcitabine ${ }^{38}$ and cisplatin ${ }^{39}$ 10

Figure 2: ATM and ATR activate their downstream targets Chk1, Chk2 and p38....13

Figure 3: DNA damage induced G1/S cell cycle checkpoint activation is controlled by p53 and pRB.

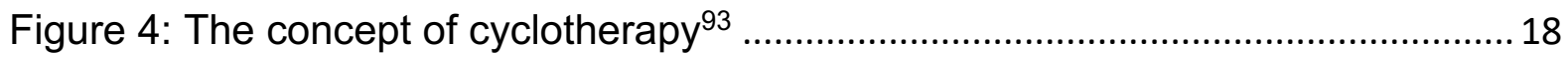

Figure 5: Chemical structures of Nutlin-3a ${ }^{102}$ and 5-Vinyl-2'-deoxyuridine ${ }^{103} \ldots \ldots \ldots \ldots . . .19$

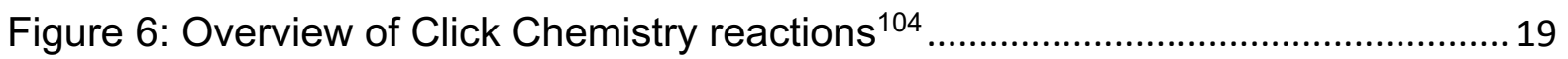

Figure 7: The concept of pretargeting in clinical radiotherapy research ${ }^{105} \ldots \ldots \ldots \ldots \ldots . . .20$

Figure 8: Synergistic lethality of 5-VdU and compound B ........................................ 38

Figure 9: Nuclear localization of the compound B signal shown by co-localization in living $\mathrm{H} 1299$ cells using fluorescence microscopy.....

Figure 10: Cell cycle analyses of H1299 cells show mostly unperturbed cell cycle profiles upon treatment with $0,5 \mu \mathrm{M} 5-\mathrm{VdU}$ or $5 \mu \mathrm{M}$ compound $\mathrm{B}$ alone for the indicated periods of time

Figure 11: $\mathrm{H} 1299$ cells were subjected to the DNA fiber assay after $24 \mathrm{~h}$ of 5 -VdU and $24 \mathrm{~h}$ of compound $\mathrm{B}$ treatment.

Figure 12: Fluorescence microscopy of $10 \mu \mathrm{M}$ Hoechst 33342 stained $\mathrm{H} 1299$ cells treated for $24 \mathrm{~h}$ with $5-\mathrm{VdU}$ and $24 \mathrm{~h}$ with compound $\mathrm{B}$ and further incubated without

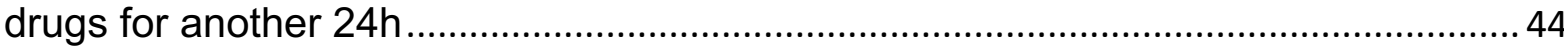

Figure 13: Pharmacological protection against the combination of 5-VdU / Compound B via Nutlin-3a in a p53 status dependent manner

Figure 14: Obligatory chronological order of treatment events in the cyclotherapypretargeting scheme.

Figure 15: Schematic representation of the labeling extent of treated cell nuclei...... 54

Figure 16: Reactions on nucleoside analogues 56

Figure 17: Schematic of the possibility to simultaneously apply up to 4 different nucleoside analogues with their specific reaction partners.

Figure 18: Reaction schemes from Figure 16 


\section{Acknowledgements}

In the year of completion of this thesis, I am turning 33 years old. To this point, it was a very long academic career of 13 years and I have accumulated multiple academic degrees during this time (B.Sc., M.Sc., Dr. med., and now Dr. rer. nat.). These long studies were not without downsides, but now I look back with confidence and forward to specialize in Gastrointestinal Oncology at the Technical University of Munich, with the feeling to have gained the theoretical knowledge to learn clinical oncology and the lab experience to lead and shape translational cancer research.

For this personal success, I am deeply indebted to:

First and foremost, to my scientific supervisor Prof. Dr. Matthias Dobbelstein. With him, I have learned molecular oncology in theory and practice, but more importantly my sense for scientific critical thinking has been sharpened, making me a more complete biologist than I was before. Without him, the endeavor to get both the doctorates in medicine and biology would have been futile. I am very thankful for the door that was always opened, the freedom granted to follow my own ideas, and for the bullseye comments on the spot, when experimental results were all messed up.

To the members of my thesis committee, Prof. Dr. Steven Johnsen, Prof. Dr. Bernd Wollnik and Prof. Dr. Heidi Hahn for constructive criticism and motivating optimism.

To Dr. Frederik Köpper, who's pioneering work in MK2 biology has given the basis for our common publication.

To Prof. Dr. Nathan Luedtke and Morten Loehr, who have generously shared their knowledge and compounds with us.

Many thanks also go to the entire group of Molecular Oncology, which is maintaining a clean and productive infrastructure, as well as a communicative and helpful scientific environment. 
To my wife Sasha, who has supported me endlessly during the last three years. Thank you for your lion's share of raising up our daughter Matilda and your patience when I was late at the dinner table again.

To my parents, who have raised me with an open mind and granted me all possible freedom for personal development. Thank you for your patience, trust and generous financial support throughout all these years.

To my daughter Matilda, who is my pride, my hope and my inspiration.

And to my dog Kowalski, who is a never-ending source of warmth and joy, no matter how dark the winter may be. 